

\section{Contents}

Chinese Customers' Banking Habits and E-banking Barriers

Xiao Ling Qiu

A Study on the Space-Time Dynamic of Global Avian Influenza and Relationship with Bird Migration

Gennian Sun \& Huanhuan Yang

Establishment of Employment Relation Management Based on Employability

Faping He

Study on the Influence of Enterprise Culture's Reform on CRM Implementation

Хiaoyu $\mathrm{Li}$

A Study on the Planning of Food Safety \& Quality Management System in Supermarkets

Xiaoping Li \& Zhijun Han

Research on the Design of Organizing Structure in Commodity Wholesale Markets

Fengling Feng \& Yongling Zhang

Entrepreneurial Venture Creation: The Application of Pattern Identification Theory to the Entrepreneurial

Opportunity-Identification Process

Ashford C. Chea

Research on Pricing Mechanism Pattern for China Electric Power Market

Mian Xing

On the Value of Traditional Confucian Culture and the Value of Modern Corporate Social Responsibility

Wenzhong Zhu \& Yucheng Yao

Modification of the Warrants Pricing Model and Validation Analysis

Jinlong Chen \& Qinhong Li

The Suitability of the GCC for Monetary Union

Michael Thorpe

Resistance, The Echo of Change

Wenhe Yue

Body Language in Business Negotiation

Hui Zhou \& Tingqin Zhang

The Characteristics of ISBN and Its Functions in Book Purchasing and Compiling

Chunlan Qiu \&Yonglin Xiao

The Risky Value in the Capital Market of Incomplete Information

Xuhong Tan \& Mingjun Tan

The Significance of Cross-cultural Communication in International Business Negotiation

Tingqin Zhang \& Hui Zhou 


\title{
Chinese Customers' Banking Habits and E-banking Barriers
}

\author{
Xiao Ling Qiu \\ Keller Graduate School of Management of Devry University \\ 30 Clara Street Brooklyn NY 11218 USA \\ Tel: 1-917-434 3418 E-mail: qiuus168@yahoo.com
}

\begin{abstract}
The purpose of this study was to investigate the Chinese customers' banking habits and the major barriers prevent them from participating in E-banking. The study was conducted in Chinatown area in New York City. There were 110 respondents completed the survey. The findings indicated that the Chinese customers did most of the banking transactions via teller stations. The Chinese customers' major concerns of online banking included security concern and the lack of bank staff support when they suffered from technical problems at home. The aging Chinese customers with low education and low income were less likely to participate in E-banking.
\end{abstract}

Keywords: Chinese customer, Banking, Habit, Barrier

\section{Introduction}

With the development of the Internet, more knowledge is accessible to people anywhere at anytime. Facilitating communication, data transmission, and global interaction, the Internet is a playing field unlike any other. Transcending the traditional barriers of time and space, the Internet is redefining the world of banking. The Internet has created new methods for carrying out a variety of financial transactions. With these developments, a new era of banking has emerged which has come to be known as "E-banking". E-banking encompasses an array of financial transactions, once done through the tangible exchange of information, now are done electronically. While the benefits of such advancements have been welcomed by most of the American customers, many Chinese customers are still uncomfortable with E-banking. The reason is that there are some drawbacks such as computer illiteracy, security, fraud, and theft have deterred Chinese customers from participating in E-banking. Many Chinese customers are still accustomed to tangible banking transactions. Some of the E-banking activities include the transactions of buying and selling goods, paying bills, transferring funds, and managing investments.

The psychological barriers involved with computer literacy, age, financial status, education, and the level of uncertainty avoidance are in relation to an individual's comfort level towards E-banking. The study was conducted in New York City Chinatown area to investigate the Chinese customers' banking habits and the major barriers which prevent them from participating in E-banking. It is important for the American financial institutions to understand the E-banking behaviors of the Chinese customers, because the Chinese population growing up fast in the United States. It is also important for the financial institutions in China to understand the local Chinese customers' E-banking behaviors, because the huge population with Internet access in China provides an attractive market for E-banking business. The findings in the study can help marketers understand more about Chinese customers' E-banking behaviors. It is obvious that the development of a successful E-banking system is based on the understanding of the banking customers' behaviors.

\section{Literature Review}

Today, the Internet is providing unlimited access to resources with real-time quality. More and more people are using the Internet to carry out actions that would have otherwise been done in person. "The online procurement industry is reportedly at least doubling in size every year" (World Almanac \& Book of Facts, 2001). In efforts to keep up with technological advancements, banks all over the world are offering E-banking as an appealing alternative to the traditional styles of banking with the intentions of luring potential customers. "Internet banking appears as a response both to the technical drawbacks of previous Home banking systems and to the growing demands of consumers" (Giannakoudi, 1999, p. 205). Despite the barriers associated with E-banking and the Internet, the advancements and benefits of E-banking to consumers as well as banking institutions is irreplaceable. From the consumer's perspective, E-banking has provided them with the ability to pay bills, manage accounts, and shop all from the convenience of their homes. This alternative has also reduced cost for the banking institutions that offer the service, "an online transaction costs the bank much less than a face-to-face interaction with a bank's teller" (World Almanac \& Book of Facts, 2001). With less paperwork to process every month and the money that is being saved, banks have been able to concentrate their efforts on improving other aspects of their organization.

As technology infiltrates the financial market, banks are anxious to capitalize on the spoils of technological 
advancements. Initially, banks implemented new systems internally improving communication and fostering standardization between branch offices. Later, banks began to use technology externally to promote interaction and increase transactions with customers. The developments of automated systems allow banks to more efficiently and effectively conduct common banking practices. With the introduction of Automated Teller Machines (ATM), the time-honored tradition of going into the bank to withdraw money or transfer funds, for example, becomes a method of the past. Through the use of ATMs, customers carry out activities such as withdrawing, transferring, or even depositing funds without having to speak to a teller. This self-service machine was a first step in the development of electronic banking.

As customers become more accustomed to ATMs and the variety of functions they can conduct on their own, the appeal for self-service automation grows. The Internet brings the bank to the customer replacing the old ideals of the customer needing to go to the bank. Customers are not the only beneficiaries from the transition to point and click banks. With the Internet in full swing, the banking sector is taking advantage of the new possibilities introduced to them. Norway is the first country in the world to offer Internet banking services (Ebersohn \& Henning, 2001). After this, the rest of the world follows, making Internet banking a worldwide phenomenon. A recent study by the American Bankers Association (ABA) and Grant Thornton found that nearly $20 \%$ of bankers believe the Internet will the dominant banking channel by the year 2005 (Poquette, 2002).

With increased appeal to offer services on the Internet, banks are seeking out and finding clients in many areas of the world. The Internet has provided banks with limitless freedom in offering services and establishing partnerships. While opening a branch in a foreign market can be a surefire way to make its presence known, a bank could loose a considerable amount of its investment if the branch is not successful in generating business. The freedom banks are experiencing in their attempts at cross-border banking is what Goutzinis (2001) calls a freedom of establishment and the freedom to provide services through the Internet.

This freedom, however attractive and beneficial, may present some challenge. Although the Internet has opened new possibilities for private and commercial banks, it also has opened the door to some challenges. Banks are becoming increasingly advanced and interconnected offering a variety of self-service banking options online and subscribing to a global payment systems and global structures. In an attempt to remain on the cutting edge in the evolutionary world, banks and bank managers are challenged by the new technology and software systems used to make the finance world run smoothly (Stewart, 2000). With constant upgrades and improvements, banks are having difficulty keeping up with the latest trends and technologies, while remaining competitive in the global marketplace. The second challenge Stewart points out is deciding what services to provide. In an effort to remain competitive in the global payment system the banking world now operates in, banks are challenged in deciding if they want to offer simple, traditional services or something completely new and radical to gain and retain customers. Often driven by corporate visions and organizational structures, banks are finding that they need to revise these strategies and cooperate with one another, working towards common interests in a cross-border situation to deter nontraditional competitors from penetrating the market. The third challenge Stewart cites is the bank's ability to manage a complex new variety of business relationships coupled with the organizational and cultural differences that will make these relationships more difficult. Stewart questions how a bank will deal with newly formed nonbank competitors, new technology partners, and an array of service providers. He advises banks to seek partnerships and alliances in the emerging cross-border banking systems.

While banks are responding to one of Stewart's challenges by deciding what services to offer, customers are familiarizing themselves with these very same services. Whether it is the traditional options such as account management or balance inquiry, or the more elaborate options such as loan applications or automated clearinghouse transactions, customers have a responsibility to know what options are available to them. Balance inquiry and account management are two of the more basic options available to an online customer. Balance inquiry refers mainly to watching the overall balance of an account and checking the daily balance. Account management implies the handling of assets such as transferring funds between accounts and general account maintenance such as balancing checkbooks and maintaining savings accounts. According to Poquette (2002), check balances (90.6\%), cash management $(81.1 \%)$ and wire transfers $(73 \%)$ are the most popular of the 19 reviewed services offered to small-business customers. In addition to these common and traditional services, bill presentment and payment are two other common elements found in the online banking package (Spiotto, 2001).

Not only are customers finding new ways to pay their bills, they are able to pay them from different places. Wireless or mobile banking has put banking transactions on the move. People are checking e-mail, receiving real-time stock quotes, and conducting conversations all with one little handheld device. With its convenience and utility, cellular phones have optimized the flow of banking information for wireless users (West, 2002). The impact that wireless phones with Internet access have on remote banking channels can be seen through the increasing improvements and 
new features being offered to cellular customers, while also targeting those customers who would conduct their finances from a wireless or Internet-based medium.

The benefits that Internet banking have brought to the modernized world does not come without a price. In the increasingly interconnected marketplace, anyone can have access to nearly anything from anywhere. People who engage in these online practices are vulnerable to a myriad of risks. The emergence of a whole new category of crimes has given both, the banking industry and customers something, to think about. Many problems affect one side of the partnership more than the other. Some of the more common problems include, but are not limited to, unauthorized access and the redirection of websites or e-mail, identity theft, credit card fraud, and phony organizations. These technology risks, as well as several others, have prompted the development of a category of safety measures for Internet transactions. Both banks and customers are expected to maintain certain levels of safety in addition to following and implementing procedures that help keep them safe. With customers accessing their money and making transactions from new places and spending in new ways, e-banking has taken them to new levels in their financial pursuits and abilities. Resulting from these new transactional capabilities is great responsibility (Jain, Hong, \& Pankanti, 2000).

Other problems facing e-banking customers are vulnerability to hackers and viruses and knowing with whom they are communication when they logon to a website. Many personal computer users are familiar with and have experienced viruses. These pathogens come from a multitude of sources, through e-mail, file downloads, and illegitimate software programs. They can cause damage in a variety of ways, weakening a computer and allowing a hacker access to personal information stored on the hard drive (Katyal, 2001).

In everyday life, credit cards fraud is an issue of concern. Verifying signatures and identification is a relatively common practice for in-store purchases, but what about online? While this is a somewhat effective technique for in-store purchases, credit card fraud still continues despite all efforts to the contrary. Credit cards fraud becomes increasing more possible and extremely easier to carry out (Bruno, 2001). With online shopping, the most common way to "check out" of a website is by using a credit card to purchase the selected items and complete the transaction. Mills (2002) reported that "One recent report says credit card fraud is now 12 times higher online than in-store, while another report pegs online fraud at four times as frequent as the oldfashioned kind" (p.7). Another result of credit card fraud online is identity theft. Using a stolen credit card number, the defrauder pretending to be the cardholder steals and assumes the victim's identity, passing off his or her actions as those of the cardholder.

Though there are several security concerns that the consumer must take into consideration to ensure their safety on the Internet, the burden to provide a safer online environment lies more so in the banking industry's hands. Banks are faced with the responsibility of making e-banking a safe venture, not only for themselves, but for their consumers as well. Key elements for establishing a security plan include reviewing intrusion detection systems, maintaining well-trained staff to handle any computer issues and protect the integrity of the data, and employee verification, including background checks if necessary. Since a customer can manage nearly all of their finances online, banks are faced with the obligations, as service providers, to guarantee their clients' security. Banks must assess the risk involved to the consumer and the companies, establish a plan for security, and analyze possible solutions and monitor their implementation to alleviate security concerns about e-banking. Banks, however are not perfect entities, and like their customers, they may make mistakes. There are generally seven management and security shortcomings that are attributed to a bank's security problems (Levitt, 2001). Carlson, Furst, Lang, and Nolle (2001) explain that this lack of consumer confidence can not only lead to large financial losses, but the lack of confidence in the security measures can lead to the slowing of company development.

\subsection{Successful E-banking Strategies}

\subsubsection{The Internal Banking Strategies}

The responsibility for safety lies heavier in the hands of banking institutions. Since they are the service providers in most cases, they have equal if not more responsibility in making their websites, databases, and networks safe for the Internet and handing e-commerce transactions. Banks should subscribe to certain requirements and prevent themselves from falling into the most common pitfalls. Some of these problem areas include the potential of internal threat and minimizing the importance of small network problems that if ignored may become larger and more damaging (McCarthy \& Campbell 2001). Some suggestions made by Pray and McCoppin (2001) for regulating internal security include staying away from passwords that are linked to an employee's name, address, or social security number, and programs that offer to store a password for easy, repeat access.

\subsubsection{The External Liability}

Another area for concern is the use of third party providers. Increasingly, most large banking institutions contract 
with third party service providers to handle issues outside their realm of knowledge. Banks should verify the integrity and identity of the companies they are dealing with, and address any and all concerns when dealing with these agencies.

\subsubsection{Technological Developments for Safety}

Authentication, identification, and authorization are three big areas that information technology developments have profoundly affected. Other security concerns that compose banks' strategies for a safer banking environment are encryption and the use of tangible identification methods. Messages that travel over the Internet are susceptible to interception by someone other than the individual at the intended destination. For this reason, sending sensitive information such as bank account numbers and credit card numbers over the Internet is troubling for some consumers. Encryption techniques exist to counter these security weaknesses. In another effort at customer security, some banks are using techniques such as tangible devices, or something a customer possess to ensure their safety (Middlemiss, 2002).

\subsubsection{Legislation}

The absence of territorial boundaries in cyberspace is causing challenges for legislation that depends on the well-defined perimeter of time and space and separation of agencies and people (Shanmugam, Suganthi, \& Balachander, 2002). Banks have the responsibility to maintain a set of goals attained through well designed security measures or a "security architecture" which provides the roadmap to an organization's strategic safety vision (Patilla, 2001). This roadmap should lead to compliance with government regulations, their best interests, and the needs of their customers to provide and promote a safe E-banking atmosphere. To that end, protecting the consumer is of vital importance for services such as e-banking and e-commerce which are dependent on continuous customer interest and usage. While it is important that a customer take responsibility for their own safety, consumers must be made aware and educated, if necessary, about the levels of security protection available to them. Customers should understand their rights and obligations as Internet users, costs they may incur and risks they may be vulnerable to by participating in actions such e-banking (Giannakoudi, 1999).

E-banking is popular in the United State today. Both the banks and the customers take the advantages of E-banking. The United State is a country with diverse cultures. People with different cultural backgrounds might have different behaviors. According to the encyclopedia Wikipedia (2006), the Chinese population in the United States is more than 3.5 millions, some of them are American-born-Chinese, and some of them are first generation of immigrants. Most of them are located in some big cities such as New York, Los Angeles, San Francisco, Boston, Washington DC, and Philadelphia. The study was conducted in New York City to investigate the Chinese customers' banking habits and the major barriers which prevent them from participating in E-banking.

\section{Methodology}

The overall purpose of this study was to investigate the Chinese customers' banking habits and the major barriers which prevent them from participating in E-banking. The findings of the study can help marketers understand more about the Chinese customers' banking behaviors, and can help financial institutions implement effective strategies to attract and serve the customers.

The respondents in the study were contacted at bank branches in Chinatown area in New York City. The data collection activities were permitted by the bank branch managers. Convenient sampling technique was applied in the study.

The instrument used in this study was questionnaire. The survey was comprised of two questions and the respondent's demographic information. These data were used to determine the respondents' banking habits and the major barriers which prevent them from participating in E-banking.

\section{Findings}

The survey was conducted at six bank branches in Chinatown area in New York City during fall 2007. Two branches were Citibank branches, two branches were Chase bank branches, and two branches were HSBC branches. Totally, there were 110 questionnaires had been completed and submitted. Table 1 shows the respondents' demographic information.

Regarding the question "With what medium do you do most of your banking transactions?" There were 62 (56\%) respondents reported they did most transactions with teller station, there were $32(29 \%)$ respondents reported they did most transactions with ATM, and there were only $16(15 \%)$ respondents reported they did most transactions with Internet (shown in table 2, table 3, and table 3).

Regarding the question "What are the major barriers prevent you from participating in E-banking?" There were 99 
(90\%) respondents reported "security concern", there were $64(58 \%)$ respondents reported "without technical assistance from bank staffs", there were 21 (19\%) respondents reported "computer illiteracy", and there were $8(7 \%)$ respondents reported "without computer or Internet access" (shown in table 5). The 99 "security concern" respondents and 64 "without technical assistance from bank staffs" respondents were from any gender group, any age group, and education level group, and any income level group. The 21 "computer illiteracy" respondents were from at least one of the following two groups: "over 50 years old" group and "high school dropout and high school diploma" group. All the 8 "without computer or Internet access" respondents were from "annual income under $\$ 25,000$ " group.

\section{Summary and conclusions}

The study shows most of the Chinese customers in New York City still prefer to do banking transactions with teller station, irrespective of their gender, age, education level, and income level. A couple reasons account for this phenomenon. First, many banks set branches in Chinatown area in New York City. It is very convenient for customers to do banking because of the location. Second, customers prefer the high-touch service channel, because they can request services or ask questions when they need. Third, customers consider on-site banking is more secure. Hofstede (1980) identified four cultural dimensions that could differentiate countries; one of the dimensions was weak versus strong uncertainty avoidance. Many Chinese customers are strong uncertainty avoidance oriented.

Compared to the on-site banking (56\%) and the ATM banking (29\%), there are only $15 \%$ of the Chinese customers prefer the online banking. Most of these $15 \%$ customers are featured with relative young age (under 30 years old), relative high education (college level education), and relative high income (annual income ranges from $\$ 25,000$ to $\$ 50,000$ ). Those customers, featured with relative old age (over 50 years old), relative low education (high school dropout and high school diploma), and relative low income (annual income under \$25,000), account for only a small portion of the group prefer online banking. The findings indicate that aging people with low education and low income are less likely to participate in online banking.

Fall in the middle between on-site banking and online banking, there are $29 \%$ of the Chinese customers prefer ATM banking. The reason accounts of this phenomenon could be: ATM banking combines the features of relative convenience (the location), relative high tough service channel (customers can ask bank staffs for assistance if they need during the business hours), and relative safety (security).

Regarding the major barriers which prevent Chinese customers from participating in E-banking, the "security concern" is the single most important barrier. There are $99(90 \%)$ respondents report that they consider the safety of the online banking. The second most important barrier is "without technical assistance from bank staffs". The findings indicate that when the Chinese customers participate in online banking, they consider the security issue and technical issue. They are afraid that their information is obtained by third party or misused by the financial institutions; and they are afraid that they can not get assistances from bank staffs when they suffer from computer technical problems at home. The "computer illiteracy" is an online banking barrier for those aging and low-educated Chinese customers, especially those aging customers. The "without computer and Internet access" is an online banking barrier for those low income Chinese customers. It is surprised that only $8 \%$ respondents report "without computer and Internet access", while $25 \%$ respondents report "computer illiteracy". That means there are $17 \%$ of the respondents who own computers but they are computer illiteracy. The reason is that other family member(s) rather than the respondent uses the computer at home. For example, it is the respondents' spouses, the children, or the grandchildren who use the computers.

It doesn't make sense for financial institutions to promote the E-banking to those customers without computer or computer illiteracy. On the contrary, the computer-skilled customers with Internet access are the financial institutions' target market of E-banking. The major task for the financial institutions is to remove the online banking barriers and convince customers to participate in E-banking. How to protect customers' information and how to set up call center to support customers are the two major concerns for many financial institutions.

Although the study was conducted in New York City, however, all the respondents were Chinese. The findings are useful for financial institutions which try to promote E-banking to Chinese customers in China. It is estimated that, by 2007 , there are 162 millions Chinese people with Internet access in China, it accounts for more than $12 \%$ of its population (Miniwatts Marketing Group, 2007).

The major limitation of the study is the sampling. The nonprobability sampling technique and the relative small amount of samples prevent the findings from being generalized. Although all the respondents in the study are China, however, the first generation of Chinese immigrants might have different characteristics as the American-born-Chinese generation does. It is believed that the first generation of Chinese immigrants is more Chinese culture oriented, while the American-born-Chinese generation is more American culture oriented. The 
researcher didn't identify the generation difference of those respondents created another limitation of the study.

\section{References}

Bruno, M. (2001). Microsoft gives boost to surrogate card numbers. Bank Technology News, 14(10), $31,34$.

Carlson, J., Furst, K., Lang, W., \& Nolle, D. (2001, revised). Internet banking: Market Development and Regulatory issues. In Society of Government Economists Conference 2000. The new economy: What has Changed, and the challenges for Economic policy. Washington, DC: Office of the Comptroller of the Currency.

Giannakoudi, S. (1999). Internet banking: The digital voyage of banking and money in Cyberspace. Information \& communications Technology Law, 8(3), 205-244.

Goutzinis, A. (2001). European banks and the cross-border provision of services vie the Internet: Commercial practices and regulatory concerns. Journal of International Banking Regulation, 3(3), 208-229.

Hofstede, G. (1980). Culture's Consequences. Beverley Hills, CA: Sage.

Henning, J. J. \& Ebersohn, G. J. (2001) Risk to the South African financial markets. Journal of International Banking Regulation, 3(3), 269- 290.

Jain, A., Hong, L. \& Pankanti, S. (2000). Biometric identification. Association for Computing Machinery, Communications of the ACM, 43(2), 90-98.

Katyak, N.K., (2001). Criminal law in cyberspace. University of Pennsylvania Law Review, 149(4).

Levitt, J. (2001). Security-the enemy within. Information Week, (834), 67-70.

McCarthy, P., \& Campbell, S. (2001).Taking e-security to a higher level. Financial Executive, 17(9), 50-51.

Middlemiss, J. Banks get smart about computer chip cards. (2002, April 8). Retrieved September 19, 2007, from http://www.banktech.com/story/techfoucus/bnk20020408s0027

Mills, S. (2002). Web security must not stop a firm from doing business. American Banker, 167(137), 7.

Miniwatts Marketing Group (2007). China Internet usage Stats and Telecommunications Market Report.

Retrieved November 24, 2007, from http://www.internetworldstats.com/asia/cn.htm

Patilla, J. (2001). Designing an e-commerce security architecture. Software Magazine, 21(2).

Poquette, B. (2002). Consumers flip to the Internet channel for financial services Bank News, 102(4), 18-22.

Pray, A., \& McCoppin, P. (2001). More convenience - more risk: Internet security Challenges to successful Treasury management. AFP Exchange, 21(2), 50-54.

Shanmugam, B., Suganthi, R., \& Balachandher, K. (2002). Malaysian regulation versus E-banking. Journal of International Banking Regulation, 4(1), 84-95.

Spiotto, A. (2001). Electronic bill payment and resentment: A primer. The Business Lawyer, 57(1), 447-473.

Stewart, J. Jr. (2000). Changing technology and the payment system. Current Issues in Economics and Finance, 6(11), 1-5.

West, L. (2002). Dial M for money: Western European banks are buying into wireless Technology. Bank Technology News. Retrieved August 26, 2007, from http://www.futurebanker.com/btn/articles/btnjan01-3.shtml

World Almanac Education Group Inc. (2001). Internet Basics. World Almanac \& Book of Facts, 566-569.

Wikipedia. (2006). Chinese American. Retrieved November 20, 2007, from http://en.wikipedia.org/wiki/Chinese_American

Table 1. Respondents' demographic information

\begin{tabular}{|l|l|l|l|l|}
\hline Gender & Age & Education & Annual Income & Total respondents \\
\hline Male 62 & $<30$ years : 41 & High school level: & $<\$ 25,000: 25$ & 110 \\
Female 48 & $30-50$ years: 38 & 34 & $\$ 25,000 \quad$ to & \\
& $>50$ years: 31 & College level: 62 & $\$ 50,000: 65$ & \\
& & Professional & $>\$ 50,000: 20$ & \\
& & school level: 14 & & \\
\hline
\end{tabular}


Table 2. I do most teller station transaction: respondents' demographic information

\begin{tabular}{|c|c|c|c|c|}
\hline Gender & Age & Education & Annual Income & $\begin{array}{l}\text { Total numbers of } \\
\text { respondents and } \\
\text { percentage }\end{array}$ \\
\hline $\begin{array}{l}\text { Male: } 35 \\
\text { Female: } 27\end{array}$ & $\begin{array}{l}\text { <30 years: } 15 \\
\text { 30-50 years: } 22 \\
>50 \text { years: } 25\end{array}$ & $\begin{array}{l}\text { High school level: } \\
20 \\
\text { College level: } 35 \\
\text { Professional } \\
\text { school level: } 7\end{array}$ & $\begin{array}{l}<\$ 25,000: 15 \\
\$ 25,000 \quad \text { to } \\
\$ 50,000: 37 \\
>\$ 50,000: 10\end{array}$ & $62(56 \%)$ \\
\hline
\end{tabular}

Table 3. I do most ATM transaction: respondents' demographic information

\begin{tabular}{|c|c|c|c|c|}
\hline Gender & Age & Education & Annual Income & $\begin{array}{l}\text { Total numbers of } \\
\text { respondents and } \\
\text { percentage }\end{array}$ \\
\hline $\begin{array}{l}\text { Male: } 17 \\
\text { Female: } 15\end{array}$ & $\begin{array}{l}\text { <30 years: } 16 \\
\text { 30-50 years: } 12 \\
>50 \text { years: } 4\end{array}$ & $\begin{array}{l}\text { High school level: } \\
10 \\
\text { College level: } 18 \\
\text { Professional } \\
\text { school level: } 4\end{array}$ & $\begin{array}{l}<\$ 25,000: 8 \\
\$ 25,000 \quad \text { to } \\
\$ 50,000: 19 \\
>\$ 50,000: 5\end{array}$ & $32(29 \%)$ \\
\hline
\end{tabular}

Table 4. I do most Internet transaction: respondents' demographic information

\begin{tabular}{|l|l|l|l|l|}
\hline Gender & Age & Education & Annual Income & $\begin{array}{l}\text { Total numbers of } \\
\text { respondents } \\
\text { percentage }\end{array}$ \\
\hline Male: 10 & $\begin{array}{l}\text { and } \\
\text { Female: } 6\end{array}$ & $\begin{array}{l}\text { 30-50 years: } 4 \\
>50 \text { years: } 2\end{array}$ & $\begin{array}{l}\text { High school level: } \\
\text { College level: } 9 \\
\text { Professional } \\
\text { school level: } 3\end{array}$ & $\begin{array}{l}<25,000: 2 \\
\$ 25,000\end{array}$ \\
& & $>\$ 50,000: 9$ & $16(15 \%)$ \\
\end{tabular}

Table 5. barriers of using online transaction

\begin{tabular}{|l|l|l|l|l|}
\hline Security concern & $\begin{array}{l}\text { Without technical } \\
\text { assistance }\end{array}$ & $\begin{array}{l}\text { Computer } \\
\text { illiteracy }\end{array}$ & $\begin{array}{l}\text { Without computer } \\
\text { or Internet access }\end{array}$ & \\
\hline 99 & 64 & 21 & 8 & $\begin{array}{l}\text { Number } \\
\text { respondents }\end{array}$ \\
\hline $90 \%$ & $58 \%$ & $19 \%$ & $7 \%$ & $\begin{array}{l}\text { Percentage of } \\
\text { respondents }\end{array}$ \\
\hline
\end{tabular}




\section{Appendix: Survey Instrument}

Welcome to my survey! The purpose of the survey is to investigate the Chinese consumers' banking habit and the major barriers which prevent them from participating in E-banking. If you are Chinese, please complete this survey. Thank you very much for your cooperation!

Indicate your gender.

- Male

- Female

Indicate your age group.

- Under 30 years old

- 30 - 50 years old

- Over 50 years old $\square$

Indicate your level of education.

- High school dropout or high school diploma $\square$

- Some college or bachelor degree $\square$

- Master or doctor degree

Indicate your annual income.

- Under $\$ 25,000$

- $\$ 25,000$ - $\$ 50,000$

- Over $\$ 50,000$

1. With what medium do you do most of your banking transactions? Choose only one.

- Teller station $\square$

- ATM

- Internet

2. What are the major barriers prevent you from participating in E-banking? Choose all apply.

- Security concern

- Without technical assistance from bank staffs

- Computer illiteracy $\square$

- Without computer or Internet access $\square$

- Others $\square \quad$ Please specify: 


\title{
A Study on the Space-Time Dynamic of Global
}

\section{Avian Influenza and Relationship with Bird Migration}

\author{
Gennian Sun \& Huanhuan Yang \\ School of Tourism and Environment Science, Shaanxi Normal University, Xi'an 710062, China \\ Tel: 86-29-8530 $7521 \quad$ E-mail: gennian.sun@gmail.com \\ This work was supported by the National Natural Science Foundation of China (40271052).
}

\begin{abstract}
In the past 100 years, the outbreak of avian influenza all over the world is periodic, and it is more and more frequent and harmful, which is thought to be related with deterioration of ecological environment. In recent 3 years, the outbreak of avian influenza is seasonal, it mainly breaks out from the end of fall to the beginning of winter and from end of winter to the beginning of spring, because at this time, the climate and temperature change fiercely, which is a possible inductive factor of avian influenza. By mapping the places where avian influenza broke out before 2000 and after 2003, we found that global avian influenza mainly distributed in the arc zone of West Europe, Mediterranean Sea, West Asia, Southeast Asia and Latin America, where the interaction of sea and land is intense, and fowls and water birds inhabit densely. It is demonstrated that the avian influenza virus exists in the water body like sea, lakes and swamps, and the chemicals discharged by human activities are the possible causes of avian influenza virus variation. By comparing the global space-time distribution of avian influenza with the flyway of migratory bird, we found that eights flyways are the main zones where avian influenza broke out frequently, so it can be concluded that bird migration is an important approach to spread the avian influenza all over the world.
\end{abstract}

Keywords: Avian influenza, Periodicity, Seasonal fluctuation, Spatial distribution, Bird migration

\section{Introduction}

Avian influenza is short for the epidemic influenza, which breaks out in fowls. It is a high infectious disease caused by the subtype of influenza a virus and is defined as list A infectious disease by the Office International Des Epizooties (Gao and Su, 1999). Avian influenza first broke out in Italy, after that, it broke out in Spain in 1918, which led to the death of 21 million people. In 1955, it was formally named avian influenza (Xue, 2003). Since 2003, a total of 250 million fowls died of avian influenza (including ones that were killed), 265 people were infected with avian influenza virus and 109 people died. The direct economic loss of the world caused by avian influenza is over 250 billion dollars. The avian influenza has aroused the attention of government and academic world in every country because it not only impedes the development of world economy, but also endangers people's health (Gao and Wang, 2006).

At present, the study on avian influenza mainly focuses on the field of animal husbandry and veterinary science, including toxicity detection, diagnosis of avian influenza in livestock and fowls, research and development of antivirus medicine, spread approaches, as well as establishment of plans and countermeasures for emergency etc. (Guo, 2004). For example, some scholars thought that avian influenza is caused by the pathogens that can be filtrated (Liao and Song, 2004); investigation carried out in the United States revealed the host of avian influenza and its main spread approaches (Pomeroy, 1982); some scholars put forward countermeasures for avian influenza (Oxford and Lambkin, 2006) In China, study on animal husbandry and veterinary science is unprecedented (Cui and $\mathrm{Li}, 2005$; Chen, et al, 2004), such as the research and development of vaccines for avian influenza (Liu et al, 2005) and the analysis on the influence of avian influenza on animal husbandry (Chen and Li, 2005). However, avian influenza is a natural focus disease, its outbreak must be related with the geological environment, and has specific and dynamic space-time characteristics. Recently, analysis on the influence of temperature variation on avian influenza was carried out (Cui and Wang, 2005), and the space-time distribution of high pathogenic avian influenza has been studied (Fang, et al, 2005). But their study only focused on the special region of Chinese mainland, and paid no attention to the global situations of avian influenza.

In this study, we collected the avian influenza information of the world through the internet, including the time when avian influenza broke out, the place where avian influenza broke out, as well as the number of fowls killed, and the number of people who were infected with avian influenza; further more, we collected the relating environmental information, such as the climate variation, environment pollution and bird migration. We integrated these data and established a dynamic database, which exhibits the space-time distribution of avian influenza, and analyzed the relationship between avian influenza and bird migration. 


\section{Dynamic analysis of the outbreak time of avian influenza all over the world}

\subsection{The periodicity of global avian influenza in the past 100 years}

In this paper, we collected a total of 2454 items of information about the avian influenza from 1950 to April 2006. We made a statistical analysis on these information and figure out the number of countries in which the avian influenza broke out in the recent 50 years (Figure 1). As we can see from Figure 1 that there are four stages when the avian influenza broke out frequently, i.e. 1957-1966, 1975-1985, 1991-1999, and 2003-now. Around 1960, avian influenza broke out in six countries and regions, they are Hong Kong in 1957, Scotland in 1959, England in 1963, and Canada in 1966; from 1975-1985, avian influenza broke out in six countries, they are Australia in 1976, Scotland and German in 1979, United States in 1983, Ireland in 1984, and Australia in 1985; in 1990s, avian influenza broke out in ten countries and regions, they are England in 1991, Australia in 1992, Mexico in 1994, Australia, Mexico and Pakistan in 1995, and Hong Kong, Italy, Australia in 1997; from 2003 to now, the outbreak of avian influenza is much more frequent than before, in 2003, it broke out in United States, Holland, German, and Korea, in 2004, it spread to 9 countries, and the number of countries in which avian influenza broke out in 2005 and 2006 are 16 and 34 respectively.

We can see from the outbreak situation of avian influenza in the recent 50 years that the global avian influenza exhibits three characteristics: the first, the outbreak of avian influenza is periodic, there are four stages when the avian influenza broke out frequently, that is around 1960s, around 1980, the early 1990s and early years of 21 century; the second, the outbreak of avian influenza is more and more frequent, from 1960s to 1980s, the period of avian influenza was 20 years, and in 1980s, it decreased to 10 years, in 1990s, it became 5 years, after 2003, avian influenza broke out every year, and the situation seems becoming worse and worse; the third, avian influenza is spread to more and more countries and regions, in 1960s, it only broke out in a few countries or regions, and in 1980s, it broke out in several countries, since 2003, the number of countries and regions in which avian influenza broke out began to grow significantly, and up to April 2004, it had spread to 54 countries of five continents, and became a global problem that endangers the animal husbandry and public health.

We made a statistical analysis on the global diseases that endanger people's health and life in recent 50 years, and classified them into traditional disease, modern disease and infectious disease according to the cause of disease. Traditional disease is brought by the underdevelopment of economy, and is decreasing with the development of social economy; modern disease is caused by the abuse of technology, bad life style and non-sustainable development, and it is more and more serious; the infectious disease is usually caused by various complex factors, and it usually breaks out periodically. Avian influenza is an infectious disease that breaks out periodically and has the modern characteristics, because since 1990s, avian influenza broke out more frequently and was spread to more and more countries and regions. Climate variation, environment pollution, and style of animal husbandry are the possible causes of avian influenza.

\subsection{Seasonal change of avian influenza all over the world since 2003}

Since 2003, avian influenza has become a common threat to health in worldwide range. We collected the reports about epidemic situation of avian influenza from February 2003 to April 2006, analyzed these data by month and educed the situation of avian influenza within a year, including the number of countries in which avian influenza broke out, the number of people infected with avian influenza, the number of people died, and the number of poultry died or killed. Three parameters of were used to draw a statistical figure about the situation of avian influenza within a year (Figure 2).

We can see from Figure 2 that the outbreak of global avian influenza is seasonal in recent four years, mainly from the end of autumn to the beginning of winter (October to November), and from the end of winter to the beginning of spring (February to April), further more, it exhibits the trend of changing from "single-peak pattern" to "double-peak pattern". The stage of February to April in 2003 is the first fastigium of avian influenza, during that time, avian influenza broke out in four countries or regions, 87 people were infected, two people died, and the situation in Holland was more serious than the other three countries. The stage of January to April in 2004 is the second fastigium of avian influenza, during that time, avian influenza broke out in nine countries, 37 people were infected, and 24 people died. The stage of January to April in 2005 is the third fastigium of avian influenza, in January, eleven people were infected and three people died, from March to April, avian influenza broke out in five countries, 32 people were infected and two people died. The October to November of 2005 and the January to March of 2006 is the "double-peak" stage, in October 2005, avian influenza broke out in ten countries, twelve people were infected, and four people died, in November 2005, avian influenza broke out in nine countries, 18 people were infected, and nine people died; in January 2006, avian influenza broke out in four countries, 28 people were infected, and eight people died, in February, avian influenza broke out in 26 countries, thirteen people were infected, and seven people died, in March, avian influenza broke out in nine countries, three people were infected and two people died. 
The seasonal outbreak of avian influenza within a year is related with the following three factors: the first, the survival and proliferation of virus need cool environment, according to the experiment on virus survival, virus will live longer if temperature is low, at zero centigrade, avian influenza virus can survive over 30 days, so it is easier for virus to infect animals or people; on the contrary, virus will live much shorter if temperature is relatively high, for example, if the temperature is over 22 centigrade, virus can only survive four days, so there is little chance for it to infect animals or people. The second, the fastigium of avian influenza usually emerges when the season changes or temperature fluctuates greatly. In the Northern hemisphere, the time of October to December is just at the end of autumn and the beginning of winter, and the time of February to April is just at the end of winter and beginning of spring, at this time, temperature fluctuates greatly, and epidemic influenza prevails easily, so temperature change is an important factor to induce the outbreak of avian influenza. The third, bird migration is an important factor to spread avian influenza to different regions of the world, at the end of autumn and beginning of winter every year, migratory birds migrate from the north to the south, which will bring the avian influenza virus of the water area in high latitude regions to the south, while at the end of winter and beginning of spring, migratory birds migrate from the south to the north, which will bring the avian influenza virus of water area in low latitude regions to the north.

\section{Analysis on the space-time distribution of avian influenza all over the world}

Being affected by bird migration, trade of livestock and fowls and flow of people, the distribution of avian influenza is very complex, and there is no agreement on the distribution of original places of avian influenza at the present time. In this paper, we discussed the distribution law of avian influenza at two stages and paid special attention to discovering the original places of avian influenza and its distribution law.

\subsection{Distribution of avian influenza before 2000}

It has been more than 130 years since avian influenza broke out for the first time. We collected 24 items of record about the avian influenza all over the world from 1878 to 2000 and drew a figure about space-time distribution of avian influenza using the Arc View of GIS software. Before 2000, there are ten countries and regions, including England, Ireland, German, Spain, Italy, Pakistan, Hong Kong of China, Australia, Mexico and United States, in which avian influenza broke out, and these countries distribute on the arc zone from the North Sea, Mediterranean Sea, via Persian Gulf, Arabian Sea, South China Sea, Banda Sea, across the Pacific Ocean, to Gulf of Mexico. In Australia (four times) and Hong Kong of China (three times), avian influenza broke out more frequent than any other countries. In Spain and Hong Kong of China, the number of people who died is the largest. In accordance with geography, the arc zone is a region where the sea and land interact frequently, islands take up the larger percent of land, and the seas in this region are usually inland sea. Further more, the arc zone is the main channel of global transportation by sea, and the main habitable region for water birds and fowls, so it is affected by human activities to a great extent.

\subsection{Distribution of avian influenza after 2003}

We collected 2430 items of information about the avian influenza all over the world from February 2003 to April 2006, of the 45 countries and regions involved, Holland and Hong Kong of China are regions where avian influenza broke out firstly, and Vietnam is the country in which the epidemic situation was more serious than any other countries, because during this stage, avian influenza broke out 1023 times in 325 places in Vietnam, 93 people were infected, and 42 people died. In this paper, we paid more attention to the macro-distribution of avian influenza, so we incorporated the small countries, which border each other as one and separated the regions, which are far from each other in one country. Using the GIS software, we established a space database and property database in Arc View, and drew the figure of global distribution of avian influenza at the present time (Figure 3).

As we can see from Figure 3 that, except South Africa, Nigeria, and Niger, global avian influenza after 2003 mainly distributes at the triangle region from West Europe to Southeast Asia. If United States and Columbia are added, the distribution of avian influenza after 2003 is similar to the distribution of avian influenza before 2000. That is, it mainly distributes at the arc region approximately from West Europe (including Greece, Holland, Poland, German, France, England etc.), via Mediterranean Sea to countries of West Asia (including Turkey, Iraq, Afghanistan, Iran, Pakistan, India etc.), then via Indo-China Peninsula (including Vietnam and Cambodia), to Southeast Asia (including Hong Kong of China, Taiwan of China, Philippine, Indonesia and Malaysia), and then across Pacific Ocean to Latin America (including Mexico, United States, Colombia).That triangle region includes the following sea areas: North sea, Baltic sea, Gulf of Bothnia, Bay of Biscay, Mediterranean Sea, Adriatic Sea, Black sea, Caspian Sea, Red sea, Persian Gulf, Arabian sea, Bay of Bengal, Gulf of Thailand, South China sea, Java sea, Malacca Strait, Caribbean Sea, Gulf of Mexico, Great Lakes, Hudson Bay. Global water birds and fowls mainly inhabit in the triangle region described above, in which nine countries are the main places where avian influenza broke out frequently and are the "disaster areas" of the world. The numbers of people infected and died are shown in table 1. 
Besides, we summed up the number of places where avian influenza broke out and the number of fowls died or killed in some countries from January 2005 to April 2006 (Table 2). We can see from table 2 that in 2005, avian influenza mainly broke out in Asian area, and influenced the animal husbandry of Vietnam, Thailand, Indonesia, Japan, China, and Turkey to a great extent. Since 2006, avian influenza began to spread to Europe and Africa, and influenced France, German, Italy, Rumania, Nigeria and Egypt etc. Avian influenza broke out in fourteen countries of Europe and four countries of Africa, further more; cat was infected with avian influenza in German.

\subsection{Analysis on the causes of the global distribution of avian influenza}

The factors that influence the distribution of avian influenza are complex. Distribution of sea and land, the ecological environment, host animals, and the flyway of migratory bird are factors that have close relationship with the distribution of avian influenza. It is demonstrated by the global distribution of avian influenza that the "original places" mainly distribute at the region where water and land interact mutually, including the countries and regions where there are many islands, archipelago, lakes, and swamps. It can be explained in the following three aspects: the first, the cool and moist water area is fit for the survival of avian influenza virus, so the probability of the outbreak of avian influenza is increased (Glass, et al 2000); secondly, water bird and fowls are the host and carrier of avian influenza virus, they inhabit at the places where water and land interact such as sea, island, lake and swamp, the dejection of birds is not only the origin of virus but also the culture medium for virus to proliferate, avian influenza virus can easily be isolated from the water polluted by bird dejection without condensation (Constandinos, 2003); the third, the direct discharge (or after elementary decontamination) of industrial waste water and life sewage make the pollution in sea, lake and swamp be more and more serious. The zone from Mediterranean Sea to the South China Sea of and Java Sea of Indonesia is the most severely polluted area, the biochemical reaction and variation of a large number of pathogens and poisonous chemicals in water may be the factors to induce avian influenza virus.

Basing on the above cognizance, we classified the avian influenza virus into "primary type" and "spread type". And we speculate that the zone from England and Holland of West Europe, via Italy and Spain beside the Mediterranean Sea to West Asia, then via Indo-China Peninsula and Southeast Asia to Indonesia archipelago, and then across the Pacific Ocean to Latin America, is the original place of avian influenza, in which avian influenza is mainly of "primary type" (including cross infection within area), and the virus may be formed by the variation of pathogens (mechanism is till unclear). The avian influenza in regions like the inland of China, Russia, Africa continent (such as Niger), in which there is a lack of water, may be of "spread type" introduced by the bird migration. It has been proved by the investigation in ten places of Chinese mainland, although more proofs are still needed. Hence, the essential measures to prevent global avian influenza are strengthening the monitoring on ecological environment, eliminating epidemic influenza pathogens and prevention and cure of water pollution.

\section{Relationship between the space-time distribution of avian influenza in recent three years and flyway of migratory bird}

Bird migration is an important approach to spread the avian influenza globally, which has been proved by research (Liu and Xiao, 2005; Li and Gu, 2006), so people now pay more attention to the relationship between bird migration and spread of avian influenza. Basing on the records about avian influenza in recent three years, we analyzed the relationship between the space-time distribution of avian influenza and flyway of migratory bird under the support of GIS, with the purpose of grasping the macro-law of avian influenza. Some scholars summed up the global flyways of migratory birds as eight routes, i.e. Atlantic Ocean, Black sea-Mediterranean Sea, East Africa-West Asia, Central Asia, Southeast Asia-Australia, America-Pacific Ocean, Mississippi River of North America, and Atlantic Ocean of America (Zhang and Yang, 1997). In this paper, the records about avian influenza in recent three years were grouped according to season and migratory route, and were compared with the flyway and direction of bird migration so as to reveal the relationship between the distribution of avian influenza and bird migration. The migration of bird is seasonal, usually, birds rise up seed in the north from May to September every year, and then they migrate to the south from October to November, and live through the winter in the south from December to February of next year, then fly back to the north. Owing to that there was little record about the avian influenza in South America, North America and Oceania, we just analyzed the avian influenza in the "World Island" of Asia, Europe, and Africa, and drew a figure about the relationship between the distribution of avian influenza and flyway of bird migratory by using Arc View. It is demonstrated that at least 8 flyways correspond with space-time distribution of avian influenza. This result will be propitious to the study on the space-time distribution of "spread type" avian influenza.

Figure 4 shows the three routes where the distribution of avian influenza corresponds with the flyway of bird migration at the end of autumn and the beginning of winter. The left one is the flyway of bird migration from Siberia to Mediterranean Sea, and avian influenza broke with the migration of bird: in July, 2005, avian influenza broke out in Russia, in August, it broke out in Kazakhstan, and then it spread to Croatia and Romania in October, and at last 
broke out in Turkey in November. It is demonstrated that avian influenza spread from the north to the south when the bird migrate to south at the end of autumn and beginning of winter. The right one is the flyway of bird migration from Japanese Sea to Indonesia, along this route, avian influenza first broke in Korea in December 2003, then in Hong Kong and Vietnam in January 2004, and then spread to Indonesia in February. The middle one is the flyway of bird migration from east China to Indo-China Peninsula, avian influenza first broke out in Liaoning Province in October 2005, then in Guangxi and Fujian in December, at last spread to Laos and Thailand in January 2006. Figure 5 shows the five routes where the distribution of avian influenza corresponds with the flyway of bird migration at the end of autumn and beginning of winter. The left one is the flyway of bird migration from Gulf of Guinea to Black Sea, at the beginning of February in 2006, avian influenza broke out in Nigeria, then broke out in Niger at the end of February, after that, it spread to Egypt at the end of March, and Turkey and Iraq at the beginning of April, at last Azerbaijan at the middle of April. The right one is the flyway of bird migration from Mediterranean Sea to Northwest Europe; avian influenza first broke out in Bulgaria at the middle of February, then in Austria at the end of February, and spread to Denmark and Sweden at the beginning of March. The left three flyways are from Arabian Sea and Bay of Bengal to China and Mongolia. And we will discuss the relationship between the distribution of avian influenza in Chinese Mainland and bird migration in another paper.

\section{Conclusion}

The first, in recent 100 years, the outbreak of avian influenza is periodic. Its period changed from 40 years to 10 years, so the outbreak frequency of avian influenza is becoming higher and higher. The outbreak of avian influenza is in accordance with the deterioration of ecological environment. In recent three years, the outbreak of avian influenza is seasonal within a year, mainly at the end of autumn and the beginning of winter, and at the end of winter and the beginning of spring, because at this time, season changes, and temperature fluctuates greatly.

The second, by mapping the places where avian influenza broke out before 2000 and after 2003, we found that global avian influenza mainly distributes in the arc zone from West Europe, via Mediterranean Sea to West Asia, and from Indo-China Peninsula and Southeast Asia, then across Pacific Ocean to Latin America, where sea and land interact intensely, climate is cool and moist, and fowl and water bird inhabit densely. The poisonous chemicals discharged by human activities and the pollution of water area are the factors that induce the variation of influenza virus.

The third, comparing the distribution of avian influenza with the flyway of bird migration, we found that eight flyways in the "world island" of Asia, Europe, and Africa correspond with distribution of avian influenza. So we conclude that bird migration is an important approach to spread the avian influenza globally.

The fourth, in recent years, the Vechta University of German developed software of Vet GIS, which is used to collect, analyze and manage the data about epidemic disease in animal husbandry. The software plays an important role in the monitoring of avian influenza in Italy from 1999 to 2000 (Munch, 2003). We suggest that China should establish GIS and network for monitoring natural focus disease as soon as possible, so as to monitor the space-time dynamic of epidemic disease, understand their space-time distribution, and reveal the relationship between epidemic disease and ecological environment, accordingly, it will provide a scientific information platform for us to face up with the large-scale outbreak of epidemic disease.

\section{References}

Chen JJ, Jin ML \& Chen HC. (2004). Research progress on avian influenza vaccine. China Biotechnology. 24(4), 34-38.

Chen MY \& Li QC. (2005). Influence of avian influenza on the fowl production of China and countermeasures. Chinese Poultry. 27(2), 5-7.

Constandinos N, Sean C, Sue G, et al (2003). Identifying West Nile virus risks areas: The dynamic continuous-area space-time system. Am. J Epidermal. 157, 843-854.

Cui SJ, Li X, Fu, F. (2005). Epidemiology analysis on the avian influenza and countermeasures. Guide to Chinese Poultry. 22(22), 4-7.

Cui SJ, Wang JF \& Wu CY. (2005). A study on the space-time distribution of high pathogenic avian influenza. Livestock and Poultry Industry. 11, 7-9.

Fang LQ, Cao CX \& Chen GS. (2005). Space-time dynamic analysis of global avian influenza based on combined Internet and GIS. Chinese Journal of Epidemiology. 26(11), 839-842.

GAO F \& Su JL. (1999). Diseases of poultry. China Agricultural University Press, 742-771.

GAO YS \& Wang C. (2006). Analysis on the epidemic situation of the global avian influenza in 2006. Inspection 
and Quarantine Science. 16(2), 3-8.

Glass GE, Cheek JE, Patz JA, et al (2000). Using remotely sensed data to identify areas at risk for Hantavirus pulmonary syndrome. Emerg. Infect Dis., 6, 238-247.

GUO XB (2004). History and hazard of high pathogenic avian influenza. Chinese Journal of Animal Quarantine. 12(3), 43-47.

Li XR \& GU MH. (2006). Discussion on the human avian influenza in the bird migration area in Abazhou. Journal of Preventive Medicine Information. 22(1), 37-38.

Liao DJ, Song B. (2004). Review and epidemiology of avian influenza. Chinese Journal of Veterinary Phraseology.

Liu J, Xiao H, Lei F, et al (2005). High pathogenic $\mathrm{H}_{5} \mathrm{~N}_{1}$ influenza virus infection in birds. Science, $309,1206$.

Liu WX, Li F \& Feng CF. (2005). A brief description on the research and application of avian influenza vaccine. China Poultry. 27(3), 58-59.

Munch Z, Van Lilly S W, Booysen C N, et al (2003). Tuberculosis transmission patterns in a high-incidence area: a spatial analysis. In J Tubers Lung Disc, 7, 271-277.

Oxford JS, Lambkin R. (2006). Influenza is now a preventable disease. International Journal of Antimicrobial Agents. 27, 271-273.

Pomeroy BS. (1982). Avian influenza in the United States (1964-1980). Proceeding of the first International Symposium on Avian Influenza. Richmond, USA: Carter Comp Corp, 13-17.

Xue JS. (2003). Study on the avian influenza. Chinese Journal of Veterinary Science and technology, 28(4), 12-16.

Zhang FY \& Yang RL. (1997). A study on the bird migration in China. China Forestry Publishing House.

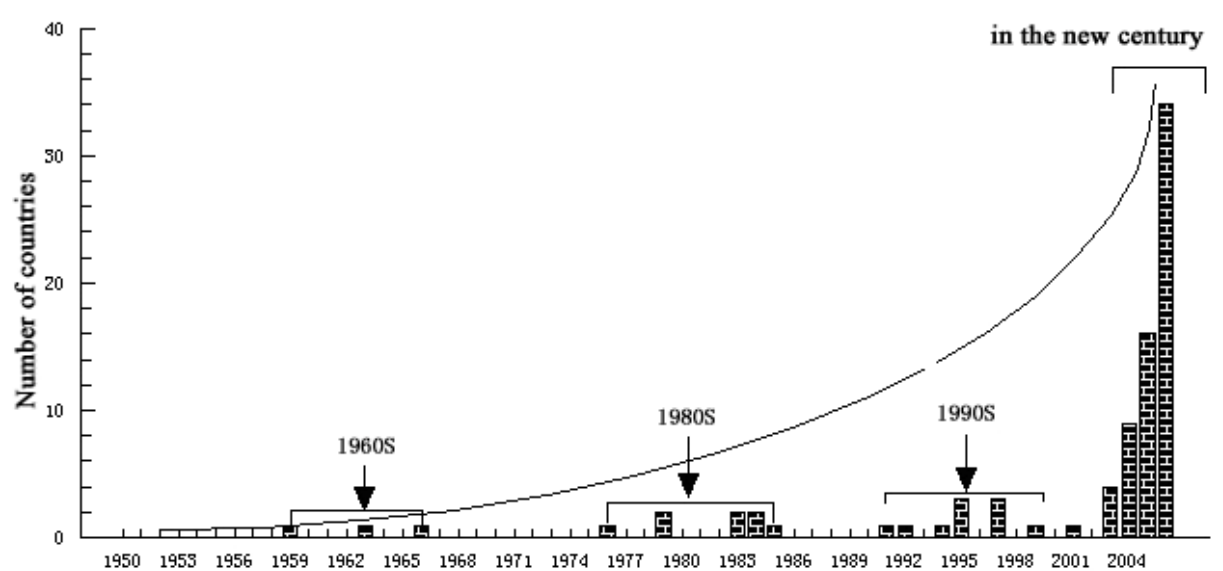

Figure 1. Outbreak cycle of Avian Influenza in recent 60 years

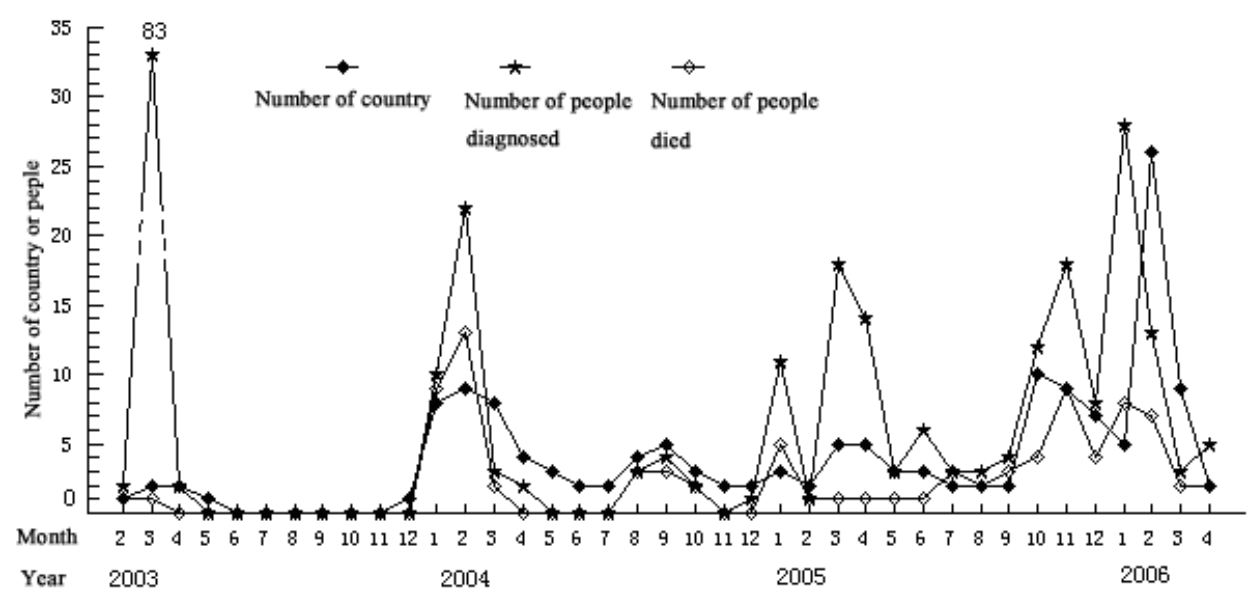

Figure 2. Statistical figure of avian Influenza from February 2003 to March 2006 


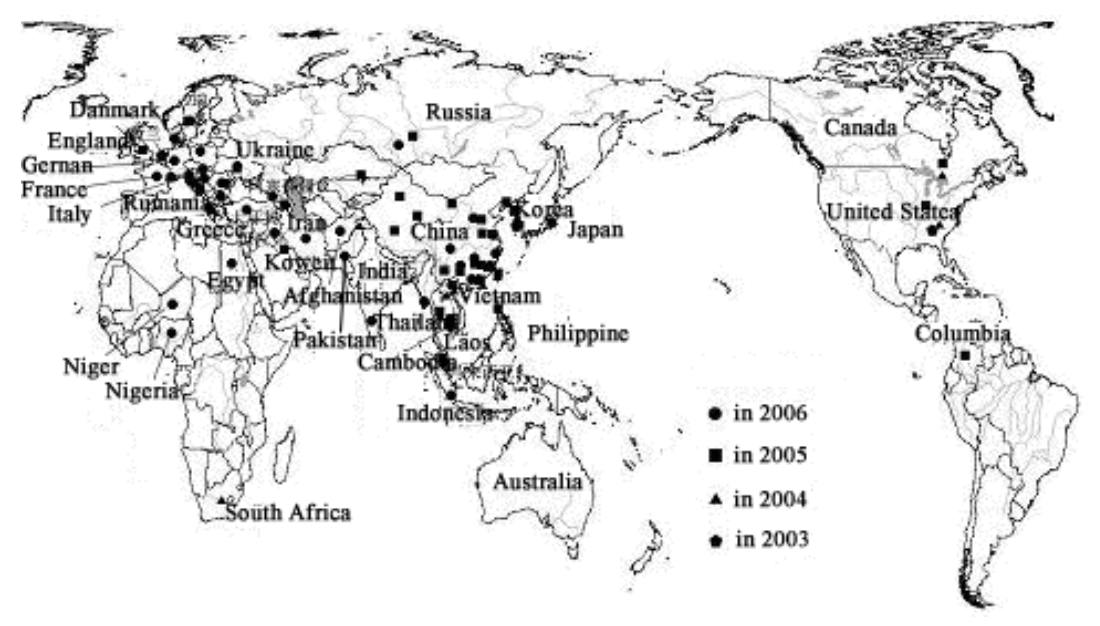

Figure 3. Distribution of Avian Influenza from February in 2003 to March in 2006

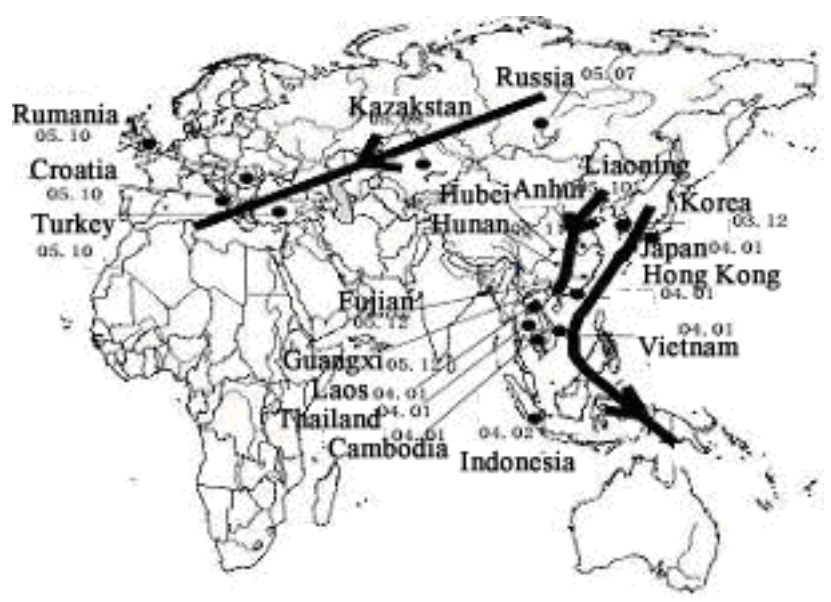

Figure 4. Flyway of bird migration and the distribution of avian influenza at the end of autumn and the beginning of winter

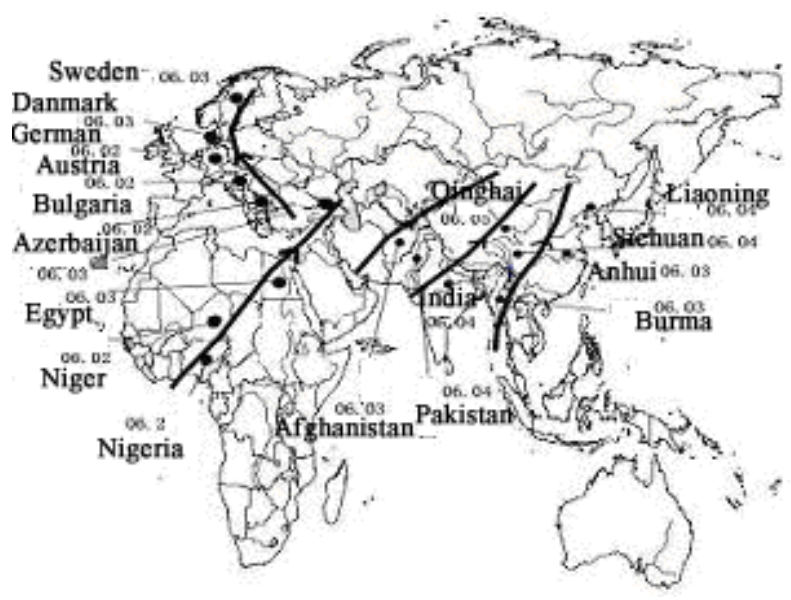

Figure 5. Flyway of bird migration and the distribution of avian influenza at the end of winter and the beginning of spring 
Table 1. Number of people infected with avian influenza and died from 2003 to 2006.

\begin{tabular}{|l|c|c|c|c|c|c|c|c|c|c|}
\hline \multirow{2}{*}{$\begin{array}{l}\text { Country/ } \\
\text { Region }\end{array}$} & \multicolumn{2}{|c|}{2003} & \multicolumn{2}{c|}{2004} & \multicolumn{2}{c|}{2006} & \multicolumn{2}{c|}{ Total } \\
\cline { 2 - 12 } & Diagnosed & Dead & Diagnosed & Dead & Diagnosed & Dead & Diagnosed & Dead & Diagnosed & Dead \\
\hline Azerbaijan & 0 & 0 & 0 & 0 & 0 & 0 & 7 & 5 & 7 & 5 \\
\hline Cambodia & 0 & 0 & 0 & 0 & 4 & 4 & 2 & 2 & 6 & 6 \\
\hline China & 0 & 0 & 0 & 0 & 8 & 5 & 8 & 6 & 16 & 12 \\
\hline Egypt & 0 & 0 & 0 & 0 & 0 & 0 & 4 & 2 & 4 & 2 \\
\hline Indonesia & 0 & 0 & 0 & 0 & 17 & 11 & 13 & 12 & 30 & 23 \\
\hline Iraq & 0 & 0 & 0 & 0 & 0 & 0 & 2 & 2 & 2 & 2 \\
\hline Thailand & 0 & 0 & 17 & 12 & 5 & 2 & 0 & 0 & 22 & 14 \\
\hline Turkey & 0 & 0 & 0 & 0 & 0 & 0 & 12 & 4 & 12 & 4 \\
\hline Vietnam & 3 & 3 & 29 & 20 & 61 & 19 & 0 & 0 & 93 & 42 \\
\hline Total & 3 & 3 & 46 & 32 & 95 & 41 & 48 & 33 & 192 & 109 \\
\hline
\end{tabular}

Data resources: Consultation Service Center of Hong Kong Special Administrative Region of the People's Republic of China, until April 12, 2006.

Table 2. Epidemic situation statistic of Avian Influenza in the world from 2005 to 2006

\begin{tabular}{|c|c|c|c|c|c|c|c|c|c|}
\hline \multicolumn{5}{|c|}{ Number of poultry lost in 2005} & \multicolumn{3}{|c|}{ Number of poultry lost from Jan. to Apr. in 2006} \\
\hline Country & Places & Infected & Died & Killed & Country & Places & Infected & Died & Killed \\
\hline Vietnam & 385 & 333356 & 303160 & 716726 & Vietnam & 258 & - & 30990 & 416272 \\
\hline S. Africa & 125 & - & - & 26454 & Turkey & 167 & 15270 & 16249 & 436222 \\
\hline Thailand & 113 & 45580 & 54013 & 376350 & China & 15 & 32800 & 32800 & 316700 \\
\hline Russia & 53 & - & - & 121287 & Iraq & 5 & 1652 & 1652 & 13478 \\
\hline Indonesia & 47 & 22665 & 346162 & - & Ukraine & 26 & 146291 & 146294 & - \\
\hline Japan & 38 & 22 & - & 1336965 & Romania & 15 & 473 & 233 & 386 \\
\hline Romania & 37 & 1563 & 1336 & 25733 & France & 3 & 10502 & 401 & 11300 \\
\hline China & 32 & 45796 & 42204 & 742348 & Italy & 12 & 2 & 17 & - \\
\hline Ukraine & 30 & 2077 & 2101 & 23589 & Egypt & 32 & 2065 & 19861 & - \\
\hline Turkey & 2 & 2900 & 2900 & 13190 & Nigeria & 17 & 54056 & 49681 & 26819 \\
\hline Total & 881 & 454260 & 752485 & 3228657 & Total & 659 & 350294 & 471204 & 2533331 \\
\hline
\end{tabular}

Data resources: Consultation Service Center of Hong Kong Special Administrative Region of the People's Republic of China, until April 12, 2006. "-” means data are not available. 


\title{
Establishment of Employment Relation
}

\section{Management Based on Employability}

\author{
Faping $\mathrm{He}$ \\ Department of Human Resource Management, Management College of Shenzhen University \\ Shenzhen 518060, China \\ Tel: 86-755-2653 5143 E-mail: fapinghe2004@yahoo.com.cn
}

\begin{abstract}
With the development of economic globalization and knowledge economic age, the traditional employment system has been gradually disorganized. How to rebuild relations between enterprises and employees and develop employment relations which can adapt knowledge economic age is an importance science task for the present research of human resource management and a realistic problem which enterprises face. In this article, we analyze the age background that the relational contract based on employee appropriability is transformed to the transactional contract based on employee employability, and discuss the reasons, concept and measures of establishment for employment relations management based on employability.
\end{abstract}

Keywords: Employability, Appropriability, Employment relation, Psychological contract

\section{Introduction}

With the development of economic globalization and knowledge economic age, the employment relations are changed in the whole world and the traditional employment system has been gradually disorganized. How to rebuild relations between enterprises and employees and develop employment relations which can adapt knowledge economic age is an importance science task for the present research of human resource management and a realistic problem which enterprises face.

In the concept of employment relations, the relations between employees and enterprises possess two meanings which include written contract relation and unwritten psychological contract relation. Because the employment has large differences with other economic businesses, so it can not implement employee management through specific contracts. With more and more universal knowledge jobs, the drive power of written contract becomes smaller and smaller, and the modern human resource management more and more emphasizes the functions of psychological contract in the employment relations management, so the psychological contract has become the core content of employment relations management. For psychological contract, it emphasizes connotative, informal and undemonstrative mutual expectations exist in the mutual relations between employees and enterprises except for contents regulated by formal employment contract, and they are the important factors to decide employees' attitudes and actions at the same time (Rousseau, 1995, p.287).

British psychologist Guest thought that the organization was a special group which was established by relations and in the process of enterprise organizational structural adjustment and employment relations change, the psychological contract was the core factor which could reflect this change through the most sensitive and centralized measure (Guest, 2001, p.98). Because traditional long-term employment psychological contract was destroyed, so in the knowledge economic age, to reestablish psychological contract through enhancing employees' employability and accordingly build harmonious and cooperative employment relations becomes the main strategy and task for employment relation management.

\section{Transformation of employment psychological contract from relational contract to transactional contract}

Rousseau named traditional psychological contract as relational contract and named new psychological contract which was forming as transactional contract (Rousseau, 1995, p.300). The relational contract more emphasizes extensive and long-term mutual relations with social feelings (such as dedication, trust and so on), and the transactional contract more emphasizes concrete, short-term and economical mutual relations (such as salary that the enterprise pays for employees because of their services). In the relational contract, the enterprise fosters appropriative employees, and in the transactional contract, enterprise should foster employees with employability.

\subsection{Relational contract based on employee appropriability}

In the past century, long-term employment system was the base platform for the management of enterprise employee. The interior development, job guarantee and income system based on longevity are characters of this employment 
system. In this employment system, the psychological contract between enterprise and employees is a sort of relational contract, and employees contribute their own loyalties and achievements to the enterprises and the latter ensures employees' job guarantee and incomes.

Lifetime employment system adapts organizational characters of industrial society and these characters include relative stable exterior environment, small interior organizational structure changes, prospective work sequence, easily intersected pipelining flow and easily decomposed functions and responsible range. In this organizational background, to establish long-term employment relations taking labor market as carrier is the effective ligament to contact enterprise and employees, which can not only effectively enhance employees' loyalties to the enterprise, but also can improve labor productivity for the enterprise. And the enhancements of employees' loyalties and labor productivity are all based on employees' appropriative skills.

In the production management mode of industrial society, the competitive predominance of enterprise comes from monopolized and dominative rights to employees' abilities to a great extent. Aiming at special consumers, techniques and equipments of the enterprise, employees' knowledge and skills are more appropriative, their productivity are higher and the domains which the enterprise engages are more effective. If there is no lifetime employment system, employees will have no interests to learn and grasp special knowledge and skills which are only useful for several enterprises, because the skills with high appropriability may have no market outside the enterprise. At the same time, if there are no guarantees for long-term employment, enterprise also doesn't want to invest resources to help employees grasp specialties relative to enterprise, because employees' job-hopping will induce the enterprise lost its all investments. Therefore, lifetime employment system becomes the base which can strengthen both investments, and the system guarantee for the enterprise to foster employees' appropriative skills, and employees become the human resource of enterprise appropriability.

Under the restriction of lifetime employment relations, the enterprise can obtain benefits brought by employees' high specialization of knowledge skill to the largest extent and doesn't worry about the job-hopping of valuable employees. And to employees, they can get occupations and life guarantee and avoid suffering unemployed mental pressures and terrified feelings from long-term employment contract, and when they have occupation guarantee, they are willing to devote energies to learn professional knowledge relative to the enterprise or their own posts and unceasingly enhance their own specialization level. Therefore, under the situation that the management environment of enterprise is relatively stable, the long-term employment system in the interior labor market can not only ensure employees' work safety and foster appropriative employees for the enterprise, but also strengthen employees' dependences to the enterprise and the enhancement of enterprise productivity.

\subsection{Transactional contract based on employee employability}

The coming of globalization and knowledge economical age changes the environment of organizational management faced by enterprises. Continually intense market competition makes enterprise lose stable development environment, and to face challenges and keep competitive predominance, the enterprise must adjust its structure and this adjustment will inevitably bring the disintegration of traditional employment system. And the strategic adjustment, technical advancement and work recombination are direct drive forces for the disintegration of long-term employment system. The strategic adjustment makes original employment relations by centralized control present the situation of decentralization, employment policies become diversification, employment relation become flexible. The rapid development of technology negates the mode developing skills through the gradual accumulation of interior labor market. The work recombination makes the organizational form of production produce essential changes, and the original enterprise specialization layer organization with single task, high degree of member specialization and specific professional limitation is gradually substituted by flexible team organization. And the flexible production system requires that employees possess various work skills.

In the process that the enterprise adjusts its organization, it gradually disorganizes traditional employment relation. The psychological contract between employer and employee was transforming from relational contract to transactional contract (Herriot and Pemberton, 1995, p.48), and "a new psychological contract taking the independence on the other party in the aspect of existence and development as its premise is occurring (Hiltrop, 1995, p.289)". The psychological balance formed by both parties of employment especially originally formed by employees is broken, and employees' work stable senses exchanged by their loyalty, obeying and hard work are weaken, and they are losing their loyalty and trusts to the organization. The traditional and stable mutual loyalty relations between organization and employees are gradually disorganized. In the forming transactional psychological contract, long-term employment relation is replaced by short-term employment relation, and the relations between employees and organization exchange relation, and employees can get enhancement of employment ability through high work performances in turn, i.e. they can obtain mobile and carriable skills to strengthen their own selections. Boxall and Purcell especially emphasized that point, and they thought people begun to notice employability but not 
stability in recent years (Boxall and Purcell, 2003, p.117).

\section{Reasons to establish employment relation management based on employability}

\subsection{Meanings of employability}

Accompanying with changes of employment relations, the research of employability begins to get people's recognition. At present, there is no a specific definition to define employability and many scholars thought employability was the ability to obtain job and be employed. British scholars Hillage and Pollard defined employability as that the employability was the ability needed to obtain original employment, maintain employment and get new employment when necessary (Hillage and Pollard, 1999, p.6). They thought one person's employability was decided by his depository of capitals such as including knowledge, technique and attitude, the method to manage and distribute these capitals, the ability to display these capitals to the potential employer and the space for individual operation.

The present research of employability emphasizes employability is a dynamic process of learning. Employability means the ability that one person shows in the process of obtaining employment post, maintaining employment post, reselecting and getting new post. The maneuverability indexes of employability are mainly presented in the skills that individual gets, such as common skill, special skill, occupation applying skill, psychological skill and so on.

\subsection{Inevitability to establish employment relation management based on employability}

In a knowledge economic society, because the security of post is difficult to be guaranteed, enterprises can attract, prompt and hold knowledge employees only depending on enhancing employees' employability. To establish new employment relations based on enhancing employees' employability has become necessary choice for the enterprise, and employees also should transform their abilities form pursuing security to pursuing employability.

Knowledge and competition are two characters of present age. Because enterprises face the threats of existence and employees face challenges of development, so to grasp knowledge is the headspring to possess competitive predominance not only for enterprise but also for employees, and knowledge pursuing has become the corporate need and aim for enterprise and employees. Employability or lifetime employment ability has become mutual beneficial base for both parties to establish new employment relations.

To develop employment relation based on employability is not only the need of organization, but also employees' As viewed from organization, it couldn't offer a stable work place and long-time employment promise for employees and it is not the aim that the organization should pursue to give employees stable works. The organization begins to think much of individual's values to organization, and for employees with more values and strong adaptive ability, the organization would pay out resources, but for employees with fewer values, the organization can not give promise. At the same time, the coming of knowledge economical age increases the value contributions of human capital in product (or service), accordingly strengthens employees' status in the negotiation between labor and capital, which also make enterprise more consider how to attract and hold talents as viewed from employees' demands. When enterprise can not give employees the promise of lifetime employment, the promise to enhance employability for employees also becomes the necessary requirement to attract and hold most talents.

The incomes that enterprise makes the promise enhancing employees' employability are obvious. First, enterprise has flexibility to implement strategic adjustments. Through receiving further education and training, employees continually refresh their knowledge, which can avoid excessively narrow knowledge and the rigidity of employment conversion, enhance their own employment abilities, and make enterprise possess the flexibility of strategic adjustment and the strength of updating and extension. Second, the promise of employability is a big inducement to make employees stay in the enterprise, because employees know that if they go to other enterprises which don't care about enhancing employees' values for higher salary, so in the age with technology changing quickly, they will finally face the threats washing out because of outdated technologies, and only in the enterprise which emphasizes employees' employability, their benefits can be guaranteed really only through continually refresh their own knowledge and skills. Just as Welch described "The employment offered by GE is the best work post all people want to compete all over the world. We possess the most excellent resources of training and development and the enterprise environment we build can offer large numbers of opportunities for the developments of individuals and their careers (Welch, 2005, p.87)". Third, it helps to enhance market competition of enterprise. To enhance the competition in the labor market, employees will have more enthusiasms to study and employees with high abilities are propitious to the market competition of enterprise. Therefore, the employment relation based on employability can not only help enterprise win and hold talents, but also can enhance the efficiencies of enterprise management and business operation.

As viewed from employees, they have to more emphasize their opportunities learning and growing in organization 
and the enhancement of employability to counteract the laid-off risk faced at any moment. Employees need obtaining knowledge, skills, ability and other characters which are emphasized by employer at present and in the future to maintain employment and ensure future employment.

In new employment relations, absolute loyalty to organization has become into relative loyalty to occupation, specialty and employability. That is to say, the organization and employees will regard each other as their own "gangplank", but not the "terminus". Baruch and Peiperl pointed that there was no any organization could guarantee employees' employment security today, and what they could do most was to make employees strengthen their skills for employment, and employers begun to give up their attitudes of householder and individuals needed depending on them more.

Therefore, only to establish new employment relation based on enhancing employees' employability and lifetime employment ability can realize the balance of benefits and aim between enterprise and employees. New employment relation fosters more sustainable relation of equality and mutual benefit between individual and organization. That is to say, enterprise increases employee's opportunities to strength their employability for exchanging better performances, loyalties and devotions that employees pay in the enterprise for the developments of the enterprise. The result implementing new contract is that the enterprise would possess a group of employees with occupation flexibility, and the employer would possess an enterprise with sustainable competition. And this new employment relation will create a sort of new enterprise mode with competitive predominance, in which the learning enterprise is composed by knowledge employees. It is a new developmental tendency of employment relation to establish the employment relation management based on employability and develop cooperative and win-win relations between organization and employees in the age background of integrative knowledge economy and global economy.

\section{Concepts and measures to establish employment relation management based on employability}

\subsection{Concepts to establish employment relation management based on employability}

To establish employment relation management based on employability, enterprise should transform management concepts first.

(1) Abandoning traditional employment concepts. Enterprise should not treat employees as one part of enterprise assets or a sort of resource occupied by it any more. New employment relation should establish equally cooperative relation between enterprise and employees and pursuing win-win. If one day the results of win-win don't exist any more, it should be reasonable that any party stops cooperation. In this way, both enterprise and employees have exact anticipations to the future cooperative relation and advance the management aim of employability together.

(2) Abandoning the traditional concept that employees are loyal. Enterprise should not think it is a sort of betrayal that talented employees resign and go to other enterprises any more. Employees' demission may indicate they want to change work environment or there is other post at which they can better exert their specialties. Only giving up this old concept, the management enhancing employability can be implemented.

(3) Establishing new enterprise ascription sense. Employees have ascription senses to those enterprises which really care about their future. Enterprise should let employees know that enterprise truly consider employees' benefits and the change of management environment induces working papers. Enterprise should let employees trust the fortune of the enterprise is just their own responsibilities, not responsibilities of super managers. In this way, employees can clearly realize the base and target that enterprise exist are to offer products (or services) satisfied by consumers and if enterprise can not do that, every one will lose his job. Only in this way, enterprise can establish stronger cohesive force in enterprise.

(4) Building people-oriented employment concept. In a good employment environment, enterprise must emphasized putting people first, respect individual occupation, evaluate objectively individual adaptive ability and maintain individual social capital and human capital. Enterprise should also respect employees' personal aim and belief and help them enhance their abilities to fulfill and adapt society through consciously changing their individual behaviors.

(5) Building enterprise culture which can be consistent with employability. To enhance employees' employability, enterprise must build enterprise culture which can be consistent with employability. This sort of culture not only can build necessary challenging atmosphere, strength employees' senses of pressure and crisis, encourage employees completely enhance their individual abilities, but also can create a sort of atmosphere which supports study, advocate the concept of lifetime study, emphasize and encourage employees' study and make it become tools to face transformation for employees, make employees obtain learning opportunities through various approaches, enhance employees' learning needs and learning responsibilities that exchange opportunities of existence and development by their own knowledge, abilities and intelligences.

\subsection{Measures to establish employment relation management based on employability}

Managers should take some concrete measures in organizing and managing enterprise to enhance employees' 
employability. In modern enterprises, familiar measures include following aspects.

(1) Post alternation in the interior of enterprise. New contract based on employability means employees have to study continually and prepare to rediscover their own potentials at any moment to adapt new environment. If one person can grasp several skills, his employability is enhanced obviously. The post alternation in the interior of enterprise can help employees achieve various specialties.

(2) Establishing occupational development center of enterprise. As the place to help employees know the demands and development tendencies of labor market in or out enterprise, occupational development center can issue opening information of job. It can help employees develop evaluations of their own occupational careers, offer occupational consultations for employees to strength employees' cognitions for themselves and accordingly increase employees' enthusiasms in occupational management and match certain occupational aim with individual. Enterprise can hold conference about occupational layout and offer reference books or evaluation software for employees' self-evaluation.

(3) Helping employees enrich their own human relation network. Enterprise should encourage employees participate in communion of same occupation such as various guilds, industrial organizations or proseminars, which can make employees communicate with talents in this industry, find differences and enhance themselves, and can make more craft brothers know our employees and enhance their employability.

(4) Actively implementing the training enhancing employees' employability. Enterprise should take training as a sort of long-term welfare and lead employees actively participate in some items to develop their general skills, new skills and special skills and store talents for the future development of the enterprise.

\section{References}

Baruch, Y. and Peiperl, M. (2000). Career Management Practices: An Empirical Survey and Implications. Human Resource Management. No.39 (4). p.347-366.

Boxall, P. and Purcell, J. (2003). Strategy and Human Resource Management. Basingstoke, Palgrave Macmillan. p.117-118.

Guest, D. (2001). Industrial relations and human resource management, in Storey, J. (ed.), Human Resource Management: A critical text (2nd edition). London: Thomson Learning. p.96-113.

Herriot, P. and Pemberton, C. (1995). New Deals: The Revolution in Managerial Careers. Chichester, Wiley. p.48.

Hillage, J. and Pollard, E. (1999). Employability: Developing a Framework for Policy Analysis. Labor Market Trends. No.17 (2). p.4-83.

Hiltrop, J. M. (1995). The changing psychological contract: the human resource challenge of the 1990s. European Management Journal. No.13 (3). p.94-290.

Rousseau, D.M. (1995). Psychological contracts in organizations. New York: Oxford University Press. p.287.

Welch, Jack. (2005). Winning. Citic Publishing House. p.87. 


\title{
Study on the Influence of Enterprise
}

\section{Culture's Reform on CRM Implementation}

\author{
Xiaoyu Li \\ School of Business Administration, North China Electric Power University, Beijing 102206, China \\ E-mail: masterlxy@163.com
}

\begin{abstract}
Customer Relationship Management (CRM) has been seen as a major trend during the recent years in Chinese companies. It is undoubted that technique plays an important role in CRM, but it is only a way and one of the factors which make CRM work normally. The keys to implementation CRM successfully are the person who uses CRM system and the proper enterprise culture. This paper analyses the reform of enterprise culture's effect on the implementation of CRM, and put forward a new customer-centered enterprise culture.
\end{abstract}

Keywords: Enterprise culture, CRM

\section{Introduction}

CRM has become known and be accepted by the companies in china with the popularization of internet and the occurrence of the E-business. It makes use of many modern methods to collect and analyze customer resources, which leads to the companies have better ability to communicate with customers and get maximum rate of customer profit. CRM puts scientific management theory of marketing into the use of software through the way of information technique. It is also used in the customer-related departments in companies, such as market, sales, and technique supporting. It attracts and keeps more customers through offering fast, considerate and good quality service and reduces the cost of collecting and keeping customers through optimizing the work flow of facing customers.

When considered from the point of technique, since CRM abides by the basic marketing theory, it should achieve expected marketing effect, but in fact the rate of failure of the operation of CRM is high, which takes huge loss to companies. To resolve this problem, this paper tries to revolve that enterprise culture is a key factor to lead the success of CRM implementation. And put forward how to build a proper enterprise culture's to effect the implementation of CRM.

\section{The influence effect on CRM implementation by traditional enterprise culture}

When companies develop to a certain level, enterprise culture's influence on the development of companies will become more important. Under a certain political background and economic environment, our traditional companies have already formed a kind of enterprise culture with Chinese characteristics, which used to play an active role in the company's development. And it is accepted by most of the staff. However, with the coming of knowledge economy era, what the traditional companies face are new economy with the characteristic of high technology and quickly developing IT technology, new management technology and management ideas. All of these have been attacked the old enterprise culture continually, which results to the occurrence of a completely new reform of enterprise culture, that is paying attention to the ability of using the customer resource-centered outside resources of the company. With these management technology and management ideas which take great influence on enterprise culture, CRM, a completely new strategy idea and work method, becomes one of the main powers to reform the traditional enterprise culture system with its unique charm and huge wallop. It makes the company from paying attention to the company's inside value and ability to the company's outside resources' ability of adoption. Many other reforms about enterprise culture originate from this one.

In order to carry out and adopt CRM system successfully, there must be some corresponding enterprise culture to support it, or there will be some obstacle. Even though the improvement of the staff can help the CRM system to succeed, there will still have some problems during the progress of adoption. The new cultural should be compatible with old ones, and it would be inclined to be helpful to the use of customer relationship resource. However, when the introduction of CRM theory brings contradiction between the old and new culture, company's old culture should give place to the new one, only those who have courage to reform the old culture of the company can carry out CRM theory completely and raise whole company's sense of culture to fit the new economic environment to make it have more powerful vitality.

\section{The enterprise culture matched with CRM}

The implementation and adoption of CRM needs corresponding new type enterprise culture. At the same time, as a 
powerful tool supporting, the new type enterprise culture offers security for the implementation of enterprise culture. The key characteristic of the new type enterprise culture which is fit for the need of the new economic era is that "considering the customer as the center", especially paying attention to maintaining the customers who have already existed.

Customers are the base of the company's existence and development. And the essence of market competition is customer resource competition. Competition raises the difficulty and cost of attracting new customers and impels more and more companies to pay more attention to maintaining old customers. The companies can reach most of their profiting if they put their marketing key on the customers, even though they don't invest on the new customers. Therefore, the aim of CRM strategy is customer retention, but not customer acquisition.

The enterprise culture which helps CRM work well also contains other characteristics which originate from "considering customers as the center". The characteristics of the enterprise culture which matched with CRM are showed as follows:

\subsection{Realizing that customers are external asserts of enterprises'}

During the process of business model transformed from product-centered to customer-centered, lots of companies, especially companies abroad, begin to consider customers as their important asserts and adopt many methods to show their consideration to customers to raise their satisfaction and loyalty to the companies. Just as what we see, more and more companies put forward these ideas, such as "customers first" and etc. Considering a company's development in a long term, it is a very important key to advocate and set up a idea that customers are company's external asserts.

\subsection{The first aim of enterprise management is making customers satisfaction}

Customers' satisfaction degree means that customers feel happy or disappointed with the comparison between their expectation and their real feeling to the product and service. Customers' satisfaction is the parametric between the perceived effect and the expectation. If the perceived effect is lower than the expectation, it shows that customers are not satisfactory; if they matched each other, it shows that customers are satisfactory; if the former is higher than the latter, it shows that customers are highly satisfactory. These judgments are very important to us, for they make us realize clearly the importance of the management of customer relationships. The reason why companies continually pursuit customers' high satisfaction is that customers who are a little satisfactory will change their suppliers if they find better and cheaper products. Only those who are very satisfactory with the products will not change their suppliers. It is this physical resonance resulted from satisfaction that creates customers' highly loyalty to the products. These customers will often buy the company's products afterwards and accept other products and service of the company.

\subsection{Paying attention to the utilization ability of the customer resources}

CRM provides a system which can make use of every kind of method to collect and analyze customer resource. It is an expert management idea and technology to manage companies' foreground, it also can help companies to make good use of customer-centered external resources and expand new market and business channels. At the same time it also raises customers' satisfaction and companies' ability of profiting in order to increase companies' integrated value.

\subsection{Realizing customers' individualized consumption demand}

In the information era, the market has from the seller's market to buyer's market. At this time, company's management structure is in a flat situation, there are multipoint connections between customers and company and the market has turned into a market environment which is lead by customers. In this situation, customers become harsher and harsher and their requirement to the products and service would also become higher and higher.

The global economic integration make products can move freely in the whole world, and the expansion of the seller's market make customers have a huge right to choose. The companies' operation strategy should be close to market and customers. They should not only understand what the customers say, but also offer different operation strategies according to customers' preference. Only in this way, they can get their market share. The new economic model resulted from the rise of internet begins to take the first step, as the companies become globalization, the boundary between industry become vague, a business environment which considers customers as the center and emphasizes on individual service begins to take its way.

\section{Problems during the transformation of enterprise culture}

\subsection{Deepening the understanding of the customer care}

The activity of caring about customers should be contained in the whole process, including the pre-chasing, chasing 
and pro-chasing customers' experience. It also runs through the whole links of business marketing, including customer service, the quality of products, the quality of service and after service. Considering through the angle of customers and companies, although the degree of customer care is difficult to measure and evaluate, it can be quantifiable. On the whole, the evaluation can be divided into three angles, that is search property, experience property and credence property.

Every property variable can be divides into two parts: the variables with search property can manage and distinguish customers' expectation through different ration methods to design out proper disciplines, rules and procedures; the variables with experience property and credence property can be improved through training and examining the workers have connections with customers. All of these depend on the worker's disciplines during their work. The companies standardize workers' acts according to making strict business operation procedures and disciplines to increase the staff's level of service.

CRM software's customer care module attracts related marketing variables into it, which make the abstract question of customer care can be measured through a series of related standard. This method can make companies adjust their strategies immediately to increase customers' loyalty to the companies.

\subsection{The confirmation of "the one-to-one customer view" in the internal of the company}

CRM is a synthesis of science and technology and human nature, when dealing with customer related problems, we should be people oriented and consider customers as the center. The staff in the internal of the company should confirm "the one-to-one customer view" and have a deep understanding of that customers are "company's external treasure" and "company's external asserts", but not "the company's one deal".

Every contact between the company and customers is a process the former learning and understanding the latter, and it's also a chance the latter experiencing the former. According to repeated visitations and interactive, the company can know the customer's preference and need to offer proper products and service to proper people in proper time and through proper methods. Only though this way, the company can care about customers sincerely, design proper, individual suggestions for every customer and make the customers feel the value of the company. The degree of satisfaction and loyalty will be increased naturally and the company's interest will be increased correspondingly.

\subsection{Increasing the vigor in the aspect of the training of worker's sense of enterprise culture}

In order to construct "customer-centered" enterprise culture and corresponding organization structure, it needs every worker's understanding and conjugation. As long as every worker understands the company's new enterprise logos, the logos can be carried out. As long as every worker can work freely in the new structure, the company can get the maximum interest, and training is the effective way to make workers avoid the contradiction of logos and make profit in the new structure quickly.

The company should consider the training of the enterprise culture which matches with CRM as a long plan and the training emphasizes on the introduction of logos, new organization structure's operation methods and the skills of communication with customers and so on. The workers should rotate among the departments of customer-supporting, sales and information and so on, for it can make them be familiar with the whole procedure, know every department's operation situation and resources and reduce the obstacles resulted from inter-departments communication. What should be paid the most attention is the integration problem of the internal of the company and customer-related departments, that is, the consistency between customers and different departments, sharing of information from different ways and the interactive rules abided by and so on.

\subsection{Paying attention to customers' loyalty often}

Just as company's products have lifecycle, customers also have lifecycle. The longer customers' lifecycle is, the company's relative mercantile rate of return is higher and the profit brought to the company will bigger. The famous "two eight discipline" thinks that $20 \%$ customers create $80 \%$ interest of the company. Someone modifies it as the following according to statistics $80 / 20 / 30$, that is to say, $20 \%$ customers create $80 \%$ interest, but half of it is offset by $30 \%$ non-profit customers. Therefore, the company should "eliminate" the weakest customers to improve its level of profiting. Those who bring the most interest to the company are not the biggest customers, because the biggest customers often require considerable service and discount which results to the reduction of the company's integrate profiting level.

Customer resource has become the origin of the company's interest. If a company can keep 5\% of its customers, its interest can be improved remarkably. Keeping customers' loyalty can make competitors can not contest the market share and maintain the stability of the workers and reduce the cost. CRM software gets the achievement of the research of customers' loyalty and qualifies it to the rules which can be measured and revaluated. It makes the company can exam its customers' loyalty easily to carry out effective strategies. 


\section{Conclusion}

In summary, with the reform of culture, the companies can pave the way for the implementation of CRM system and make the implementation and adoption of CRM go normally. At the same time, as a powerful tool which supports the new type enterprise culture, CRM will offer safeguard to the implementation and operation of the enterprise culture. However, the companies should realize that if they want the reform of enterprise culture to achieve the goal CRM requires, the companies will experience a miserable time, which is a very tough time. The companies' leaders should be the firm supporters of the implementation of cultural reform and make each worker contribute to the success of the reform. This is a very important step for the CRM implementation of company.

\section{References}

Liu, Xiaohong \& Zou, Peng. (2005). The Study of CRM Value Management Model in Commercial Bank. Management Science. (03): 58 61(in Chinese)

Peppard, Joe. (2000). Customer Relationship Management (CRM) in Financial Services. European Management Journal. June: 312 327

Yang, Luming. (2004).Customer Relationship Management theory and practice. Beijing, Electronic Industry publishing: 36 42 (in Chinese) 


\title{
A Study on the Planning of Food Safety \& Quality
}

\section{Management System in Supermarkets}

\author{
Xiaoping Li \\ School of Economics and Management, Nanjing University of Science and Technology \\ Nanjing 210094, China \\ E-mail:lixiaoping610@163.com \\ Zhijun Han \\ School of Economics and Management, Nanjing University of Science and Technology \\ Nanjing 210094, China \\ E-mail: hanzhij4531@ sina.com
}

This article is funded by the scientific and technological project of "research and development of HACCP and its Standardization in Supermarkets in Jiangsu.

\begin{abstract}
This article studies the standards for food safety\&quality management system, proposes the establishment of food safety\&quality management system to ensure food safety and focuses on the planning of such system in supermarkets.
\end{abstract}

Keywords: Supermarket, Food safety, Quality, Management system, Planning

With food being a kind of indispensable energy for our human beings, its safety issue is the baseline in our consumption. In the recent years, with increasing food-related diseases endangering our health, food safety has attracted more attention. According to a report from China Business Information Center, food sales in supermarkets will have taken up over $90 \%$ of the total by 2010 , hence revealing the important role of supermarkets in food retail. Therefore, this article will focus on the construction of food safety\&quality management system to conduct overall and standardized management on the sources and processes of food sales, and consequently, to ensure food safety.

At the very beginning of this article comes the current situation of researches on food safety management standards in and outside China. Then comes the construction of such system. Finally, our focus is paid to the planning of this system in supermarkets.

\section{The Current Situation of Researches on Standards of Food safety\&quality management system in and outside China}

The researches on food safety management system outside China are mainly based on HACCP, which was proposed by Pillsbury and Natick Lab of NASA in their joint development of space foodstuff in 1959. Later, many countries formed their respective standards for HACCP with their researches and applications of this system. In order to present a universal food safety management system shared all over the world, ISO issued ISO22000:2005 Food safety management systems - Requirements for organizations throughout the food chain on Sep. 1, 2005.

Referring to GB/T 19538-2004, GB/T 19001-2000, GB/T 19080-2003 and other food safety systems, China issued SN/T 1443.1-2004 Requirements of Food Safety System ( put into practice since Dec. 1, 2004) for the organizations in production, processing, packing, storage, transportation, sales involved in food chains as well as those producing and selling food and raw materials for human consumption. Actually, this regulation has provided bases for the construction of the food safety management system in the enterprises in food chains. Currently, China is planning to perfect it according to ISO22000 in order to issue a national standard for food safety management.

ISO9000 series standards were first laid down by ISO in 1987 and after some corrections were put into practice in 1994. Later with complete corrections, the 2000 edition was issued on Dec. 15, 2000. Currently, more than 90 countries and areas all over the world have adopted the standards as their national ones. As for China, its GB/T19000 is equivalent to the series standards. Actually, as a set of mature standards for safety management system, ISO9000 can be used in a variety of organizations with different scale, products, ownership and so on.

\section{The Construction of Food safety\&quality management system in Supermarkets}

Following ISO Guide 72, some standards for the construction of management system have been laid down in ISO 9001:2000 Requirements for Quality Management System and ISO22000:2005 Food safety management systems — 
Requirements for organizations throughout the food chain. Due to their consistent structure, we are able to integrate the two in management ideas and other aspects in order to provide standards for the construction of our integrated food safety\&quality management system.

This article, following ISO9001 and ISO22000 as well as taking in the reasonable parts in other management systems, aims at establishing an integrated food safety\&quality management system in accordance with the characteristics of supermarkets and of great feasibility by organically integrating the special requirements, standards and key technologies of food industry and the current advanced quality management systems. Here, the construction process includes planning, control, guarantee and improvement of this management system. Only the planning course of food safety\&quality management system in supermarkets will be mentioned in this article.

\section{The Planning of Food safety\&quality management system in Supermarkets}

\subsection{The policy and objectives for food safety \&quality in supermarkets}

The policy for food safety \&quality in supermarkets are issued by the supreme administrator of supermarkets to be used as their overall tenets and directions. By establishing such guidelines, supermarkets are able to strengthen the staff's cohesive force internally and reveal their faithful pursuit for food safety and hence achieve customers' trust externally.

\subsubsection{Policy for Food Safety in Supermarkets}

The general manager is responsible for the establishment and issuance of food safety policy. They should comply with the following aspects:

(1) They are supposed to be in accordance with companies' overall management guidelines as well as their own requirements for food safety;

(2) They should include promises about food safety and quality as well as great efforts to improve their management systems;

(3) They should reflect the framework for the establishment and realization of management goals and be put into practice with these goals set up in relevant functional departments and at different levels;

(4) They are expected to be understood by the whole organization;

(5) They should be evaluated in constant appropriateness.

And the supreme administrator (the general manager) is responsible for the implementation of the guidelines.

\subsubsection{Objectives for Food Safety in Supermarkets}

The general manager is responsible for the establishment of food safety objectives. The following standards should be followed:

(1) They should be measurable and in line with food safety policy;

(2) They are expected to be disintegrated in relevant departments and levels;

(3) They should be examined annually, the result of which should be kept in records.

\subsection{Process Recognition}

Here the process just refers to a series of interactive activities to convert input into output. Pursuing their additional value, organizations usually plan their processes to be conducted in controlled conditions. Meanwhile, the food-supplying processes in markets ( purchase $\rightarrow$ storage $\rightarrow$ sale) should be recognized, with special attention to the key stages and the interaction among different stages.

3.2.1 Recognizing the Process of Constructing Food safety\&quality management system and Its Application

(1) Planning: this process should be based on Item 4.1, Item 5.3 and Item7 of ISO22000:2005as well as Item 4.1, Item 5.4.2 and Item 7.1 of GB/T 19001-2000 idt ISO 9001:2000;

(2) Creating value, such as purchase, storage and sale stages;

(3) Offering support, including administration, resource management, the confirmation, verification and improvement of food safety system.

\subsubsection{Confirming the Order and Interaction of Processes}

(1)The order of food safety planning and realization processes is shown as follows:

Planning of safe food---Prerequisite programs---Preliminary steps to enable hazard analysis---Hazard analysis---Design and redesign of the operational PRPs---Design and redesign of the HACCP plan---Updating of 
preliminary information and documents specifying the $\operatorname{PRP}(s)$ and the HACCP plan---7.8 Verification planning---Operation of the food safety \&quality management system.

(2) The interaction among processes

Here, the supporting process is employed to support and monitor the operation of food safety\&quality management system; the safe food realization process and the supporting one interact with each other, forming a dynamic PDCA cycle of food safety\&quality management system, which is shown in Figure 2.

\subsection{Resource Allocation}

Reasonable allocation of necessary resources is another factor to ensure the effective operation of food safety\&quality management system, which includes resource supply, human resources, basic facilities and work environment.

\subsubsection{Resource Supply}

Through the planning course required by food safety system, a company will know what resources are necessary for it and then supply them in order to implement, maintain and constantly improve its food safety\&quality management system as well as to fulfill customers' satisfaction better.

\subsubsection{Human Resources}

(1) The middle-level and higher administrators in supermarkets as well as the technicians related to food safety should be trained about food safety\&quality management system to be qualified for their work;

(2) The staff should be educated, trained and assessed in sense of quality, food safety and the knowledge about HACCP, through which they will realize the importance of customer satisfaction and laws and regulations. In this way, they will be better qualified for their work and therefore make great contribution in their positions.

(3) The staff playing a particularly important role in food safety should be trained in the basic knowledge about HACCP and other relevant information. Only those passing the exam should be permitted to work.

(4) Human resource departments should keep the records on the staff's education, training, skills, experience and examination and so on.

\subsubsection{Basic Facilities}

The following basic facilities should be supplied, maintained and cleaned to meet the requirements in function and sanitary standards: relevant facilities in selling places and storehouses, food storage facilities and relevant monitoring appliances, sterilization facilities for washrooms, dressing rooms and sinks and other service facilities such as transportation vehicles, telecommunication and computers and so on.

\subsubsection{Work Environment}

The following requirements should be fulfilled:

(1) In order to guarantee the staff's health and energy, a shift system should be conducted in different work groups. In addition, they should receive regular physical examinations and be supplied with necessary labor protection devices according to Food Hygiene Law of People's Republic of China and the universal standards in food industry;

(2) The sanitary conditions of selling places and storehouses should be guaranteed;

(3) The work environment should be protected against any external pollution.

\subsection{The Planning of Food safety\&quality management system Documents}

In order to ensure the effective operation of the whole process, we are expected to produce some relevant documents of food safety\&quality management system in supermarkets at five levels according to ISO22000 and ISO9001. It is shown in Figure 3.

The first level: The policy and objectives for food safety \&quality in supermarkets reflect the overall tenets and directions of an organization;

The second level: The manual of food safety \&quality management in supermarkets, a programmatic document, gives instructions and restrictions on all the documents at lower levels.

The third level: The documented procedures of food safety \&quality in supermarkets, which is a supportive document for the one at the second level, lays down duties, procedures and methods for those universal inter-departmental activities, including the document controlling procedure, the record controlling procedure, the internal examination procedure, the procedure of controlling potentially unsafe products and so on;

The fourth level: HACCP plans, operational instructions, management regulations, technical specifications and so 
on are employed to instruct different departments to conduct their activities;

The fifth level: Quality records here serve as proof documents for food safety\&quality management system.

\section{Conclusion}

To sum up, Chinese supermarkets are expected to focus on food safety and exert efforts to set up their food safety\&quality management system according to relevant standards in order to implement the overall management of their food supply quality.

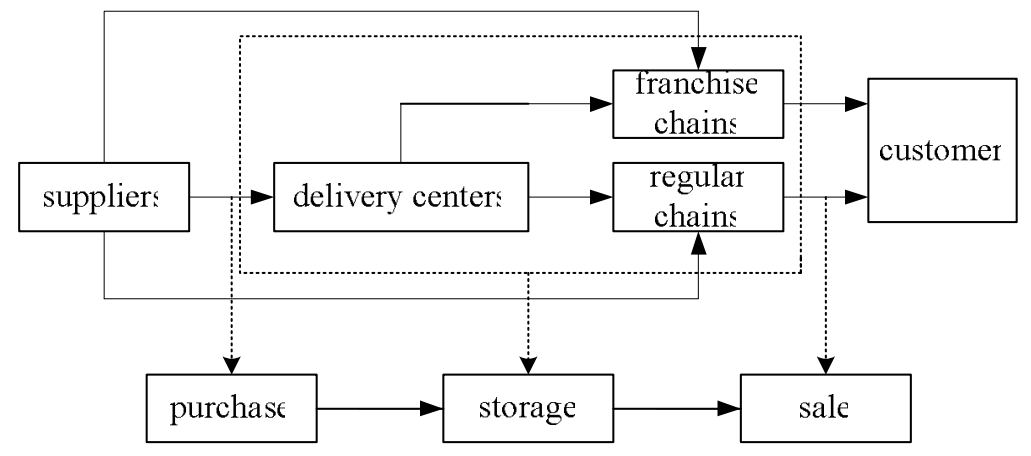

Figure 1 . The pattern of the supply chains of supermarkets

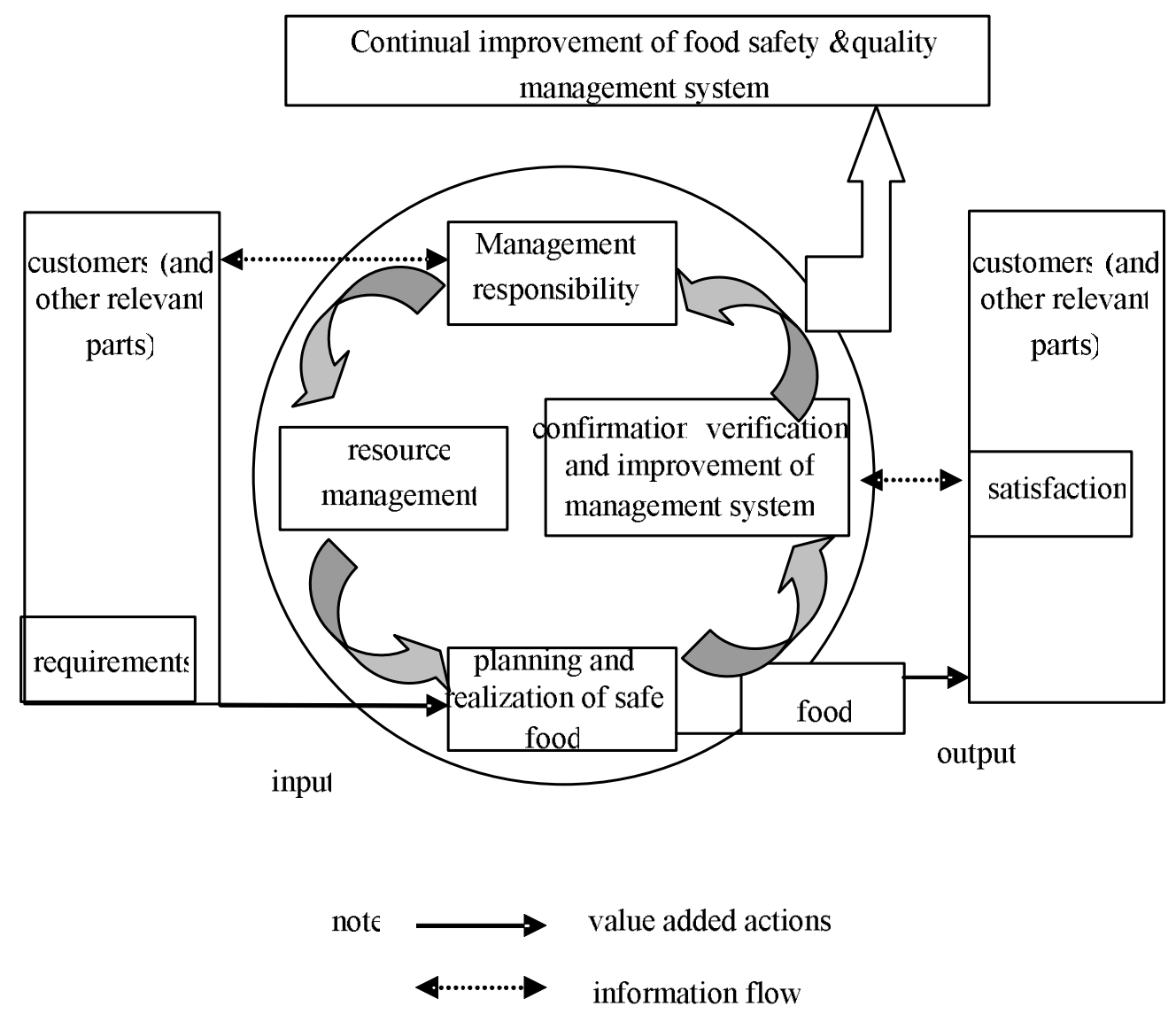

Figure 2. The flowchart of food safety\&quality management system processes 


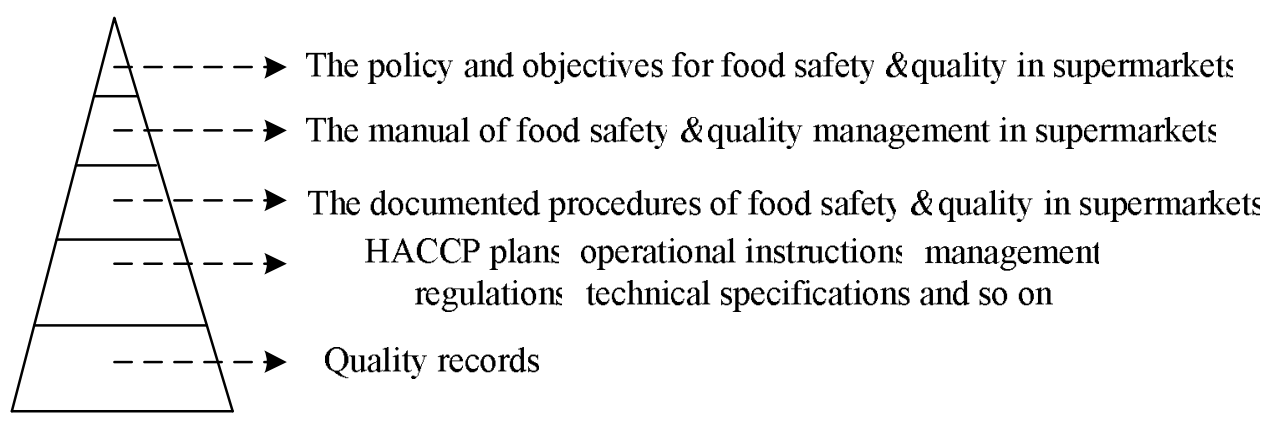

Figure 3. The framework of food safety\&quality management system in supermarkets

\section{References}

Han, Zhijun \& Xu, Qian. (2003). Quality Management. Beijing: Science Press.

Jiang, Nan et al. (2003). HACCP and Its Application to Food Production. Beijing: Chinese Journal of Chemical Engineer.

Khandk, S. S. e\& Mayes, T. (1998). HACCP Implementation: a Practical Guide to theIimplementation of the HACCP Plan. Food Control 9.1998.103-109.

Li, Xiaoping \& Han, Zhijun. (2006). Problems and Countermeasures in Food Safety in Chinese Supermarkets. Jiangsu Commercial Forum. May 2006.

Li, Xiaoping \& Han, Zhijun. (2006). Two PDCA Cycles--- Constructing Food safety\&quality management system in Supermarkets. China Quality. Sep 2006.

McAnelly, John K. (1994). HACCP: A Total Quality System For Assuring Food Safety \& Quality. 1994 PROCEEDINGS Annual RELIABLITY and MAINTAINABLITY Symposium

Sperber, William H. (1998). Auditing and Verification of Food Safety and HACCP. Food Control 9, 1998, 157-162

Sperber, William H. (2005). HACCP and Transparency. Food Control 16, 2005, 505-509. 


\title{
Research on the Design of Organizing
}

\section{Structure in Commodity Wholesale Markets}

\author{
Fengling Feng \\ Management Department, Wu Han University of Technology, Wuhan 430070, China \\ Economic Research Institute, Hebei University of Economic and Business, ShiJiazhuang 050061, China \\ Yongling Zhang \\ Ren Cheng Town middle school, Hebei, Xing Tai District, 055150, China
}

\begin{abstract}
The organizing structure of commodity wholesale markets is the fundamental guarantee for the markets to create value. At present, there are many wholesale markets in our country which have the problem of exerting its efficiency. The aim of designing the organizing structure is to realize the value of the markets. This thesis has done some research on the elementary elements and structure of organizing in terms of the types of wholesale markets.
\end{abstract}

Keywords: Commodity wholesale market, Organizing structure, Organizing elements, Design

\section{Introduction}

The organizing structure of commodity wholesale markets is the fundamental guarantee for the markets to create value. The aim of designing the organizing structure is to realize the value of the markets and to make the overall development stable and sustainable to achieve reasonable and efficient application of resources. The design in terms of various types of wholesale markets contains three aspects - for the newly founded wholesale markets in the countryside, design a new organizing structure according to the new environment; for the present wholesale markets in small towns and cities, where the inner and exterior environment is changing and new policies and strategies need to be adjusted, reconstruct the organizing structure; for those would-be or newly-founded large and modern markets, an innovative design is needed.

\section{Design Elements of Organizing Structure of the Commodity Wholesale Markets}

According to the types and situation and the three models of fundamental organizing elements: (1. Leavitt's diamond model, 2. Galbraith's pentagon model, 3 Pascale and Athos's 7S model) design the essentials of the organizing structure. The markets in the countryside are usually small-scaled and dominated by such commodities as farm produce, subsidiary farm produce and daily-used commodities. The consumption group is fixed. The customers mainly consist of the pedlars working in the wholesale markets and the villagers nearby. The fundamental organizing elements are: the personnel, strategy, structure and process. The selected elements here are the four in Galbraith Pentagon Model. Encouragement is not chose, because of the low interdependence between the wholesalers and the objects managed by the market administrative organization, the small direct mutual influence and less staff in the administration.

\section{The System of Organizing Structure of Commodity Wholesale Markets}

The system of organizing structure, formed from the aspects of function purview, duty and power mainly includes the structure of function distribution, of administrative levels, of departments and of authority.

\subsection{Structure of various administrative levels}

Structure of various administrative levels refers to the horizontal administrative level from the top administrative and decision-making level to the executives, such as the decision-making level, the senior administrative level, the intermediate administrative level, the grass-root administrative level, the executive administrative level etc. The horizontal administrative structure of wholesale markets in the countryside is usually not very obvious. The governments of the towns and villages don't set up a specified administrative departments. The only function of the wholesale markets in the countryside is to supply a place for exchange commodities, while the administrative levels of modern and large-scaled wholesale markets is obvious and thus they are multi-functional. This will be discussed later.

The horizontal administrative level from the top administrative and decision-making level to the executives -- such as the decision-making level, the senior administrative level, the intermediate administrative level, the grass-root administrative level, the executive administrative level etc. The horizontal administrative structure of wholesale markets in the countryside is usually not very obvious. The governments of the towns and villages don't set up a 
specified administrative departments. The only function of the wholesale markets in the countryside is to supply a place for exchange commodities, while the administrative levels of modern and large-scaled wholesale markets is obvious and thus they are multi-functional. This will be discussed later.

\subsection{Function distribution structure}

Function distribution structure refers to lay out reasonably the size and quantity of organizing function to realize the strategic goal of the wholesale markets, and distribute the function to different departments. The functions can be overlapped or lost. The function of wholesale markets determines its elementary capacities.

\subsection{Structure of authority}

It refers to the power and its purview of various administrative managers and ways or methods of the transverse coordination and communication.

\subsection{Structure of different departments}

It refers to the all operating units that are set up, in accordance with the scale and quantity of function, to realize the function of the wholesale markets and the relationship between these units. For instance, the investors, market administration committee, departments of information and security etc. Two offices as statistic collection and information publication can be attached to the department of information.

\section{Design of Organizing Elements and Institutions}

\subsection{Staff design}

The staff can be divided into two parts: macro- administrative staff and micro-administrative staff. The former mainly include the employees from the government and business and administration departments, and the departments of security, tariff environmental protection, sanitary and quarantine and layout and construction etc.At present, there are four main types of administrative body in rural wholesale markets:The first one is organized and managed by the farmers and state or collective business departments to supervise the rural wholesale markets. This kind of administration is usually in a backward situation with its outdated administrative methods. The aim is just to win profits and the majority of the staff is comprised of farmers. The second type is launched and managed by the government. For example, the present big-scaled modern wholesale markets in rural area and in the towns are launched and run by the governments aiming at promoting the local economic development by virtue of these markets. The administrative ability is relatively higher. In addition to the employees from the government to macro-manage these markets, the administrative staff also include people from departments of security, tariff, environmental protection, sanitary and quarantine and layout and construction etc. For the micro-administration of the markets, a committee is needed, whose task is to deal with the routine work. The third type is set up and managed by business departments. "It is advanced and exemplary. Most of the wholesale markets in charge are developed from some fairs, which proves that development of commodity exchange is from simple to complicated. During this process a department is needed to sponsor and manage big-scaled commodity exchange activity, so the business department due to its special function, undertakes this mission." (Peng Wenqiang, 2001, p.56) The structure of the administrative staff in the wholesale markets is out of balance - the employees dealing with routine work are more than enough, while those dealing with internet information is in short and the information construction level is relatively low. The establishment of the personnel engaging in auction, agency, and artificial administration markets has not been set up yet.

\subsection{Strategy structure}

From the point of view of administration science, strategic administration has two representative schools: one is competition strategy by Michael.E.Porter, based on industry economics; the other is industrial ability based on the analysis of the ability of the enterprises. The theory of strategic administration has already become an independent branch of administration science mainly including strategy and management of enterprises, strategy environment analysis (consisting of analysis of demand, resources distribution and analysis of competition ), strategy plan, strategy implementation and control and strategy organizing etc. To make developing strategy for the organizing structure of commodity wholesale markets, first of all, a target should be established -- to build a system of large-scaled and modern farm produce wholesale markets to establish a sound system to ensure a healthy development of the markets. "The establishment and development of farm produce market system should accord with the objective law of farm produce circulation, the development of the agricultural productivity, the present situation and power of our nation." (Long Shaoqun, 2002, p69) The common rule for the development and establishment of wholesale markets in many towns is: from low-class to high-class; from junior markets to mediate markets and finally to a large and advanced wholesale markets. It is true of the development of the hardware and software of the market system. Therefore, the strategic goal of the wholesale markets is flexible in the long run and its development should accord to the developing situation of the markets and the development of the productivity. It 
is characteristic of diversity, timeliness, hiberarchy and coordinatability.

\subsection{Structure Design}

According to the present situation and features of wholesale markets, it is necessary to improve the organizing structure of market management, make the investors and the proprietors, establish a legal-person-responsible system under the supervision of the board of directors and carry out a new administration model of modern collectivized corporations. A market is a bridge connecting the producers and retailers. It is a systematic structure of multiple procedures, mainly including production base, transportation, wholesale markets, and retailers. Thus, the structure design should be made from the angle the systematic science -including the investors (the board of directors), the commissioned manager (the president), that is, the legal person, production base, material circulation institutions, wholesale markets and retailers institutions. Some adjustments can be made in accordance with different types of markets. For example, the structure design for the wholesale markets in rural area can be simplified, while for those modern and large-scaled wholesale markets, a sound organizing structure should be built. (The structure is shown in Figure 1)

In Chart 1, the market design institutions mainly consist of the board, which is in charge of establish the development strategy of the market construction, important policies, the choice of the location for the market, the orientation of development, the size of the market, investment and the rate of profit sharing etc. It is also in charge of the selection of general manager. Under the leadership of the board, general manager is responsible for the management of the whole market. Some departments such as the personnel department, the treasury department, the operation department and the office dealing with daily work, are in the charge of the general manager. The duty of the office is to supply civil service and general reception work, organize conferences or meetings, administer the archives and undertake the security work. The treasury department is responsible for financial affairs, accountants, accounting, statistics, capital operation and the audit of financial accounts and their report forms. The operation department can set up one or more offices according to the specific situation, for instance, operation departments in the manufacture base, in the wholesale markets and the export and import operation department. The function of this department is to undertake the duty of a department according to the strategic planning.

The department of market planning is in charge of analyzing the interior and exterior environment of the organization, making short, mediate and long-term plans, and development target and plan. The personnel department is responsible for the allocation of posts and positions, organization and administration of cadres and reserve human resources, case study, personnel shift, and salary allocation etc.

\subsection{Function design}

This design refers to the overall distribution of the task, make clear the function of each department and distinguish their administrative levels. The common function design consists of basic function design, key function design and administrative level analysis.

Related to the overall task of commodity wholesale markets, its function can be summarized into five aspects: investment, planning, human resources, operation and service. The investment mainly contains the investment channel for market construction and reform, and the trade income as well as its distribution. Planning refers to investment construction and development planning, task distribution, function of departments, quantity and scale. The aspect of human resources includes personnel distribution in various departments, personnel training and instruction, the structure of the personnel and their salary allocation. Operation is chiefly in charge of the overall administration or management of the exchange process in the rural wholesale markets. Due to the different market situation, and different quantity and task of the operation department, for the modern large-scaled wholesale markets, it is comprised of the management of products supply, the sale in production markets, products circulation trade expenses, information and resources, and administration of the real estate market. The service includes rear service, catering service and accommodation service etc.

For those relatively small-scaled rural wholesale markets, we can simplify or weaken some of the basic functions. For example, the material circulation center can be combined with service center; operation department with catering department; accommodation department to rear service department. For those big-scaled modern wholesale markets, these departments can be further divided onto smaller and more specific departments. For instance, with the expansion and promotion of the markets, its contact with exterior world has increasingly wide and close. The market depends more and more on it. The greater influence on the markets requires more departments with specific functions. The supply of new products should be added to the function of products supply department. Sale function should include the aspects such as customer demand and feedback.

Key function design is to choose one or two important function among all the basic functions. The realization of key functions will have a direct influence on the realization of strategic target. For example, the key function of rural wholesale markets is to provide a smooth channel for commodity supply and sale, therefore the key function should 34 
be supply and sale --- the supply of products in production bases and the sale of selling markets.

At present, the wholesale market construction in our country has a problem of repeated construction, blind development and lack of production wholesale markets based on large-scaled central wholesale markets. Therefore, it is necessary to adjust and reorganize the present markets and build a large-scale trade center. In addition, the wholesale market construction of production base is also a weak point. Thus, the key function at present is to form a smooth chain of production base market, sale market and material circulation to emphasize the key function of the market organizing pattern.

\section{5 design of administrative levels}

It refers to the horizontal organizing level of administration or management, the number of departments from the top administrative level to the lowest level. If it is defined by the positions of the leaders, its design refers to quantity and level of leaders from the top leader to the lowest leader. From the point of administrative levels, it refers to the number of organizing levels, but virtually refers to the different forms of inner labor division - each level has its own duty. The basic administrative level is usually determined by its labor division. The methods and procedures are as follows:

\subsubsection{The basic level is determined by the horizontal labor division}

Those complicated and disperse administration organizations have more levels, those organizations, whose task and administration are centralized, have less levels. The most distinguished levels are decision-making level, administrative level and working level. Those departments with less people, centralized administration and simple task, have even less levels.

4.5.2 Calculate the specific administrative levels in accordance to the range of the efficient administration. The calculation can be referred to the standard value of the following Table 1. (Ren, Hao and others, 2005, p81 83)

4.5.3 According to the organization optimization principle, set up specific administrative levels

The administrative levels should be set up based on the function distribution and the characteristics and ability of the personnel. When the top administrative level is of high capability, the range of administration can be widened. For professional and technical management, the administrative levels can be lessened to supply a chance for the professionals to participate the administration and policy making to develop their ability and encourage their innovation and meanwhile, to avoid influencing the making of professional design schemes. Departments with simple functions and capable personnel more functions can be added and the levels and departments can be cut. The target of optimizing structure is to achieve the highest organizing efficiency.

The basic forms of the present typical organizing structure are: functional type, parent-and-subsidiary company, matrix type, regional type, mixed type, and internet organizing type. Which type of structure one wholesale market will take is determined by the environment and scale.

\subsection{Department structure design}

The overall task of organization can be divided into different functions and allocate them to different departments. The quantity of functions determined that of the departments, so the organization can be regarded as different parts. The position of each department can be determined by its feature, function, and its interrelation with other departments. The commodity wholesale market is a place to realize the circulation of commodities; it is a place with the exchange of material products as its purpose. Its system is made up of two braches - the commodity market and the market of productive elements. The wholesale market is the key function of the whole market system, connecting the two procedures of production and consumption. It also has such subsidiary functions as collecting and spreading information and supply service. In the structure design of departments, those directly related to the procedures of production and consumption will in a significant position, such as markets in the production base, the sale market and circulation department. Any single department cannot make profits alone. Each department in the system of the commodity wholesale market is like a procedure in the assembly line. The lack of each will probably result in bad or not qualified products. First of all, in the process of value creation, the interrelationship and order of different department should be make clear during the development and operation of the market system. Secondly, the position and its function in value creation of the whole market system should also be distinguished. The organization should offer a rational orientation of each department according to their particular features.

\section{References}

Long, Shaoqun. (2002). Study on the Sale Strategy of Chinese Agricultural Produce Wholesale Markets. A thesis for master's degree in Wuhan Polytechnic University .pp. 69

Madhok, A. (1996). The organization of economic activity: Transaction costs, firm capabilities, and the nature of governance. Organization Science. 7: pp. 577-590. 
Mahoney, J. T. \& Pandian, J. R. (1992). The resource-based view within the conversation of strategic management. Strategic :lfanagement Journal. 13: pp. 368-380.

Peng, Wenqiang. (2001). On the Establishment and Development of Professional Wholesale Markets in Rural Area in China. Dissertation to apply doctor's degree in China Social Science Academy. pp.56

Ren, Hao and others. (2005). The Organizing Structure of Small and Mediate Scaled Enterprises. Xuein Press. 8. pp. 81 83.

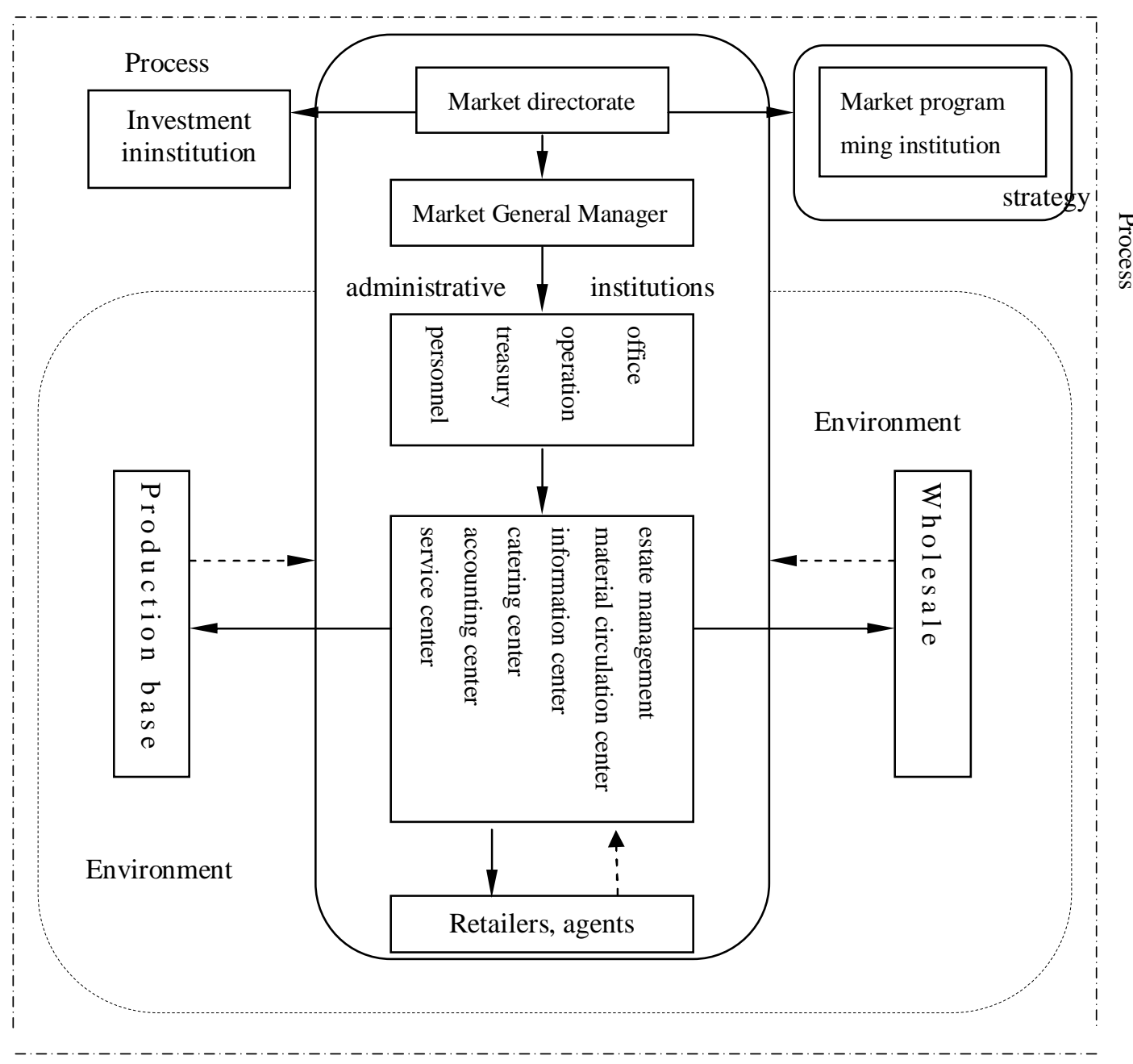

Figure 1. Organizing structure of modern commodity wholesale markets

Table 1. The standard value of administrative range

\begin{tabular}{|c|c|}
\hline $\begin{array}{c}\text { authority summation affecting various } \\
\text { administrative variables }\end{array}$ & a standard range of personnel \\
\hline $40 \sim 42$ & $4 \sim 5$ \\
\hline $37 \sim 39$ & $4 \sim 6$ \\
\hline $34 \sim 36$ & $4 \sim 7$ \\
\hline $31 \sim 33$ & $5 \sim 8$ \\
\hline $28 \sim 30$ & $6 \sim 9$ \\
\hline $25 \sim 27$ & $7 \sim 10$ \\
\hline $22 \sim 24$ & $8 \sim 11$ \\
\hline
\end{tabular}




\title{
Entrepreneurial Venture Creation: The Application of
}

\section{Pattern Identification Theory to the Entrepreneurial}

\section{Opportunity-Identification Process}

\author{
Ashford C. Chea \\ School of Business, Stillman College \\ $19258^{\text {th }}$ Avenue \#12H \\ Tuscaloosa, AL 35401, USA \\ Tel: 1-205-366-8829 E-mail: achea@ix.netcom.com
}

\begin{abstract}
In this paper, the author argues that pattern identification plays a pivotal role in the entrepreneurial opportunity-identification process. He structures the paper into eight sections. First, the author introduces the reader to a brief review of historical studies into entrepreneurial opportunity identification. Second, he provides the theoretical underpinning of the paper. Third, the author outlines major factors that influence the opportunity identification. Fourth, he assesses the link between entrepreneurial behavior and perceived technological changes. Fifth, the author puts forth a brief review of alternative models of opportunity identification. Sixth, he analyzes the pattern identification models and their applications to the opportunity identification. Seventh, the author briefly discusses some key issues in the paper. Eight, he draws three implications for entrepreneurial practice. The author concludes the paper with an emphasis on the importance of the pattern identification perspectives to the short-term survival and long-term success of entrepreneurship, and offers suggestions for further research.
\end{abstract}

Keywords: Entrepreneurship, Pattern identification, Opportunity identification, Venture creation

\section{Introduction}

In recent years, substantial progress has been made in conceptualizing the opportunity-identification phenomenon. Empirical studies have been conducted to generate new knowledge and validate the conceptual framework (see, for example, Kaish and Gilad, 1991; Shane, 2000). The above studies each make an important contribution, by identifying specific factors in opportunity- identification process. For example, Hill et al (1997) point out the importance of networking as a prerequisite for an ability to identify more opportunities, and stress the importance of entrepreneurial alertness. Shane (1998) uses Kirzner's (1979) information asymmetry theory to explain the opportunity-identification process; Kaish and Gilad (1991) maintain that entrepreneurs are opportunistic learners and combine search for information with opportunistic reactions to chance events.

Following successive shifts and movements in entrepreneurship enquiry in which research attention has highlighted the traits, personalities, orientations, motivations, structures, policies, mechanisms, processes and cultures that shape entrepreneurial practice, there is now general accord that the process of opportunity discovery is distinctive or unique to entrepreneurship. Studies investigate how opportunities are discovered, for example, at the individual-opportunity nexus (Shane, 2003) in relation to peoples' special cognitive skills (Shane and Venkataraman, 2000), organizational learning processes (Lumpkin and Lichtensten, 2005), networking skills (Arenius and Clercq, 2005) or career choices (Lee and Venkataraman, 2006). These frameworks (including Shane, 2000; Shane and Venkataraman, 2000; Lumpkin et al., 2003) collectively offer a range of concepts that characterize the opportunity-identification process (i.e., networks, experience, ideas sharing, prior knowledge of markets, entrepreneurial alertness). The aim of such models is to identify how (in varying degrees) these conceptual categories are central to the incubation, evaluation, recognition, discovery and formation of entrepreneurial opportunities. However, the above opportunity-identification frameworks are limited in their ability to account for why people enact opportunities in the way (and at the time) that they do in relation to broader societal, economic and political processes. This limitation arises for three reasons. The first relates to the assumption that opportunities, having been generated by certain market disequilibria, sit 'out there' in the market place waiting to be seen and realized by certain alert individuals. The second problem related to this is that too much agency tends to be attributed to individual people who make judgments about where there are gaps in the market on the basis of their market knowledge, perceptual abilities or special skills in 'seeing', identifying and selecting from a range of opportunities. The third problem is that, beyond the inclusion of networks and personal background experiences, there is little attention to the wider societal, economic or cultural structures or patterns that shape entrepreneurial practice. 
The study of entrepreneurial networks informs the field of entrepreneurship by highlighting the role of individual entrepreneurial action on the discovery of opportunities and mobilization of resources (Shane and Venkataraman, 2000). Study of entrepreneurial networks at the individual level focuses on the relationships or ties of entrepreneurs - as agents of the firm-with other individuals and organizations (Anderson and Miller, 2003). The network ties of an emerging firm can provide the conduits, bridges and pathways through which the firm can find and access external opportunities and resources. Thus an entrepreneurial firm's network ties can facilities successful firm emergence, growth and performance. However, the characteristics of these networks ties can influence the extent to which opportunities and resources can be identified, accessed, mobilized and exploited. When a network tie is embedded within the social relationship and influences the firm's economic decision making, the tie is called relationally embedded (Granovetter, 1985).

\section{Purpose of the Paper}

As mentioned above, a number of research propositions have been advanced based on the analysis of the current literature, and then validated by analysis of in-depth cases of opportunities identification that led to the creation of successful entrepreneurial ventures. Despite the importance of above studies and their individual contributions, we are still far from a model of opportunity-identification process that integrates multiple variables such as technology, social, economic, and cultural changes. The pattern-identification perspective fills this gap. Therefore, the purpose of this paper is to offer the pattern identification perspective of opportunity-identification process. The author argues that pattern identification plays an important role in the entrepreneurial opportunity-identification process.

\section{Operating Definitions}

While many definitions of the term opportunity have been proposed (Bhave, 1994; Herron and Sapienza, 1992; Kirzner, 1979), most include references to three central characteristics: potential economic value (i.e., the capacity to generate profit), newness (i.e., some product, service, or technology that did not exist previously), and perceived desirability (e.g., moral or legal acceptability of the new product or service in society). For the purpose of this paper, the author defines opportunity as a perceived means of generating economic value (i.e., profit) that previously has not been exploited and is not currently being exploited by others. If opportunity is defined as such, then opportunity identification can, in turn, be defined as the cognitive process or processes through which individuals conclude that they have identified an opportunity. It is important to note, as stated by other authors, (Ardichvilli, Cardozo, and Ray, 2003) that opportunity identification is only the initial step in a continuing process, and is distinct both from detailed evaluation of the feasibility and potential economic value of identified opportunities and from active steps to develop them through new ventures. It should also be said that the focus is on innovative opportunities - ones that truly break new ground rather than merely expand or repeat existing business models, such as, for instance, opening a new Italian restaurant in a neighborhood that does not currently have one (Gaglio and Katz, 2001).

\section{Theoretical Basis of the Paper}

The theoretical framework of this paper is the theory of pattern identification. The theory of pattern identification suggests that cognitive frameworks serve as template (patterns or guides), assisting specific persons to recognize connections between apparently independent events and trends and to detect meaningful patterns in these connections. This aspect of pattern identification theory suggests an intriguing explanation of the fact that particular business opportunities are recognized by specific persons but not by others. Briefly the persons who recognize specific opportunities may do so because they possess relevant cognitive framework that help them accomplish this task-frameworks that enable them to perceive the emergent patterns (i.e., technological, economic, social, cultural, etc.) that underlie many new business opportunities. An aspect of the theory of pattern identification with important implications for understanding opportunity identification is the suggestion that cognitive frameworks, developed through individuals' unique life experiences, play a crucial role in pattern identification.

\section{Factors That Influence Opportunity Identification}

The author's literature review indicates that researchers have hypothesized about a number of factors that influence the way opportunities are identified by entrepreneurs. Among the major factors include a) entrepreneurial awareness and alertness; b) information asymmetry and prior knowledge; c) discovery versus purposeful search; d) networking versus solo entrepreneurship; and e) creativity. These concepts are discussed in order.

\subsection{Entrepreneurial Awareness and Alertness}

Kirzner (1973) was the first to use the term "alertness" to explain entrepreneurial identification of opportunities. Ray and Cardozo (1994) argue that any identification of opportunity by a prospective entrepreneur is preceded by a state of heightened awareness of information. They called this state entrepreneurial awareness (EA), and define EA 
as "a propensity to notice and be sensitive to information about objects, incidents, and patterns of behavior in the environment, with special sensitivity to maker and user problems, unmet needs and interests, and novel combinations of resources" (p. 10). Furthermore, in keeping with several authors, they claimed that personality characteristics and the environment interact to create conditions which foster higher EA ( Gaglio and Taub, 1992). Imbedded in this line of thought is the notion that higher EA increases the likelihood of an opportunity being identified. There are, however, reports of studies that testify to the contrary. For example, Busenitz and Arthurs (2006) conducted an empirical test of Kaish and Gilad's (1991) proposition that entrepreneurs are more alert to new opportunities and use information differently than managers do. Busenitz and Arthurs found little empirical support exists for the Kaish and Gilad theoretical framework, but indicated that the measures of entrepreneurial alertness need further development.

\subsection{Information Asymmetry and Prior Knowledge}

People tend to notice information that is related to information they already know (Von Hippel, 1988). Based on this reasoning, Shane (2000) postulated that entrepreneurs will discover opportunities because prior knowledge triggers identification of the value of new information. Drawing on the Austrian economics argument that entrepreneurship exits because of information asymmetry between different actors (Hayek, 1945), Shane maintain that any given entrepreneur will discover only those opportunities related to his or her prior knowledge. In his three-stage study of opportunity-identification processes, Shane tested and confirmed two hypotheses, which are summarized as follows:

(1) Any given entrepreneurial opportunity is not obvious to all potential entrepreneurs (the rationale being that all people do not possess the same information at the same time (Kirzner, 1997)).

(2) Each person's idiosyncratic prior knowledge creates a "knowledge corridor" which allows them to recognize certain opportunities, but not others (Hayek, 1945; Ronstadt, 1988). According to Shane (2000), three major dimensions of prior knowledge are important to the process of entrepreneurial discovery: prior knowledge of markets, prior knowledge of ways to serve markets, and prior knowledge of customer problems. In this paper, the author will use the first part of this definition, and discuss only opportunities for creating a new business.

\subsection{Accidental Discovery Versus Systematic Search}

A large part of the erstwhile literature on entrepreneurship implicitly assumed that identification of opportunity is preceded by a systematic search for available opportunities. Some researchers have challenged this approach, arguing that people do not search for opportunities, but, rather, happen to recognize the new value of new information which the happen to received. Kirzner (1997) explains that: "What distinguishes discovery (relevant to hitherto unknown profit opportunities) from successful search (relevant to the deliberate production of information which one knew one had lacked) is that the former (unlike the latter) involves the surprise that accompanies the realization that one had overlooked something in fact readily available" (pp. 71-72). Shane (2000) reported that most entrepreneurs recognized, rather than sought the opportunities for their firms. Teach, Schwartz, and Tarpley (1989) found that firms founded on "accidentally" discovery venture ideas and which had not been subjected to formal screening achieved break-even sales faster than those firms that had undergone more formal search. Teach et al (1989) also found different styles of opportunity identification among the software firm presidents studied: only about half favored systematic approaches to searching for opportunities.

\subsection{Networking}

Hills et al (1997) indicate that entrepreneurs' network are important to opportunity identification. They base their argument on Granovetter's (1973) classic paper on the strength of weak ties, which argues that weak ties (including casual acquaintances) are "bridges" to information sources not necessarily contained within an individual's strong-tie network (including friends and family). Granovetter (1973) argues that the casual acquaintance is more likely to provide unique information because most people have more weak ties than they have strong ties. A test of this hypothesis in a survey-based study allowed Hill et al (1997) to assert that entrepreneurs who have extended networks identify significantly more opportunities than do entrepreneurs who lack such networks. Hill et al also hypothesize that the quality of network contacts can affect other characteristics, such as alertness and creativity, which in turn lead to increased identification of opportunities.

\subsection{Creativity}

Schumpeter (1934) was the first to introduce the notion that successful entrepreneurs discover opportunities that others do not see due to a special attribute: creativity. Dimov (2003) seems to take for granted that creativity and entrepreneurship are similar if not the same. Argyis (1990) concluded that creative factors play a great role in entrepreneurial decision making. Hill et al (1997) report that 90 percent of those surveyed by them find creativity very important for the opportunity- identification process. There are numerous definitions of creativity; several researchers have made attempts to define entrepreneurial creativity. For the purpose of this article, the author uses 
a definition provided by Ray and Cardozo (1996): "entrepreneurial creativity is an ability to rapidly recognize the associations between problems and their purported solutions by identification of non-obvious associations and/or by reshaping or reforming available resources in a non-obvious way" (p. 12).

\section{Entrepreneurial Behavior and Technological Opportunities}

Entrepreneurial behavior is spawned when environmental shifts create information asymmetries or gaps in an industry (Aldrich and Cliff, 2003). The ability to identify and exploit opportunities created by environmental shifts is therefore important to entrepreneurship (Covin and Selvin, 1997; Wiklund and Shepherd, 2003). Indeed firms that are able to spot opportunities have been found to be the most entrepreneurial (Salvato, 2004). A change in technology is a common trigger that spurs such environmental shifts (Aldrich and Cliff, 2003; Shane and Venkataraman, 2000). Accordingly, technological opportunities are often consider and important driver of entrepreneurship (Shane and Venkataraman, 2000) and therefore a firm's ability to perceive technological opportunities in its environment may be a key factor that distinguishes the most entrepreneurial firms.

Technological opportunity refers to the degree to which firms perceive their industry to be rich in opportunities for innovation and breakthrough technologies (Zahra, 1996). Perceived technological opportunities refer to a firm's ability to see opportunities for innovation and research and development within one's industry. Being able to spot such technological opportunities is then expected to promote entrepreneurship. For example, in a study by Blake and Saleh (1995) it was suggested that firms operating in uncertain environments rich in opportunity had greater innovative activity than firm in more stable environments. When firms perceive their environment as opportunity rich, they should invest in building new capabilities and be proactive (Dess and Lumpkin, 2005). The ability to identify technological opportunities should therefore encourage a firm to more vigorously pursue entrepreneurial activities. Indeed, it has been shown that firms operating in environments perceived as being rich in technological opportunities are more likely to invest in entrepreneurship (Zahra, 1996; Zahra, et al., 2000).

In contrast, a lack of adaptation to environmental changes will transform core competencies into core rigidities (Leonard-Barton, 1992). Firms that are unable to see beyond their current customers and markets (Hamel and Prahalad, 1991) may fail to see the importance of entrepreneurship. Indeed, research has suggested that the opportunities present in an environment are important in predicting entrepreneurial activities (Shane and Venkataraman, 2000; Venkataraman, 1997). Without a mindset that can identify technological opportunities, the competitive exploitation and adaptation to one's environment through entrepreneurship is unlikely. In the sections that follow, the author presents the different models of entrepreneurial opportunity identification.

\section{Models of Opportunity Identification}

\subsection{Organizational Learning and Opportunity Identification}

A quote from the organizational learning literature (e.g., Garvin, 1993) suggests the close link between opportunity identification and organizational learning: "New ideas are essential if learning is to take place. Sometimes they are created through flashes of insight or creativity; at other times they arrive from outside the organization or are communicated by knowledgeable insiders. Whatever their source, they are a trigger for organizational improvement" (Garvin, 1993, p. 81). Garvin's statement is one of many that demonstrate how the qualities valued by learning organization are similar to the elements of the opportunity-identification process. In particular, opportunity-identification involves the conversion of information into knowledge: ideas are generated and evaluated for their quality and viability in the same way that information is analyzed and combined to create knowledge (Nonaka, 1994). Framed in this way, the opportunity-identification process may be viewed as an example or type of organizational learning. In a formal sense, organizational learning is the ongoing process of acquiring and interpreting information that leads to the creation of new knowledge and ventures (Brown and Duguid, 1998; David and Botkin, 1994; Galunic and Rodan, 1998; Huber, 1991).

Similarly, the activity of acquiring and interpreting information is at the heart of the opportunity-identification process, and the result of both endeavors is an increase in knowledge and value to the firm. Just as the creative process involves the generation of new knowledge and new forms of expression, entrepreneurial opportunity identification is a learning process that initiates the creation of new wealth (Corbett, 2002; Dimov, 2003). The author concurs that the principles and practices of organization learning can strengthen the opportunity-identification process. Given this assumption, the author now shows how the three related approaches to learning (behavioral, cognitive, and action) link to the two phases of opportunity identification (discovery and formation) (Lumpkin et al., 2004). Specifically, the shifts in mental constructs that occur in cognitive learning are indicative of the discovery phase of opportunity identification; behavioral learning is expressed in the evaluation and elaboration aspects of formation in opportunity identification; and action learning, in its ability to challenge underlying assumptions in a recursive way, creates a contextual openness that supports both the discovery and 
formation phase of opportunity identification. Based on the three categorization of organizational learning, the author now shows how each of the categories of learning can increase innovation, creativity, and the identification of new venture opportunity:

\subsubsection{Opportunity Recognition through Cognitive Learning}

As mentioned earlier, cognitive learning involves changes in individual and/or organizational patterns of cognition, and shifts in the way knowledge is transferred within the organizational system (Glynn et al., 1994). To the extent that these changes generate new products or open up new markets, cognitive learning is a source of opportunity identification for new ventures creation. In most cases, cognitive learning in entrepreneurial companies occurs as a type of transformational capacity (Garud and Nayyar, 1994), that is, the ability to redefine the meaning and value of currently existing ideas or resources into a new economic opportunity for the firm. This redefinition can occur in at least two ways: through a transformation of currently existing resources into new products, or through a reinterpretation of internal processes such that more information and knowledge can be generated. For example, cognitive learning is exemplified by two employees at Patterson Fan Company who created an unusual-looking grill out of spare parts from the industrial fans being manufactured in the South Carolina plant (Rosenwein, 2001). By cognitively reframing the use (meaning) of the flared fan parts, these industrious employees developed a unique design that allowed for greater heat circulation while maintaining cooler unit temperatures than standard grills. CEO Vance Patterson patented the grill in his name and the names of the two inventors, and the spin-off company-Down South, Inc.-represents a new opportunity in the form of a unique product in a new market for the corporation. In this way, cognitive learning in product design and the creation of a new organization led to new opportunity for the venture.

\subsubsection{Behavioral Learning and Opportunity Identification}

Behavioral learning is primarily adaptive, focusing on the modification of routines and structures in the face of experience. "The classic prediction is that success yields stability in routine functioning, while failure produces change" (Glynn et al., 1994, p. 46). Yet as Feldman (2000) shows, routine may be more mutable than previously thought. Similarly, one of the benefits of newness is flexibility, the capacity to change direction by altering even core properties of the organization (Lichtenstein, 2000). In this sense, behavioral learning can spark new opportunities for new ventures in at least two ways - through modifications of routines that create unexpected extensions to a firm's offerings, and through an ongoing stream of organization-wide adaptations that can lead to unexpected synergies and marketable solutions.

The story of Philadelphia Pharmacy exemplifies how a serendipitous change in routines can generate unexpected strategic opportunity (Petzinger, 1999). One day, its founder, Leon Ost, found an assistant writing out a prescription by hand, rather than using the computer-generated labeling system. To his surprise, Ost found that the assistant was writing the personalized label in Spanish, as she often did for the neighborhood's Hispanic population. Rather than berating her for circumventing standard operating procedures, Ost leveraged this knowledge into a change in routines by translating every computer-generated prescription into Spanish, thus opening up the market for a huge local clientele. Then following a rapid influx of Vietnamese residents into the neighborhood, he added a third language to the computer program. These adaptive actions brought him even more recognition, and within a few years, Philadelphia Pharmacy was doing four times more business per square foot than the average American drugstore (Petzinger, 1999). In this way, incremental adaptations can result in the creation of new opportunities through expended markets and more valuable product offerings.

\subsubsection{Action Learning and Opportunity Identification}

The third mode of change, action learning, creates the potential for new opportunities by transforming the context within which new ideas can emerge. By focusing on the underlying norms of the organization and questioning whether the rules of engagement are appropriate, action learning can create a culture of openness, effectiveness, and creativity (Argyris, 1990). This broadening awareness can increase individuals' connection between espoused theory and theory-in-use (Schon, 1983), setting up conditions for increased discovery and more refined evaluation and enactment of ideas. The first outcome of action learning-agreeing to new rules of engagement that free individuals to speak honestly and act with fewer defenses-can transform an organization's ability to innovate and excel. Such a second-order transformation was enacted in The Natural Step, an entrepreneurial organization that has significantly advanced the movement toward environmental sustainability in Sweden and the United States (Bradbury and Clair, 1999). The organization's CEO wanted to develop scientific guidelines for sustainability that could be understood by non-scientists and applied in business. However, given the prevailing industrial-age assumption the environmental and economic gains are mutually exclusive (Shrivastava, 1995), he recognized that conventional decision-making approaches would be inappropriate. Instead he enacted a double-loop action 
learning model; a form of thinking that goes beyond solution-seeking to reconceive the very foundation of one's problem, such that entirely new solutions may emerge (Hawken, 1993).

Through a highly iterative process of collaborative dialogue, a consensus document emerged that was endorsed by 50 of the top scientists in Sweden, and, at the same time, was clearly understandable to public firms in education, politics, and business. Soon a network of business leaders and others, encouraged by the king of Sweden, provided funding to disseminate the colorful booklet and audiotape to the entire population of Sweden. In addition, several of the supporting businesses including IKEA, Scandic Hotels, and Electrolux have led the country in developing highly innovative products that are ecologically sustainable and commercially successful. By shifting the rules of engagement, a learning-based context was generated that secured the organizational success of The Natural Step and, at the same time, transformed the society in which the organization exists (Bradbury and Clair, 1999). In sum, each of these categories of learning — cognitive, behavioral, and action—has been successfully utilized to create new and unexpected opportunities with great success.

\subsection{Social Capital Model of Opportunity Identification}

Although there is much interest in and research on the concept of social capital, the concept is still in an emerging phase, comprising different uses and connotations from various scholarly perspectives (Alder and Kwon, 2002; Hirsch and Levin, 1999). Consequently, it is important for researchers to clarify their approach to and definition of social capital. Social scientists have described two forms of social capital: bonding and bridging. The bonding social capital perspective explores the impact of a collective's internal ties and the substance of the network relationships within that collective (Alder and Kwon, 2002). For example, Coleman (1988) suggests that dense connections between parties within a group facilitate the development of self-enforcing norms and trust within a collective allowing the group to more easily attain communal goals.

Alternatively, bridging social capital, sometimes referred to as the private-goods model of social capital, focuses on individuals and their network relationship (Alder and Kwon, 2002; Burt, 1997). Compared with the bonding social capital approach, the bridging social capital's focus is on an individual's external social ties and how the social capital, as a resource within this network, is used for the individual's private benefit. Social capital assists in the explanation of individuals' success as they can utilize their contacts and connections and the resources that they bring for personal gain (Alder and Kwon, 2002; Leanna and Van Buaren, 1999). For example, Burt (1992) characterizes social capital as a resource that brings a higher rate of return on investments. He suggests that social capital creates an advantage in the way in which social structure renders competition imperfect by creating entrepreneurial opportunities for certain players and not for others. Indeed, both the entrepreneurship ( Uzzi, 1996; Walker, Kogut, and Shan, 1997) and social capital literature (Alder and Kwon, 2002; Nahapiet and Ghoshal, 1998) have emphasized the importance of connections and networks to the establishment of new ventures and innovation in general.

Consistent with the literature on how entrepreneurs use network connections for competitive advantage (Aldrich and Zimmer, 1986), this author takes the bridging approach to social capital, that is, social capital manifested through the individual's external connections. In doing so, the author suggests that in the context of entrepreneurship, social capital is the goodwill and resources that emanate from an individual's network of social relationships, and its effects flow from the information, influence, and solidarity available to the entrepreneur (Alder and Kwon, 2002). Two direct benefits of this type of social capital are relevant to entrepreneurs: information and influence. Social capital may facilitate access to information, which is a critical component of entrepreneurial opportunities (Shane and Venkataraman, 2000). Social capital enhances the timing, relevance, and quality of information (Adler and Kwon, 2002; Burt, 1992). For example, entrepreneurs with access to university professors either directly or through association may find out about an emerging technology before others. Thus, they may be poised to act upon this before it becomes public knowledge. Another benefit of social capital consists of influence. Individuals accumulate obligations from others in the network and leverage these commitments at a later time. Burt (1992) has discussed the influence and power that entrepreneurs who span disconnected networks have. These entrepreneurs determine who will gain from the disconnection, locating them in a favorable position during negotiation.

\subsubsection{The Dimensions of Social Capital}

While traditionally, scholars have studies social capital as a uni-dimensional concept (e.g., Burt, 1992; Coleman, 1988; Walker et al., 1997), increasingly, researchers are adopting a multi-dimensional perspective of social capital (e.g., Lesser, 2000; Nahapiet and Ghoshal, 1998). In this paper, the author adopts Nahapiet and Ghoshal's (1998) three dimensions of social capital: structural dimension, relationship dimension, and cognitive dimension.

Structural Dimension. The structural dimension refers to the network structure's overall pattern of connection between actors (Nahapiet and Ghoshal, 1998). Most notably, network structure includes such factors as the 
existence or absence of direct connections between a focal actor and others, and the pattern and number of indirect ties between a focal actor and others (Burt, 1992). For instance, Burt (1992) suggests that a structural hole is said to exist when different clusters of interconnected actors are only sparsely connected to one another. Consequently, any individual who holds the only or one of the few connecting position(s) between the two clusters is able to capitalize on information that exists in one cluster but not in another by acting as a broker for nonredundant information. Burt $(1992,1997)$ suggests that entrepreneurs will act as tertius gaudens - the third who benefits through leveraging the nonredundant information for profit.

Relational Dimension. While the structural dimension refers to the overall pattern of network connections, the relationship dimension refers to the nature of the personal relationship that develops between specific people (Nahapiet and Ghoshal, 1998) as manifested in strong versus weak ties. The strength of a tie is a reflection of the combination of the amount of time, emotional intensity, intimacy, and reciprocal services that characterize that tie (Granovetter, 1985). Strong ties are typically associated with trust and facilitate the flow of fine-grained information (Gulati, 1998; Rowley, Behrens, and Krackhardt, 2000) and the transfer of tacit knowledge (Uzzi, 1996). While many factors make a tie weak or strong, trust plays a pivotal role (Granovetter, 1985; Uzzi, 1999). Trust has been conceptualized as a willingness to be vulnerable_placing one's welfare in the hands of others-and a feeling of positive expectations - an individual's confident beliefs that another will behave in a beneficial manner (Rousseau, Sitkin, Burt, and Camerer, 1998). Being embedded in a network gives rise to a form of trust known as relational trust (Nahapiet and Ghoshal, 1998). Relational trust refers to a trustor's confident beliefs that the trustee will act beneficially because the trustee cares about the trustor's welfare (Rousseau et al., 1998) which emerges from repeated interactions between individuals over time that yield feelings of reliability and positive expectations. Relational trust is based on continual reciprocity-the notion that "I'll do this for you now, but you will do something for me later" (Adler and Kwon, 2002; Lesser, 2000).

Cognitive Dimension. The cognitive dimension of social capital refers to "shared representations, interpretations, and systems of meaning among parties" (Nahapiet and Ghoshal, 1998, p. 244) that enable individuals within a network to make sense of information and to classify it into categories (Augoustinos and Walker, 1995). Shared systems of meanings and language facilitate the exchange of information, learning and knowledge creation that allows individuals to share each other's thinking processes. These common ways of looking at the world help individuals to make sense of new information and knowledge (Grant, 1996; Nonaka, 1994).

\subsection{Creativity-Based Model of Entrepreneurial Opportunity Identification}

Opportunity identification — one of the central ideas of entrepreneurship — is the ability to identify a good idea and transform it into a business concept that adds value and generates revenues. Bygrave and Hofer (1991) define an entrepreneur as one who recognizes an opportunity and creates an organization to pursue it. Shane and Venkataraman (2000) argued that the discovery, evaluation, and exploitation of opportunities is a defining feature of the field of entrepreneurship. Recently, a model of the opportunity-identification process has been proposed that builds on the idea of discovery and evaluation (Lumpkin, Hills, and Shrader, 2004). Based on a classic psychological theory of creativity (Csikszentmihalyi, 1996), the model depicts opportunity identification as a staged process that involves a discovery phase consisting of preparation, incubation, and insight, and a formation phase consisting of evaluation and elaboration. A key feature of this general model of opportunity identification is its recursive nature. Opportunity identification is not limited to a singular "aha" experience; it is an iterative process through which insights are contemplated, new information is collected and considered, and knowledge is created over time. In this way an idea for a business must be formed into an opportunity that adds value to the firm (Timmons, 1994).

Proponents of this perspective argue that a creativity-based model of opportunity identification is well suited for entrepreneur opportunity identification for several reasons. First, entrepreneurship is an emergent process especially at its earliest stages. The recursive nature of creativity parallels the back-and-forth activities that entrepreneurs often engage in when trying to grasp an emerging business concept (Sarasvathy, 2001). Second, the model is distinguished from other models of creativity in the organization literature because it is used principally to describe an individual-level activity whereas other creativity-based approaches typically address the use of group-level creativity techniques in the context of established organization (Woodman, Sawyer, and Griffin, 1993). Based on the analysis of the above models, researchers have derived five stages of the opportunity-identification process. The author presents these stages in order.

\section{The Five Stages of Opportunity Identification}

Several scholars have endeavored to characterize the opportunity-identification process (e.g., Fiet, 2002; Shane, 2003). Some opportunity models depict opportunity identification as a staged process (e.g., Bhave, 1994) where 
the outcome of the process is defined as "recognition" (Christensen, Masden, and Peterson, 1989). Most scholarly attempts to model opportunity identification have characterized it as the confluence of many factors such as the background of the entrepreneur and the influence of the business and general environment (Gaglio and Taub, 1992). In a synthesis of these perspectives, Hill et al. (1997) and Lumpkin et al. (2004) proposed a model suggesting that a "stages of creativity" framework (Csikszentmihalyi, 1996) provides the necessary elements for modeling opportunity identification. These stages include: (1) preparation; (2) incubation; (3) insight, which form the discovery phase; (4) evaluation; and (5) elaboration, which constitute the formation phase. In the subsections that follow, each of these five elements is discussed in terms of how it relates to the opportunity-identification process.

\subsection{Preparation}

Previous research suggests that preparation and prior knowledge are essential to the opportunity-identification process (e.g., Shane, 2000). Preparation refers to the experience and knowledge that precedes the opportunity-discovery process (Kao, 1989). Such preparation is typically a conscious effort to develop expertise in a domain and develop a sensitivity to the issues and problems in a field of interest (Csikszentmihalyi, 1996). But preparation also includes knowledge and experience that is gathered unintentionally, that is, without aiming to discover opportunities. In an organizational setting, the ideas that result in successful venturing often emerge incrementally from the firm's background, current line of product or services, or technological knowledge. However, individuals may bring new ideas and skills to a firm that result in new ventures.

\subsection{Incubation}

Incubation refers to the part of the opportunity-identification process in which entrepreneurs or an entrepreneurial team contemplates an idea or a specific problem. It does not, however, refer to conscious problem-solving or systematic analysis. Rather, Csikzentmihalyi argues that during incubation, "ideas churn around below the threshold of consciousness" (1996, p. 79). Thus, incubation is typically an intuitive, non-directional style of considering various possibilities or options. Gaglio and Taub (1992) described incubation as the period when the "pre-identification stew" is "simmering." It is the part of the opportunity-identification process in which the new combinations that Schumpeter (1934) envisioned might emerge (Ward, 2004).

\subsection{Insight}

Insight refers to the "eureka" moment or "aha" experience. Whereas incubation refers to an ongoing process, insight refers to a moment of identification (Csikszentmihalyi, 1996). In many cases, it is the point at which a whole answer or core solution springs into awareness suddenly and unexpectedly. This sudden convergence is the result of a cognitive shift that existing means-ends relationship (Gaglio and Katz, 2001). Insights may provide sweeping catalysts to new venture creation or uncover incremental knowledge that advances an ongoing discovery process. It is unlikely that an insight is a singular "event"; insights often occur recursively throughout the opportunity-identification process (de Koning, 1999). Entrepreneurial insights typically consist of either the sudden recognition of a business opportunity, the solution to a well-considered problem, or the acquisition of an idea from colleagues, friends, or other associate.

\subsection{Evaluation.}

Evaluation signals the start of the second phase of the opportunity-identification process---formation. It involves analyzing whether concepts developed in the discovery phase are workable, whether the entrepreneur has the necessary skills to accomplish it, and whether it is truly a novel enough idea to pursue. In the context of entrepreneurial opportunity-identification, evaluation may involve feasibility analysis wherein ideas are put to the test via various forms of investigation such as preliminary market testing, financial viability analysis and/or feedback from business associates and others in one's social network (Bhave, 1994; Singh et al., 1999). Evaluation also involves an internal process in which the entrepreneur(s) must question the prospects for the new insight and risk, "Is the business concept sufficiently valuable and worthwhile to pursue?" (Csikszentmihalyi,1996).

\subsection{Elaboration.}

In the context of entrepreneurial creativity, elaboration involves "capturing value from the creative act" (Kao, 1989, p. 17). In contrast to the confidence- seeking aspects of evaluation, elaboration involves legitimacy seeking: forming the business into a viable opportunity by subjecting it to external scrutiny and building its support system. Elaboration is typically the most time-consuming part of the process since it represents the relatively more tedious work of selecting options, finalizing choices, and organizing resources (Csikszentminhalyi, 1996). Assuming the business idea is still considered viable after the evaluation process, elaboration may involve detailed planning activities to reduce uncertainty. The elaboration process itself, however, often reveals aspects of the business concept that need attention or more careful analysis and thus may result in further evaluation (Aldrich, 1999). The 
author now turns to the pattern identification perspective of opportunity identification and its application to the entrepreneurial opportunity-identification process.

\section{Pattern Identification Model and the Opportunity Identification Process}

One topic long investigated by cognitive science that may be closely related to the identification of new business opportunities, and to the cognitive events and processes that lead to such identification, is pattern identification-the process through which individuals identify meaningful patterns in complex arrays of events or trends (Matlin, 2005). Applying pattern identification to the identification of business opportunities, it seems possible that specific persons identify opportunities for new ventures because they perceive connections between apparently independent events (e.g., advances in technology, changes in markets, shifts in government policies, to mention a few possibilities), and then detect meaningful patterns in these connections-patterns that point to new business opportunities.

An aspect of the theory of pattern identification with important implications for understanding opportunity identification is the suggestion that cognitive frameworks, developed through individuals' unique life experiences, play a crucial role in pattern identification. Theory of pattern identification suggests that these cognitive frameworks serve as template (patterns or guides), assisting specific persons to identify connections between apparently independent events and trends and to detect meaningful patterns in these connections. This aspect of pattern identification theory suggests an intriguing explanation of the fact that particular business opportunities are identified by specific persons but not by others. Briefly the persons who recognize specific opportunities may do so because they possess relevant cognitive framework that help them accomplish this task-frameworks that enable them to perceive the emergent patterns in technological, economic, and social changes that underlie many new business opportunities. In the sections that follow, the author put forth an analysis of two types of pattern identification perspectives and their application to the opportunity-identification process. He begins the prototype model.

\subsection{Prototype Theory: A cognitive Model of Pattern Identification}

While several different theories of pattern exist, one that is supported by a large body of evidence (e.g., Hahn and Chatter 1997) and that appears to offer important insights into the nature of opportunity identification, is known prototype theory (e..g., Whittlesea, 1997). This theory suggests that through experience, individuals acquire prototypes, cognitive frameworks representing the most typical member of a category-the instance of that category best capturing its essential meaning or nature. Prototype model of pattern identification further suggests that as individuals encounter new events or objects, their existing prototypes play an important role in the perception of these events or objects and in the detection of connections between them. In essence, prototypes serve as templates, assisting the persons who possess them to notice links between diverse events or trends and perceive identifiable, meaningful patterns in these connections. In part, this process involves comparison of new events or objects with existing prototypes. If the match is not close, these events or objects are identified as fitting within the prototype. If, instead, the match is not close, the events or objects are not perceived as fitting within this cognitive framework. For example, consider the prototype for "car," one cognitive framework most persons possess. This framework is broad enough so that everything from a huge limousine or sports utility vehicle (SUV) to a small sports car can be recognized as a "car," while other objects used for transportation not match this prototype will (e.g., motorcycles, scooters, bicycles) be excluded.

Applying prototype model to opportunity identification, research suggests that entrepreneurs engage in an analogous process with respect to identifying new business opportunities. Specifically, they compare ideas for new products, services, means of production, or markets with their existing prototype for "business opportunity" (Shane, 2003). The closer the match, the more likely they are to conclude that they have identified a potential business opportunities. The theory of pattern identification further suggests that the cognitive frameworks (i.e., prototypes) playing a role in this process change in several respects with increasing experience (Knowlton, 1997; Nosofsky and Palmeri, 1998). Among these changes, however, are three that have received considerable emphasis—shifts in clarity, richness of content, and degree of focus on key attributes of the content domain. It can be reasoned that changes in these respects would be visible in the business opportunity prototype of novice and experienced entrepreneurs.

In other words, reflecting differences in their experience as entrepreneurs, the "business opportunity" prototypes of the two groups would differ in several respects. It can also be reasoned that to the extent such differences were found to exist, this would provide evidence for the role of pattern identification in the identification of new business opportunities. With respect to clarity, previous research on prototype (Matlin, 2005) indicates that these cognitive frameworks become more clearly defined with increasing experiences. One index of such clarity is the degree to which the prototypes of different individuals converge on the same set of basic dimensions-in other words, the 
extent to which the prototypes possessed by different persons agree on basic attributes. For example, when automobiles were a new product, different individuals might well have included different attributes in their prototypes for this new method of transportation. As experience with automobile increased, however, these prototypes would be expected to show increasing agreement on basic attributes (e.g., all automobiles are self-propelled, have a system for steering, a separate system for stopping, etc.) Agreement with respect to basic dimensions is generally interpreted as one indicator of increased prototype clarity (Knowlton, 1997).

Similarly, applying prototype models to opportunity identification, entrepreneurs may use prototypes as a means for identifying patterns among seemingly unrelated events or trends. For instance, consider a physician engaged in medical research. Because of extensive on-the-job experience, this individual has a clearly developed prototype for "effective treatment" of various diseases (e.g., the treatment is safe, it can be used ethically with patients, it enhances recovery from the illness, etc). Furthermore, this prototype may be especially clear for illness in which the physician specializes—ones which she or he has had considerable experience. Now, imagine that this physician reads an article about a new advance in scientific knowledge concerning some basic physiological process - a process that is suspected to play a role in certain diseases. In addition, the physician knows from actual experience that existing treatments for these diseases have major side effects. Using her prototypes of "effective treatment" and perhaps other prototypes as well (e.g., prototypes concerning the nature of a given disease and how it develops), she now recognizes potential links between the new scientific advance and potential treatments for a specific illness. In other words, her prototypes help her to perceive an emergent pattern in these perceived links are confirmed, this will suggest ways of developing new drugs effective in treating this illness. In short, she has noticed this possibility (this opportunity) because prototypes she possesses have helped her to do so- to notice an emergent pattern among seemingly diverse and independent events. Much evidence suggests that individuals do indeed form prototype and that once they exist, these cognitive frameworks are employed in many ways. For instance, individuals often use them for perceiving patterns in diverse and seemingly unrelated events or trend. (Whittesea, 1997). Used in this manner, prototypes may well play an important role in opportunity identification.

\subsection{Exemplar Model}

Another model of pattern identification emphasizes the importance of specific knowledge rather than idealized prototypes. Such exemplar models suggest that an individual encounter new events or stimuli, they compare them with specific examples (exemplars) (Hahn and Chater, 1997). For instance, physician's concept of effective treatment for a given disease would not consist solely of an idealized representation of the most typical effective treatment she or he can imagine (a prototype); rather, it would also include numerous examples of effective treatments the physician has actually encountered, exemplars that vary in many respects (e.g., exemplars of excellent treatments with few negative side effects and exemplars of very poor ones that are not highly effective and that do involve negative side effects). Exemplar models seem especially relevant to opportunity identification because they do not require the construction of prototypes. Rather, individuals simply compare newly encounter events or stimuli with examples of a given concept already present in memory. This fits well with entrepreneurs' reports that they just know a good opportunity when they see it, and do not have to engage in complex processing to reach this conclusion (as would be required for the development of prototypes). Moreover, exemplar models fit with recent findings indicating that experienced, repeated entrepreneurs generally search for opportunities in areas or industries where they are already knowledgeable-where, in short, they have many exemplars stored in memory (Feit et al, 2004).

Overall, research in cognitive science suggests that both prototype and exemplar models may be necessary to fully understand how individuals notice emergent patterns in diverse and apparently unrelated events or changes (Nosofsky and Palmeri, 1998). For example, some findings suggest that initially, before they gain expertise in a specific area, individuals may rely on prototypes and on comparing newly encountered stimuli and events with these idealized representations. As they gain experience in a given domain, however, they may shift to greater reliance on exemplars, which allows them to perform the process of identifying complex patterns (Johnson and Mervis, 1997). Furthermore and perhaps even more intriguing, it appears that prototypes and exemplars may be represented (and processed) in different regions of the brain. Specifically, prototypes appear to be stored and processed in the left cerebral hemisphere while exemplars are stored and processed in the right cerebral hemisphere (Gazzaniga, Ivry, and Mangun, 1998). Together, these findings suggest that opportunity identification may well involve both prototype and exemplars. In addition, other cognitive frameworks may also be involved (e.g., schemas) (Gaglio and Katz, 2001).

\subsection{Opportunity Identification and the Search for Patterns}

Thus far, the analysis seems to suggest that opportunity identification occurs in a single step: entrepreneurs observe various events or changes, and upon examining them, recognize links or connections between them that then suggest 46 
new business opportunities. While this may be true in some stances, basic research on pattern recognition suggests that often the process is one involving many steps and repeated efforts to identify emergent patterns (Gaglio and Katz, 2001). Initially, individuals may notice that two or more variables are related, but this in itself does not yield a clear-cut pattern. Rather, it may only suggest that there is "something there," and that additional information is required to examine it more closely. As this input is obtained, the overall pattern may begin to take shape, and the possibility of a new business opportunity to emerge. For instance, consider how Expedia.com and other online travel services were developed. A number of changes and events paved the way for this opportunity: a huge increase in the number of individuals who owned personal computers; development of software that could track literally thousands of flights and provide information on thousands of hotel; plus techniques for conducting secure financial transactions over the Internet. Did the founders of companies such as Expedia.com notice, in a single step, that these events and trends formed a pattern suggestive of a new business opportunity? Not at all. Rather, this idea took shape in a more gradual manner, the entrepreneurs recognizing first one portion of the overall pattern and then another. For instance, early on, they recognized that people were dissatisfied with making airline reservations by phone and that this could be handled faster and more efficiently online. They also noted that many people were unhappy about huge variations in ticket prices; for instance, the person sitting next to them on a given flight might have paid much less then they did. This suggested the possibility of offering customers the lowest possible prices when they made reservation online. Later, the entrepreneurs realized that many travelers needed hotel and car reservations, too, so they expanded the scope of their business to include the aspects of travel. It is probably reasonable to say that they did not, during early stages, have a fully-formed vision of the business they actually developed. Rather, it unfolded one step at a time as they gradually perceived more connections between the relevant factors and ways in which these could be used to develop a profitable business.

In many cases, this is precisely how new ventures take form; their founders do not initially identify all aspects of an opportunity. Rather, they notice some aspects and proceed with these. Then, they obtain experience and information, their view of the opportunity is expanded and refined. In a sense, the process is never completed; rather it evolves just as growing business do. The idea that opportunity identification often develops in a gradual manner is consistent with the fact that venture capitalist rarely expect new ventures to take precisely the form presented in business plans. On the contrary, they realize that opportunities-even very good ones—will almost certainly develop in new and initially unforeseen ways. Reflecting this fact, venture capitalists value very highly founders' abilities to adapt and change, and often seek entrepreneurs who demonstrate these characteristics.

Overall, then, it should be emphasized that the process of opportunity identification is not a simple one in which entrepreneurs perceive all links between relevant variables at once and start with a fully-formed idea of the opportunities they will ultimately pursue. Rather, during early stages, (and perhaps later ones, too), opportunity identification involves repeated steps in which entrepreneurs perceive the opportunities they are developing with increasing clarity, and adjust their business models and goals to reflect these changes. That said, it is important to note that the process of searching for connections between various changes and trends in the external world, identifying emergent patterns in these connections, and then using such patterns as the basis for identifying new business opportunities, remains essentially the same. In short, while opportunity identification does indeed often involve repeated efforts to identify patterns in seemingly independent events or trends, the search for these patterns remains an essential part of the process well beyond the point at which new ventures are actually launched.

Furthermore, several lines of evidence suggest that pattern identification may indeed play a key role in opportunity identification. First, it is clear that many opportunities exist for years before they are noticed and developed. For instance, consider wheeled luggage of the type that is now in used by a large majority of all air travelers. Such luggage was used for decades by air flight crews before it was introduced into the market for general sale. Why? Perhaps because no one spots the patterns between several pertinent trends: a large increase in the number of passengers, growing problems with checked luggage, expansion in the size of airports, and so on. Once these trends were seen as connected, the benefits of wheeled luggage become apparent, and this product soon came to dominate the market. Second, there is a large body of evidence in cognitive science suggesting that pattern identification is a basic aspect of our efforts to understand the world around us. That is, we do indeed expend considerable effort searching for patterns among various events or trends in the extended world (Matlin and Foley, 1997). To the extent that opportunity identification also involves perceiving links or connections between seemingly independent events or trends, it may be closely related to this basic perceptual process.

Finally, research points to the conclusion that pattern identification is indeed closely related to opportunity recognition by entrepreneurs. For instance, in one revealing study, experienced entrepreneurs were asked to describe the process involved in the identification of the opportunities they pursued (Fiet, Clouse, and Norton, 2004). Findings indicate that these highly experienced entrepreneurs uniformly mentioned engaging in an active search, 
and also in restricting these searches for opportunities to areas in which they already possessed considerable knowledge. In other words, they reported engaging in a process very similar to that involved in pattern identification - a process in which they employed their existing cognitive frameworks and knowledge to notice connections between diverse events and trends. Indeed, many stated explicitly that they had identified opportunities by combining a number of external factors into a meaningful pattern. Finding such as these suggest that pattern identification may indeed play an important role in the identification of new business opportunities.

\section{Discussion}

At this point, it should be noted that three factors—search for opportunities, alertness, and prior knowledge—may be interrelated. For instance, it appear that when alertness is very high, active searches for opportunities may not be necessary; entrepreneurs are so sensitive to them that they do not have to engage in formal, systematic search processes. Similarly, high levels of prior knowledge may reduce the necessity for active searches. A cognitive perspective can readily explain these relationships. Within this perspective, high alertness implies well-developed cognitive frameworks useful for perceiving meaningful patterns in diverse events or trends. To the extent these frameworks exist, an active search for opportunities may not be necessary because such frameworks permit highly efficient interpretation and processing of new information. Similarly, a large store of prior knowledge may contribute to the formation of broad and richly-connected cognitive frameworks, again, rendering participation in formal search activities less crucial. In short, yet another advantage of a pattern recognition perspective is that it can help explain interrelationships between searches, alertness, and prior knowledge, thus clarifying the effects of these three important factors.

Two additional points are also worth noting. First, in addition to search, alertness, and prior knowledge, another factor - the breadth of entrepreneurs' social networks - has recently received growing attention, and also appears to play an important role in opportunity identification. Specifically, the findings by (Hills, Lumpkin, and Singh, 1997) indicate that the broader entrepreneurs' social networks (the more people they know and with whom they have relationships), the more opportunities they identify. This finding, too, is consistent with a pattern identification perspective. Social networks are an important source of information for entrepreneurs, information that may contribute to the richness of their store of knowledge and the development of their cognitive frameworks. Further, social networks may be especially helpful to entrepreneurs in terms of honing or refining these frameworks (prototypes). For instance, by discussing opportunities they have identified with family, friends, and others, entrepreneurs may form more accurate and useful prototypes for identifying opportunities-cognitive frameworks helpful in determining whether ideas for new products or services are practical and potentially valuable rather than merely interesting or novel. In short, the benefits of an extended social network, too, can be understood within a pattern-identification framework.

However, not all patterns connecting diverse events, changes, or trends perceived by entrepreneurs serve as the basis for founding new ventures. Such patterns lead to new ventures only when they suggest new products or services that seem, on initial examination, to be feasible. If emergent patterns do not point to products or services that appear to be feasible, they will often be discarded by current or potential entrepreneurs.

In sum, the factors that have been found to play important roles in opportunity recognition by entrepreneurs are searches, alertness, and prior knowledge. These factors and others can all be understood within the context of pattern identification. Integrating them in this manner provides increased insight into the basic nature of opportunity identification. Moreover, understanding the effects of these variables within a single framework suggests practical steps for enhancing entrepreneurs' ability to identify opportunities. Since assisting entrepreneurs in every way possible is a key goal of entrepreneurship, this appears to be a very beneficial outcome.

\section{Implications for Entrepreneurial Practice}

Three entrepreneurial implications are drawn from the analysis of the role of pattern identification in the opportunity-identification process in this paper. First, the pattern identification perspective offered here suggests that individuals can be trained to be more proficient at identifying opportunities by teaching them not merely to be alert to opportunities or to search actively for them, but rather, to search in the best places and in the best ways. Specifically, they should focus their efforts on identifying changes in technology, demographics, markets, and other pertinent factors that play an important role in the success of almost any business. Second, while engaging in such searches, they should also focus on actively seeking to identify ways in which these trends and changes are linked or connected; in other words, they should search for emergent patterns. The framework offered here suggests that identifying such patters in often a key initial step in the process of identifying new business opportunities. Can individuals really learn to notice such patterns? Research on pattern identification and recent research in the field of entrepreneurship suggests they can (Fiet and Migliore, 2001). When individuals focus their attention on pertinent 
factors and also attempt to perceive ways in which these may be related, the likelihood that they will perceive emergent pattern is increased.

This, in turn, suggests that the likelihood that current or would-be entrepreneurs will identify opportunities in specific domains (industries, markets, etc.) can be increased by training them to focus on the most relevant factors and to search for connection between these variables or changes. Consider an entrepreneur with strong interests in the restaurant business. The individual might be encouraged to focus on such factors as changing technology (e.g., technology that assist in food preparation or storage), changing demographics (which might indicate that certain kinds of restaurants serving specific kinds of food will be more likely to thrive then others), and shift in government policies concerning safety and working conditions. Through careful attention to these and other relevant sources of information, the would-be entrepreneur might realize that opportunities for certain kinds of restaurants are now emerging - for instance, restaurants that cater to the needs and preferences of senior citizens or those growing ethnic minorities. In the absence of careful attention to relevant changes and trends, these opportunities might not be readily discernable.

Third, a pattern recognition perspective also suggests that opportunity identification can be enhanced by providing potential entrepreneurs with a very broad range of experience. The broader this experience (e.g., the wider the range of positions held, the greater the number of different industries) the richer will be the prototypes at their disposal, and hence, the more likely the entrepreneurs will be to perceive connections between seemingly unrelated events or trends-especially connections that are not immediately apparent to any casual observer. Research findings offer support for this possibility: entrepreneurs with greater experience and knowledge have been found to be more effective at identifying opportunities than those with less experience and knowledge (Shepherd and De Tienne, 2001).

\section{Concluding Remarks}

New ventures offer fertile ground for the best practices that are emerging from pattern identification and opportunity-identification research to take root and grow. Chances for both short-term survival and long-term success, the author believes, will be enhanced if entrepreneurs adopt pattern identification practices. The ability to identify patterns may provide a key advantage by which entrepreneurs can remain viable and competitive in today's ever-changing environments. Future research should expand on these insights and endeavor to empirically test how pattern identification methods might best be integrated into venture creation and growth processes so that pattern identification and other opportunity identification processes become essential elements of an entrepreneur's strategy and culture. It is therefore the hope of the author that by providing these perceptions, entrepreneurs will be supported in generating more opportunities and enact them in ways that expand the capabilities of their firms and themselves. The author also hopes that this paper will spur a program of research that will enrich the conceptual foundations of opportunity identification and evaluation based on a pattern-identification approach. The end goal, of course, would be that entrepreneurs have a better-developed body of knowledge from which to draw in order to effectively and efficiently make decisions.

\section{References}

Alder, P. \& Kwon, S. (2000). Social capital: Prospects for a new concept. Academy of Management Review, 27, 17-40.

Aldrich, H. (1999). Organizations evolving. Newbury Park, CA: Sage Publications

Aldrich, H. \& Cliff, J. E. (2003). The pervasive effects of family on entrepreneurship: Toward a family embeddedness perspective. Journal of Business Venturing, 18, 573-596.

Aldrich, H. \& Zimmer, C. (1986). Entrepreneurship and opportunity recognition. Small Business Economics, 24, 249-265.

Ardichvilli, A., Cardozo, R. \& Ray, S. (2003). A theory of entrepreneurial opportunity identification and development. Journal of Business Venturing, 18, 105-123.

Argyris, C. (1990). Overcoming organization defenses. Boston: Allyn \& Bacon.

Augoutinos, M. \& Walker, I. (1995). Social cognition: An integrated introduction. London: Sage Publications

Bhave, M. P. (1994). A process model of entrepreneurial venture creation. Journal of Business Venturing, 9, 223-2242.

Blake, C. G. \& Saleh, S. D. (1995). A model of family owned small business performance, Family Business Annual, 1, 22-31. 
Bradbury, H. \& Clair, J. (1999). Promoting sustainable organizations with Sweden's Natural Step. Academy of Management Executive, 13, 63-73.

Brown, J. S. \& Duguid, P. (1998). Organizing Knowledge. $\quad$ California Management Review, 40, 90-111.

Burt, R. S. (1992). Structural holes: The social structure of competition. Cambridge, MA: Harvard University Press.

Burt, R. S. (1997). The contingent value of social capital. Administrative Quarterly, 42, 339-365.

Busenitz, L. \& Arthurs, A. (2006). Entrepreneurial cognition's toolbox: Potential contributions from the field of cognitive science. Entrepreneurship Theory and Practice, 28, 553-573.

Bygrave, W. D. \& Hofer, C. W. (1991). Theorizing about entrepreneurship. Entrepreneurship Theory and Practice, 16, 13-22.

Christensen, P. S., Madsen, O., and Peterson, R. (1989). Opportunity identification: The contribution of entrepreneurship to strategic management. Denmark: Aarhus University Institute of Management.

Coleman, J. S. (1988). Social capital in the creation of human capital. American Journal of Sociology, 94, 95-121.

Covin, J. G. and Selvin, D. P. (1997). High growth transition: Theoretical perspectives and suggested directions. In D. Sexton and R. Smilor (Eds.), Entrepreneurship 2000, pp. 99-126.

Corbett, A. C. (2002). Recognizing high tech opportunities: A learning and cognitive approach. In Frontiers of Entrepreneurship, pp. 49-61. Wellesley, MA: Babson College.

Csikszentmihalyi, M (1996). Creativity. New York: HarperCollins

Davis, S. \& Botkin, J. (1994). The coming of knowledge-based business. Harvard Business Review. September-October: 165-170.

Dess, G. \& Lumpkin, G. T. (2005). Entrepreneurial orientation as a source of innovative strategy. In S.S. Floyd, J. Ross, C. D. Jacobs, and F. W. Kellermanns (Eds.), Innovating strategy process, pp. 3-9. Oxford: Blackwell Publishing.

De Konning, A (1999). Opportunity formation from a socio-cognitive perspective. Paper presented at the UIC/AMA Research Symposium on the Interface of Marketing and Entrepreneurship, Nice, France.

Dimov, D. P. (2003). The nexus of individual and opportunity: Opportunity recognition as a learning process. Paper presented at the 2003 Babson-Kauffman Entrepreneurship Research Conference, Wellesley, MA.

Feldman, M. (2000). Organizational routines as a source of continuous change. Organization Science, 11, 611-629.

Fiet, J. O. (2002). The systematic search for entrepreneurial discoveries. Westport, CT: Quorum Books.

Fiet, J. O., Clouse, V. G. H. \& Norton, W. I. (2004). Systematic search by repeat entrepreneurs. In J. E. Butler (Ed.), Opportunity identification and entrepreneurial behavior. Greenwich, CT: Information Age Publishing.

Fiet, J. O. \& Migliore, P.J. (2001). The testing of a model of entrepreneurial discovery by aspiring entrepreneurs. In W. D. Bygrave et al. (Eds.), Frontiers of Entrepreneurship Research, 1-12. Babson Park, MA: Center for Entrepreneurial Studies.

Gaglio, C. M. \& Katz, J. A. (2001). The psychological basis of opportunity identification: Entrepreneurial alert. Journal of Small Business Economics, 16, 95-111.

Gaglio, C. M. \& Taub, P. (1992). Entrepreneurship and opportunity recognition. In Frontiers of entrepreneurship research, pp. 136-147. Wellesley, MA: Babson College.

Galunic, C. \& Rodan, S. (1998). Resources recombinations in the firm: Knowledge structures and the potential for Schumpeterian innovation. Strategic Management Journal, 19, 1193-1201.

Garud, R. \& Nayyar, P. (1994). Transformation capacity: Continual structuring by intertemporal technology transfer. Strategic Management Journal, 15, 365-385.

Garvin, D. (1993). Building a learning organization. Harvard Business Review. July-August: 78-91.

Gazzaniga, M. S., Ivry, R. B. \& Mangun, G. R. (1998). Cognitive neuroscience: The biology of the mind. New York: Norton.

Glynn, M. A., Lant, T. \& Milliken, F. (1994). Mapping learning processes in organizations: A multi-level framework linking learning and organizing. In Advances in managerial cognition and organization information processing, pp. 43-83. Greenwich, CT: JAI Press. 
Granovetter, M. S. (1973). The strength of weak ties. American Journal of Sociology, 78, 1360-1380.

Granovetter, M. S. (1985). Economic action, social structure and embeddedness. American Journal of Sociology, 91, 481-510.

Grant, R. M. (1996). Knowledge, strategy and the theory of the firm. Strategic Management Journal, 17, 109-122.

Gulati, R. (1998). Alliances and networks. Strategic Management Journal, 19, 293-317.

Hahn, U. \& Chater, N (1997). Concepts and similarity. In K. Lamberts and D. Shanks (Eds.), Knowledge, concepts, and categories, pp. 43-92. Cambridge, MA: MIT Press.

Hamel, G. \& Prahalad, C. K. (1991). Corporate imagination and expeditionary marketing. Harvard Business Review, 69, 257-276.

Hawken, P. (1993). The ecology of commerce. New York: Harper Business/HarperCollins.

Hayek, F. (1945). The use of knowledge in society. American Economic Review, 53, 519-530.

Herron, L. \& Sapienza, H. J. (1992). The entrepreneur and the initiation of new venture lunch activities. Entrepreneurship: Theory and Practice, 16, 49-55.

Hills, G., Lumpkin, G. T., and Singh, R. P. (1997). Opportunity recognition: Perception and behavior of entrepreneurs. Frontiers of Entrepreneurship Research. (203-218). Wellesley, MA: Babson College.

Hills, G. (1991). Organizational learning: The contributing processes and literatures. Organization Science, 2 , 88-115.

Hirsch, P. \& Levin, D. Z. (1999). Umbrella advocates versus validity police: A life-cycle model. Organization Science, 10, 199-212.

Johnson, K. E. \& Mervis, C. B. (1997). Effects of varying levels of expertise on the basic level of categorization. Journal of Environmental Psychology: General, 126, 248-277.

Kao, J. (1989). Entrepreneurship, creativity, and organization. $\quad$ Englewood Cliffs, NJ: Prentice-Hall.

Kaish, S. \& Gilad, B. (1991). Characteristics of opportunities search or entrepreneurs versus executives: Sources, interests, general alertness. Journal of Business Venturing, 6, 45-61.

Kirzner, I. M. (1973). C Competition and Entrepreneurship. Chicago, IL: University of Chicago Press.

Kirzner, I. (1979). Perception, opportunity, and entrepreneurship. Chicago, IL: University of Chicago Press.

Kirnzer, I. M. (1997). Entrepreneurial discovery and the competitive market process: An Austrian approach. Journal of Economic Literature, 35, 60-85.

Knowlton, B. (1997). Declarative and nondeclarative knowledge: Insights from cognitive neuroscience. In K. Lamberts, D. Shanks, (Eds.), Knowledge, Concepts, and Categories, pp. 215-246. Cambridge: MIT Press

Krueger, N. F. (2000). The cognitive infrastructure of opportunity emergence. Entrepreneurship Theory and Practice, 18, 91-104.

Leana, C. \& Van Buren, H. (1999). Organizational social capital and employment practices. Academy of Management Review, 24, 538-555.

Lee, J. H. \& Venkataraman, S. (2006). Aspirations, market offerings, and the pursuit of entrepreneurial opportunities. Journal of Business Venturing, 21, 107-123.

Leonard-Brown, D. (1992). Core capabilities and core rigidities: A paradox in managing new product development. Strategic Management Journal, 13, 111-125.

Lesser, E. L. (2000). Leveraging social capital in organizations. In E. L. Lesser (Ed.), Knowledge and social capital: Foundations and applications, pp. 3-16. Boston: Butterworth-Heineman.

Lichtenstein, B. (2000). Emergence as a process of self-organizing: New assumption and insights from the study of nonlinear dynamic systems. Journal of Organizational Change Management, 13, 526-544.

Lumpkin, G. T., Hills, G. E. \& Shrader, R. C. (2003). Opportunity recognition. In H. P. Welsch (Ed.), Entrepreneurship: The Way Ahead, pp. 73-90. New York: Routledge.

Lumpkin, G. T., Hills, G. E. \& Shrader, R. C. (2004). Opportunity recognition. In H. P. Welsch (Ed.), Entrepreneurship: The Way Ahead, pp. 73-90. London: Routledge.

Lumpkin, G. T \& Lichtenstein, B. (2005). The role of organization in the opportunity recognition process. Entrepreneurship: Theory and Practice, 29, 421-430. 
Matlin, M. W. \& Foley, H. J. (1997). Sensation and perception. Needham Heights, MA: Allyn \& Bacon.

Matlin, M. W. (2005). Cognition, $6^{\text {th }}$ ed. New York: John Wiley \& Sons.

Nahapiet, J. \& Ghoshal, S. (1998). Social capital, intellectual capital, and the organizational advantage. Academy of Management Review, 23, 242-266.

Nonaka, I. (1994). A dynamic theory of organizational knowledge creation. Organization Science, 5, 14-37.

Nosofsky, R. M. \& Palmeri, T. J. (1998). A rule-plus-exception model for classifying objects in continuous-dimension spaces. Pyschonomic Bulletin \& Review, 5, 345-369.

Petzinger, T. (1999). The new pioneers. New York: Prentice-Hall.

Ray, D. M. (1994). The role of risk-taking in Singapore. Journal of Business Venturing, 9, 157-177.

Ray, S. \& Cardozo, R. N. (1996). Sensitivity and creativity in entrepreneurial opportunity recognition: A framework for empirical investigation. London: Global Entrepreneurship Research Conference.

Ronstadt, R. (1988). The corridor principle. Journal of Business Venturing, 3, 31-40.

Rosenwein, R. (2001). Hiding in plain sight. Inc. Magazine, 23, 54-55.

Rousseau, D., Sitkin, S., Burt, R. \& Camerer, C. (1998). Not so different after all: A cross-discipline view of trust. Academy of Management Review, 23, 224-253.

Rowley, T., Behrens, D. \& Krackhardt, D. (2000). Redundant governance structures: An analysis of structural and relational embeddedness in the steel and semiconductor industries. Strategic Management Journal, 21, 369-386.

Salvato, C. (2004). Predictors of entrepreneurship in family firms. Journal of Private Equity, 7, 68-76.

Sarasvathy, S. (2001). Causation and effectuation: Toward a theoretical shift from economic inevitability to entrepreneurial contingency. Academy of Management Review, 26, 243-263.

Schumpeter, J. (1934). Theory of economic development. Boston, MA: Harvard University Press.

Schon, D. (1983). The reflective practitioner. New York: Basics Books.

Shane, S. (2000). Prior knowledge and the discovery of entrepreneurship opportunities. Organization Science, $11,448-469$.

Shane, S. (2003). A general theory of entrepreneurship. Northampton, MA: Edward Elgar Publishing.

Shane, S. \& Venkataraman, S. (2000). The promise of entrepreneurship as a field of research. Academy of Management Review, 25, 217-226.

Shepherd, D. A \& De Tienne, D. R. (2001). Discovery of opportunities: Anomalies, accumulation and alertness. In W. D. Bygrave et al. (Eds.), Frontiers of Entrepreneurship Research, 138-148. Babson Park, MA: Center for Entrepreneurial Studies

Shrivastava, P. (1995). The role of corporations in achieving ecological sustainability. Academy of Management Review, 20, 936-960.

Singh, R., Hills, G., Hybels, R. \& Lumpkin, G. (199). Opportunity recognition through social network characteristics of entrepreneurs. In P. Reynold, W. Bygrave, S. Manigart, C. Mason, G. Meyer, H. Sapienza, K. Shaver (Eds.), Frontiers of Entrepreneurship Research, 228--241. Babson College, Babson Park, MA.

Teach, R. D., Schwartz, R. G. \& Tarpley, F. A. (1989). The recognition and exploitation of opportunity in the software industry: A study of surviving firms. In Brockhaus, R. H. et al, (Eds.), Frontiers of Entrepreneurship Research, pp. 383--397. Wellesley, MA: Babson College.

Timmons, J. (1994). New venture creation (4 ${ }^{\text {th }}$ ed.). Homewood, IL: Richard D. Irwin.

Uzzi, B. D. (1996). The sources and consequences of embeddedness for economic performance of organizations. American Sociology Review, 14, 361-384.

Uzzi, B. D. (1999). Embeddedness in the making of financial capital: How social relations and networks benefit firms seeking financing. American Sociology Review, 64, 481-505.

Von Hippel, E. (1988). The sources of innovation. New York: Oxford University Press.

Venkataraman, S. (1997). The distinctive domain of entrepreneurship research. Advances in Entrepreneurship, Firm Emergence and Growth, 3, 119-138. 
Walker, G., Kogut, B. \& Shan, W. (1997). Social capital, structural holes and the formation of an industry network. Organization Science, 8, 109-126.

Ward, T. B. (2004). Cognition, creativity, and entrepreneurship. Journal of Business Venturing, 19, 173-188.

Whittlesea, B. W. A. (1997). The representation of general and particular knowledge. In K. Lamberts and D. Shanks (Eds.), Knowledge, Concepts, and Categories, pp. 211-264. Cambridge, MA: MIT Press.

Wiklund, J. \& Shepherd, D. (2003). Aspiring for, and achieving growth: The moderating role of resources and opportunities. Journal of Management Studies, 40, 1919-1941.

Woodman, R. W., Sawyer, J. E. \& Griffin, R. (1993). Toward a theory of organizational creativity. Academy of Management Review, 18, 293-321.

Zahra, S. A. (1996). Governance, ownership, and corporate entrepreneurship: The moderating impact of industry technological opportunities. Academy of Management Journal, 39, 1713-1735.

Zahra, S. A., Neubaum, D. O. \& Huse, M. (2000). Entrepreneurship in medium-sized companies: Exploring the effects of ownership and governance systems. Journal of Management, 26, 947-976. 


\title{
Research on Pricing Mechanism
}

\section{Pattern for China Electric Power Market}

\author{
Mian Xing \\ Institute for Theoretical Physics, North China Electric Power University, Baoding 071003, China \\ E-mail: hdxm01@126.com
}

\begin{abstract}
With the rapid development of global economy, people begin to pay more and more attention to the reform of electric power market. Under the background of China electric power market reform, in this article, we will research on the present power price patterns of China, i.e. two-parts power price and single power price, analyze their advantages and disadvantages, point out problems existing in the pricing on power network, put forward methods to solve these problems and establish good market environment for pricing on power network.
\end{abstract}

Keywords: Electric power market, Pricing on power network, Market environment

\section{Introduction}

\subsection{Actuality and characteristics of China electric power market}

With the unceasing reforms of China economy, essential changes has appeared in China electric power industry when the new century is coming, which are embodied from short supply to surplus supply of electric power. In order to actualize the sustainable development of electric power industry for a long term, the reform plan of "Factory and Web Separation, Pricing on power network" was put forward by China State Economic and Trade Commission in 1999. For China electric power industry, the core of this reform is the tremendous transformation of management concept which is changed from the haul pattern to marketing haul pattern. The 10th Five-year Plan of China Electric Power Development definitely put forward that the power price reform should be further deepened and the power price examination and approval should be reformed. According to the requirements of "Factory and Web Separation, Pricing on power network", the reasonable power pricing mechanism should be perfected and the legal supervision and management of power price should be strengthened. The "Factory and Web Separation, Pricing on power network" has become the general trends and urgent, but the relative discussions about how to pricing are still in dispute and there is no a recognized rule up to now.

\subsection{Difficulties encountered in power price reform}

As the experimental area, the Northeast of China has encountered many difficult problems in the practice, and the electric power market of Northeast was in logjam several times. To some extent, the difficulties of the electric power reform in Northeast include two linkage difficult problems, bottleneck of power system transmission and difficulty of capacity power price.

\subsubsection{Two linkage difficult problems}

Since the simulating operation was announced in 2003, the Northeast electric power market was trudging all along. And since the late of 2005, the Northeast electric power market was in logjam again, and even part power enterprises has retreated from the market up to now. The main reason of this logjam is the markup of coal and the linkage between coal and electric power can not follow it in time. In a healthy market, the markup of upper cost can be directly extended to lower cost. Whether the generation power dealers want to directly enhance trade quoted prices to digest coal costs or the linkage between coal and electric power is actualized through policies, which all directly induce the benefit cut of electric network enterprises, because the power sales price is fixed and the enhancement of power price must extrude the benefit space of power network. To keep the stabilization of pricing on power network in the regional electric power market for a long time, two linkages must be solved well, and one is the linkage between coal and electric power, and the other is the linkage between the price on power network and sales power price.

\subsubsection{Bottleneck of power network transmission}

The Northeast electric power market is the first regional market reform experimental region of electric power. This region involves three provinces and one region, i.e. Liaoning Province, Jilin Province, Heilongjiang Province and the East of Inner Mongolia. In fact, China took the Northeast as the first experimental region to implement regional electric power reform because the power supply of Northeast was relative rich and convenient for pricing on power network. However the electric power market of Northeast is mostly centralized in the south such as Liaoning 
Province, and because of the restriction of power network channel through which the electric power of north of Northeast is transmitted to the south, which induces furious competitions among power generation enterprises in province. When this situation is pushed to the regional electric power market, the original intention balancing regional electric power supply can not be actualized.

\subsubsection{Difficulty of capacity power price}

The pricing mechanism on power network implemented in China is divided into two sorts including two-part power price and single power price. At present, the pricing pattern competed between two-part power price and full power capacity price is implementing in Northeast. In the marketization operation of "Factory and Web Separation, Pricing on power network" for two-part power price, obvious limitations were founded. The system reform of electric power is in logjam, and the essential reason rests with the deficiency of theory and unreasonable system.

\section{Pricing pattern analysis of China electric power market}

\subsection{Advantages of pricing on power network}

The electric power industry is treated as the natural monopoly industry for a long time in China, so the public monopoly enterprises are established generally in this industry. However the low efficiency and bad service of monopoly enterprise induce the policy of "Factory and Web Separation, Pricing on power network" which means the power plants compete on the price on power network. After biding on power network, the competitions in the electric power industry among power plants have active influences on the developments of electric power.

2.1.1 Being propitious to establish modern enterprises system for the power plant, and making electric enterprises do well enterprise management according to market rule

Many jamming factors exist in the past pricing mechanism, and enterprises tried to make the reported prices in favor of themselves through many non production approaches, which decentralize much energy of enterprises. After pricing on power network, various power plants compete fairly, and which costs are low, which can obtain better benefits. Therefore, all power plants will actively adopt measures to reduce costs. For example, they adopt advanced management methods, decrease consumptions to enhance the economic benefits of the enterprise, reconstruct old facilities of power generation or introduce advanced facilities to enhance production efficiency, enhance operation abilities of employees. These measures can decrease the costs of enterprise, enhance the competitive power of enterprise, and make social resources optimized, avoid wastes, so when the power plants pursue their own benefits, they also increase the total welfare of the society.

\subsubsection{Eliminating the phenomena of lagged price}

After power plants implemented the pricing on power network, the power price will be changed with the change of production management costs of power plant. When the price of coal rises, the power generation will increase and the power price will rise with it. When the supply of power generation is bigger than demand, the price on power network will decrease, here, the power plants with higher production costs will take various measures to reduce production costs and finally make the power price achieve the marginal cost of the power plant.

\subsection{Present power pricing pattern of China and its advantages and disadvantages}

The price mechanism is the core of market mechanism, and the intention of "Factory and Web Separation, Pricing on power network" is to clear the price mechanism of electric power market. The direction of electric power reform is to establish reasonable price mechanism to adapt the change of electric power market as soon as possible. The pricing mechanism implemented in China includes two-part power price and single power price.

\subsubsection{Rule of two-part power price}

The two-part power price consists of the price on power network and power capacity price. The power capacity price is constituted by marginal cost and a few incomes, which is decided by the changeable costs and reasonable incomes. The power plants with different power qualities pay different capacity prices according to their sorts and same sort plant has same power capacity price. The two-part power price can make power generation enterprises possess power generation capacity and obtain stable capital yields, and store more spare capacity for power network and offer reliable capacity guarantees for the security of the power network. Because it can offer stable yields, its price mechanism is welcomed by investors and extended by the theory horizon. But in the marketization operation of pricing on power network, some certain problems appeared. The two-part power price makes against mutual power purchase among networks, the combination of middle-sized and small-sized power plants, and the apex-adjustment of power network.

\subsubsection{Rule of single power price}

The single power price is the price of the electric power that enterprises supply in certain range according to market demand and their own costs, which is based on the social average price of all power generation enterprises 
computed according to long-term marginal cost method. The single power price is abroad applied in practice because of its simple operation and balance.

The two-part power price and single power price mutually exist according to their own advantages and disadvantages, respectively adapt certain range, but with the strengthening of competition and the perfection of electric power market, the two-part power price will be extended abroad.

\subsection{Establishing market environment for pricing on power network}

For the market economy in the electric power market, the market patterns of electric power competition are different. When the market function is emphasized, the directional function of plan must be seen. To make pricing on power network operate normally, the following works must be implemented.

\subsubsection{Power network planning}

The essential of power network planning is to establish uniform and open electric power market with higher efficiency of power distribution, and make various market principal parts can compete fairly in the electric power industry. At present, the China power network is divided into six regional power networks, and effective interconnection is implemented among these six regional power networks. After the implementation of "Factory and Web Separation, Pricing on power network", the construction of interconnection among regional power networks in whole China becomes especial important. Only under the premise of effective interconnection of network in the whole country, the electric power market can be established, and optimized distribution of electric power resources can be realized, accordingly the total economic benefits of electric power industry can be enhanced. Therefore, one of important contents of present electric power system reform is to do power network planning well.

\subsubsection{Fluctuant prices}

The pricing on power network requires not only the generation power side implements bidding, but also the power price of demand side should correspondingly change with it, and both the incomes and risks obtained in the pricing on power network should be assumed by consumers. Only in this way, the normal operation of pricing on network can be ensured. Contrarily, the electric power crisis such as in US California will occur again.

\subsubsection{Flexible policies}

On a fair platform, the competition is fair to most power generation enterprises, which is helpful to enhance enterprise efficiency, reduce costs, and make power price return to the average level recognized by the society. However, it makes against the development of special power generation enterprises such as thermal power plant, wind power plant and garbage-cremation power plant and so on. To these enterprises, they must follow the pricing mechanism, and the government should not treat them differently for the power price, or else, which will influence the normal operation of pricing mechanism. However, if the government wants to support the developments of these enterprises, they can derate their revenues and fees, or offer allowances according to their power generation capability. The pattern reform of governmental management and treatment on electric power should combine enterprise reform, government reform and system reform.

\section{Conclusions}

The above discussion is the analysis to the pricing mechanism of electric power market, which is summarized through consulting and analyzing references and present actual situations. Under the reform plan of "Factory and Web Separation, Pricing on power network" in electric power market, in this article, we research on the present power price patterns of China, i.e. two-parts power price and single power price, analyze problems existing in the pricing on power network, put forward methods to solve these problems and establish good market environment for pricing on power network.

\section{References}

Carlos Vazquez, Michel Rivier, Ignacio J PE rez-Arriaga. (2001). If Pay-as-Bid Auctions Are not a Solution for California, then Why Not a Reliability Market. Elsevier Science Inc. May 2001.

Guoqiang, Zhang, Yunzhou \& Lvjian. (2005).Study on Scheme for Structure and Construction of Synchronous Power Grid in China from 2010 to 2020. Power System Technology. No.11. p.14-16.

Kahn Alfred E, Cramton Peter C, Porter Robert H, et al. (2001). Uniform Pricing or Pay-as-bid Pricing: a Dilemma for California and Beyond. The Electricity Journal. 14 (6). p.70-79.

Liu, Jichun. (2004). Operation System of Electric Power Market. Beijing: China Power Press. p.7-9.

Liu, Manping. (2005).Price Argument between Coal and Electricity Needs Marketed Operation. Electric Power. No.3. p.1-4. 
Maojin. (2006). Regional Power Market Construction's Latent Worries. China Power Enterprise Management. No.1. p.24-27.

Wang, Xiangqin \& Liu, Minshan. (2002). Manual of Electric Power Marketing and Management. Beijing: China Power Press. p.125-127, 371-382, 479-488.

Zhang, Lizi \& Zhenghua. (2004). Power Price Mechanism of Regional Electric Power Market. Beijing: China Power Press. p.84-98. 


\title{
On the Value of Traditional Confucian Culture
}

\section{And the Value of Modern Corporate Social Responsibility}

\author{
Wenzhong Zhu \& Yucheng Yao \\ School of English for Business, Guangdong University of Foreign Studies, Guangzhou 510420, China \\ School of Business, Sun Yat-sen University, Guangzhou 510275, China \\ E-mail: zhwenzhong@oa.gdufs.edu.cn
}

\begin{abstract}
The core values of the Chinese Confucian Culture such as "humanity, righteousness, harmony, courtesy, honesty and cleanness" represent the soul of five-thousand-years Chinese traditional culture, which may represent the value of maintaining the balanced social benefits and harmonious development of the whole society from the prospective of a whole society, and which may also have some important uses for reference and roles of enlightenment for establishing the values of modern corporate social responsibility if it is effectively integrated into the practice of modern business management.
\end{abstract}

Keywords: Confucian culture, Corporate social responsibility, Close relationship, Enlightenment

\section{Introduction to the value of traditional Confucian culture}

The Chinese nation has a civilization history of over 5,000 years, among which the Chinese have been deeply influenced by the Confucian culture for over 2,000 years. Recent years, following the rapid growth of the Chinese economy for over 20 years, has seen an upsurge of research into the "Chinese style" of management by domestic and foreign management researchers. Among the three Chinese schools such as "Confucianism, Taoism and Buddhism", Confucianism, as the dominant culture of the Chinese nation, has undergone an evolvement history of thousands of years so that it has become the gene of the Chinese nation widely carried on by people in the world. And simultaneously it has deep influences over the shaping of corporate culture and business ethics in China and even foreign countries.

In ancient China, Chinese businessmen had countless ties with the Confucian culture, and in modern times, the doctrine of "Confucian businessmen" has existed in the Chinese society for many years, which has long influenced the management philosophy of Chinese businesses. In the contemporary era, Chinese Haier Group has established its unique corporate culture of "Attach importance to collective value, strengthen harmony as key, and emphasize on self-discipline" through making use of the Confucian culture, and this corporate culture does have helped the company to achieve a great success in both domestic and foreign markets. In East Asia and Southeast Asia, under the edification of the Confucian culture, economic miracles have appeared one after another. The well-developed countries or regions such as Japan, Korea, Singapore, and Chinese Hong Kong are typical examples of such influences. The Confucian cultural values based on "family culture", "relative feeling culture", "mutual exchange culture" and "collective tropism" have influenced the Japanese enterprises to form a strong cultural feature of "employee loyalty" and to establish a managerial ideology of intensive participation and collective responsibility such as in the practices of "human capital and TQM"; it has also influenced enterprises in Singapore to form an economic and ethical value of "family-centered management like Li Guangyao"; it has also influenced the Korean to shape a strong commitment spirit of "putting the national interest at the top priority over individuals"

The Confucianism with its representatives such as Confucius and Mencius simply refers to the traditional cultural value of attaching importance to human capital, interpersonal relationship and harmonious development. However, seen from the perspective of corporate management, all the core thoughts advocated by the Confucian culture such as "humanity, righteousness, harmony, loyalty, courtesy, honesty and cleanness" may closely link to the modern management philosophy and operation behavior, and may provide the sources of contemporary business management culture and practice.

\section{1 "Humanity", namely the "love" and kindheartedness mentioned by Confucius in the article called Yanyuan.}

In connection with the modern management, it represents business leaders and managers should have kind hearts to love their underlings and to be responsible for the society by helping the people to live a richer life.

1.2 "Righteousness", namely the personal character and moral value of "righteousness is essential for a man with honor" mentioned by Confucius in the article called Yanhuo.

In connection with the modern management practice, it may mean that managers should cultivate a character like a 58 
man with honor, that's to say, a manager should be able to deal with the relationship between righteousness (good ethics)and benefit(personal material interest). Persons and organizations should try to accord with their code of conduct in their management concepts and behaviors, and should regard the so-called interests as the interests for the whole group or people, not only their individual interests, which means that holistic interests should be put at the first place while individual interests should not harm public interests as a general principle.

1.3 "Harmony", namely the philosophy of "syncretism for sky and human" and "harmonious coexistence" contained in the Book of Changes as well as the development law of interactive influences and restrictions between individuals, nation, society and nature.

In relation with the modern management practice, it may represent organizations as a part of the society must seek a certain degree of balance and harmony between their own interests and the societal interests. To pursue one's own interests while neglecting others' interests is sure to be short lasting as it is in breach with the law of nature as a harmonious whole. Therefore, it is crucial for modern managers to understand how to achieve a harmonious development result for all stakeholders like organizations, employees, customers, investors and society, and to emphasize a peaceful solution in competition and a "win-win" situation instead of putting your competitors to death so as to enable the organizations to realize an objective of sustainable growth.

1.4 "Loyalty", namely the ethical value of "loyalty and allegiance" advocated by Confucius and Mencius. In relation with the modern management practice, it may represent mutual loyalty between people, allegiance and obedience of subordinates to their superiors, workers' loyal and commitment spirit to their jobs, and managers' honesty and trust to their coordinators. The quality of "doing one's duty and keeping one's faith" is regarded as a fundamental guarantee for the development of individuals and organizations.

In addition, judging from the perspective of modern management, the "courtesy and honesty and cleanness" advocated in the Confucian culture may represent the principle of "legalized and regulated operation" and the principle of "ethical love for gain as a man of honor".

\section{Introduction to the value of modern CSR}

To put it simply, corporate social responsibility (CSR) refers to the management philosophy that highlights the economic and social benefits of managerial decisions or the management's acceptance to the obligation of considering the profit, consumer satisfaction and societal well being of equal value in evaluating the performance of a business (Louis E. Boone and David Kurtz, 2002). The basic elements of CSR cover not only the protection of interests for shareholders, employees and customers, but also the protection of interests for the general public in the local community and even the whole world in terms of ensuring sustainable development, protecting environment and contributing to non-business sectors, etc. It must be noted that CSR does not simply mean donations of money or goods to philanthropy, but it may refer to contributions to all the stakeholders in order to achieve a harmonious society.

From the history of theoretical development, the concept of CSR originated from the European and American developed nations, dating back to the $18^{\text {th }}$ and $19^{\text {th }}$ century when enterprises began to conduct so-called "actions beyond laws" such as sincere, friendly and fair treatment to their employees. But in fact, most of these values at that time came from the influence of religious thoughts. In 1924, however, the American researcher called Shelton firstly put forward the idea of "corporate social responsibility". Over the years, such an idea has become so popular in the world that CSR is frequently regarded as one of the important standards for the evaluation of business performance, such as in the assessment of business rankings by Fortune and Forbes. In the Chinese modern society, there had been the so-called doctrine of "Confucian businessman", which, however, had not shaped the enterprises' automatic action to take their social responsibility. The modern concept of CSR reflects a mature attitude and practice of enterprises to contribute to the society as a management philosophy. In recent years, lots of illegal and unethical events have occurred in China's businesses such as explosion of coal mines, deduction of employee payment in factories, employment of teenagers, etc., all of which show that Chinese enterprises do have a trend of weakening their social responsibility.

From the perspective of economics development, the concept of CSR can be classified into the classical view, namely purely economic idea, and the social economic view. One of the representatives for the former is the American Milton Friedman who argued in his article in 1970 that a free private enterprise system, "an organization has only one social responsibility, which is to make use of its resources to conduct profit-seeking activities for its shareholders in the principle of open, free and no-fraud competition", that is to say, the only social responsibility of a business in his mind is to maximize profitability for its owners or shareholders. In his argument, an enterprise must produce products needed by the society in the most efficient way so that what is good for the enterprise must be beneficial for the society. In fact, his argument had been based on the theory of "Invisible Hand"put forward by 
Adam Smith, the world-famous Scottish political economist in the 18th century. Adam Smith thought that private interests equaled to public interests so a business's profit maximization was the same as the benefit maximization for the public and society.

On the hand, the idea of the social economics for CSR thinks that the social responsibility of a business not only includes the profit-making for its investors but also includes the improvement of societal well being. Furthermore, an enterprise should be regarded as an integrated part of the society, thus making contributions to the community where it operates is an unavoidable obligation. There are quite a number of similar arguments to the social economic view such as: the management's acceptance of obligation to the consideration of profits and social well being of equal value in evaluation of a business's performance(Louis E. Boone and David L. Kurtz,2002); the value of social networks thinking that an enterprise needs to create a value chain in the society through its contribution to the society; the value of corporate citizen thinking that an enterprise as part of a harmonious society should be responsible for the society so as to protect its own long term benefits, etc.

In summary, the above-mentioned points of view have analyzed the concepts of CSR, however, they have actually expressed one uniform theme which means that the objective of a business should be not only to seek economic benefits for itself but also simultaneously to emphasize social benefits for the general public including all stakeholders. Only by doing so can an enterprise maintain its sustainable competitiveness and harmonious development.

\section{Possible relationships between the value of Confucian culture and the value of CSR}

Based on the above discussion and analysis on the value of Confucian culture and the value of CSR, we can easily conclude that there are some close relationships between them, which can be illustrated as in the table 1 .

Based on the above table, we can see that the vale of CSR and the value of Confucian culture do have some relationships between them. In fact, to some extent, the value of Confucian culture has invisibly formed the fundamental sources of modern CSR as an earlier ethical element.

3.1 The so-called "humanity" advocated in the value of Confucian culture representing the ethical standard of making contributions to the general public with public or collective interests being superior to individual interests has no difference from the core contents contained in the social responsibility of an enterprise to the society.

This Confucian value indicates that in the management practices of modern enterprises, they should care for the public health and safety, and support the philanthropy, protect the natural environment, create job opportunities, participate in the social projects in the local community, etc.

3.2 The so-called "righteousness"advocated in the value of Confucian culture representing the ethical code of kindly and friendly treatment of subordinates coincides with the core contents contained in the social responsibility of an enterprise to its employees.

This Confucian value, in connection with modern business management practices, means that enterprises are expected to care for their employees' work safety, health, life quality, and fair and adequate compensation as well as fringe benefits such as social insurance and pension, etc.

3.3 The so-called "honesty and cleanness"advocated in the value of Confucian culture representing the personal character of earning money legally and ethically is basically the same as the core contents contained in the social responsibility of an enterprise to its customers.

This Confucian value, in connection with modern business management practices, indicates that enterprises are supposed to be responsible for their customers' benefits such as protecting their basic rights and trying to provide them with high-quality products and services without conducting any fraudulent and cheating activities, etc.

3.4 The so-called "harmony" advocated in the value of Confucian culture representing the doctrine of a harmonious universe or a mutually reliable society is closely linked with the core contents contained in the social responsibility of an enterprise to its business partners or competitors.

This Confucian value, in connection with modern business management practices, conveys that enterprises are expected to regard "harmonious co-existence" as essential in their management of fierce competition, in other word, they should not try to put their competitors to death, but to consider them to be their friends, or they should allow their business partners to share a fair benefit from mutual cooperation so as to achieve a win-win situation in the marketplace.

3.5 The so-called "courtesy and loyalty" advocated in the value of Confucian culture representing the people's interpersonal attitude and ethical principle for compliance to laws and regulations and commitment to owners and posts matches closely with the core contents contained in the social responsibility of an enterprise to its investors. 
This Confucian value, in connection with modern business management practices, indicates that enterprises should not conduct any illegal, immoral or unethical behaviors in their business operations for the sake of protecting the benefits of their investors or financial communities. Only by doing so can they basically protect the long-term interests for the investors or sustainable development of the business.

\section{Implications}

Based on the above discussion and reflection into the possible links between the value of Confucian culture and the value of CSR, we can at least draw some beneficial enlightenments as follows:

4.1 The value of traditional Confucian culture may be regarded as the thinking sources for the value of modern CSR to evolve.

In fact, it can be concluded that the modern value of CSR has to some extent been developed and promoted on the basis of researchers having partially absorbed Japanese and Chinese Eastern cultures which both belong to the cycle of Confucian culture integrated with Western cultures. For instance, the so-called Z theory put forward by an American professor is a very good example for the combination of Eastern and Western cultures in business management. The value of "collective concern or harmonious competition" advocated in the Confucian cultural value has a role of compensation and correction on the value of "individual concern or fatal competition"advocated in some Western cultures. Furthermore, the Confucian culture emphasizes the importance of humanistic management from the layer of spirit while the Western culture stresses the importance of legalized management from the layer of regulatory control. Both cultures may have some advantages and disadvantages, therefore, it will make sense if we can integrate the good elements of both Eastern and Western cultures in shaping a more proper value of modern CSR for domestic and foreign businesses.

\subsection{The value of Confucian culture is suggested to carry on with criticism rather than copy without digestion.}

It is widely accepted that the value of Confucian culture has formed the core basis of "Chinese-style management", which has been proven to have facilitated the modernization of Chinese economy as well as the rapid development of the Southeast countries or regions. However, we must be aware of the strengths and weaknesses contained in the culture. That's to say, it may have some negative sides in it, for instance, the idea of humanistic management on the basis of "Guanxi" advocated by the Confucian culture in the assumption that people are born with the nature of kindness may lead to the neglecting of regulatory function and corporate governance in modern business management, which may have a negative influence over legal operation and fair competition in the marketplace.

\section{References}

Bryan W Husted, et al. (2006). Corporate Social Responsibility in the Multinational Enterprises: Strategic and Institutional Approaches. Journal of International Business Studies. pp. 838-849

Christmann, P. (2004). Multinational Companies and the Natural Environment: Determinants of the Global Environmental Policy Standardization. Academy of Management Journal. Pp.747-756

David A Waldman, et al. (2006). Cultural and Leadership Predicators of Corporate Social Responsibility Values of Top Management: a GLOBE Study of 15 Countrie. Journal of International Business Studies.pp. 823-837

Dou Yanguo (2006). Confucian Values of Honor \& Dishonor and their Present Importance. Ethics and Civilization.

Louis E. Boone and David Kurtz (2002). Contemporary Business. Tenth Edition. Harcourt College Publishers, 6277 Harbor Drive, Orlando, FL32887-6777.

Peter Rodriguez, et al. (2006). Three Lenses on the Multinational Enterprises: Politics, Corruption, and Corporate Social Responsibility. Journal of International Business Studies. pp. 733-746

Tian, Muyu. (2005). Confucian Culture and its Influence over Modern Business Management. Market Weekly.

Vanessa M, Strike, et al. (2006). Being Good while Being Bad: Social Responsibility and the International Diversification of US Firms. Journal of International Business Studies. pp.850-862 
Table 1. Correlations between core contents of the value of Confucian culture and the value of CSR

\begin{tabular}{|c|c|}
\hline $\begin{array}{l}\text { Core contents of the value of Confucian } \\
\text { culture }\end{array}$ & Core contents of the value of CSR \\
\hline $\begin{array}{l}\text { Advocation of "humanity" for leaders to make } \\
\text { contributions to the general public. }\end{array}$ & $\begin{array}{l}\text { Social responsibility to the general public: } \\
\text { care for social development programs, and } \\
\text { contribute to the general public and the local } \\
\text { community }\end{array}$ \\
\hline $\begin{array}{l}\text { Advocation of "righteousness"for leaders to } \\
\text { care and love subordinates. }\end{array}$ & $\begin{array}{l}\text { Social responsibility to employees: care for } \\
\text { employees' work safety and health, and } \\
\text { contineously improve their social benefits }\end{array}$ \\
\hline $\begin{array}{l}\text { Advocation of "cleanness" for people to earn } \\
\text { money in a correct way }\end{array}$ & $\begin{array}{l}\text { Social responsibility to customers: protect } \\
\text { employees' basic rights such as the right of } \\
\text { safety, the right of free choice, the right of } \\
\text { being informed and the right of being heard }\end{array}$ \\
\hline $\begin{array}{l}\text { Advocation of "harmony"for people to shape } \\
\text { an attitude of a cooperative and "win-win" } \\
\text { situation }\end{array}$ & $\begin{array}{l}\text { Social responsibility to competitors and } \\
\text { business partners: show respect to business } \\
\text { partners and competitors, establish a } \\
\text { harmonious relation to seek } \\
\text { a"win-win"situation }\end{array}$ \\
\hline $\begin{array}{l}\text { Advocation of "courtesy and loyalty" for } \\
\text { people to obey regulations and to be } \\
\text { committed to their cause }\end{array}$ & $\begin{array}{l}\text { Social responsibility to investors: obey laws } \\
\text { and regulations as well as ethical codes, and } \\
\text { demonstrate an attitude of trustworthiness } \\
\text { and honesty in business activities to } \\
\text { guarantee the long term benefits of investors }\end{array}$ \\
\hline
\end{tabular}




\title{
Modification of the Warrants Pricing
}

\section{Model and Validation Analysis}

\author{
Jinlong Chen \& Qinhong Li \\ College of Business Administration, Huaqiao Unversity, Quanzhou 362021, China \\ Tel: 86-595-2269 2437 E-mail: jinlong@hqu.edu.cn
}

\begin{abstract}
Based on the previous study in this article, modified Black-Sholes model was more suitable for the domestic warrants price, and calculated 6 warrants' price in the listed time, It also confirmed the rationality of the model comparing the pricing theory with the actual market price. The result of the computation of the modified warrant price model shows that though in the warrant market the realistic price deviates from theoretical price, the deviations of realistic and theoretical prices is smaller from May, 2006 to May, 2007.
\end{abstract}

Keywords: Call warrants, Black-Sholes model, Market present status

\section{Introduction}

Has been published since the Black-Sholes option valuation model (Black, Scholes, 1973) for its computation convenience and the theoretically consummation, it is widely applied. At the same time the researchers have studied it deeply because of its strict supposition and expanded its assumptions greatly and made it more realistic. Now the warrant pricing theory research is generally based on the B-S option valuation model.

Merton relaxed the assumption on the risk-free interest rate as constant and the pricing model that allows rate is a random variable (Merton., 1973). Under the assumption of the effective capital market, Galai and Schneller (Galai, Schneller, 1987) put forward warrant pricing model considering the flow of the dilution effect through the analysis of single-phase and multi-phase framework and inspected that the warrants issued affected the firm value. Leland (Leland, 1985) developed a hedging strategy which modifies the Black-Scholes hedging strategy with a volatility adjusted by the length of the rebalance interval and the rate of the proportional transaction cost. Boyle and Vorst (Boyle, Vorst, 1992) designed a perfect hedging strategy in the Cox, Ross and Rubinstein binomial model with transaction costs. The perfect hedge is possible due to the assumption of a binomial process for the underlying stock price. Ukhov Andrey (Ukhov, Andrey, 2004) develop an algorithm for pricing warrants using stock prices, an observable variable, and variance of stock returns.

The theoretical study in foreign countries provided a good foundation for the domestic warrants pricing, but in view of the fact that the domestic and foreign transactions environment is different and the products differ, many foreign theories don't apply to the domestic warrants pricing.

Chinese scholars have been studying foreign theories that apply to the domestic market. Tang Bing and Li Hong-rong (Tang Bing, Li Hongrong, 2004) study subscribing for capital stock from the market perspective of warrants pricing. Zhan Shi-guang (Zhan Shiguang, 2005) considered the warrants pricing model with dilution effect, proportional transaction costs, ex rights and ex divided the factor, and did a sensitivity analysis of the model . This article, based on the previous scholars' study, first introduces the model in which stock proportion transaction cost and the division factors are considered, then the warrants pricing is affected by the compound dilution effect and the warrant exercises cost for the warrant modified model. The value of 7 warrants' products which are first introduced in China's warrant market is assessed daily. The two investment portfolios are developed for comparison and validation to verify that the model is rational. At last, the computation is shown that in China's warrant market the actual value's deviation from theoretical value has been well controlled.

Fischer Black and Scholes (1973), in his famous paper "The pricing of options and corporate liabilities", proposed the European call option formula pricing warrant value, a series of assumptions are needed:

(1) Assume that the underlying security price follows the lognormal process-geometric Brownian motion. The parameters, the rate of return $\mu$ and the instantaneous variable of the asset $\sigma$, are constant.

(2) In a frictionless market there are no taxes and transaction costs. And all assets are entirely unlimited breakdown without restrictions on short selling.

(3) In derivative securities period, from $t=0$ to $t=T$, no cash or no dividend pay for the underlying securities.

(4) In derivative securities period, from $t=0$ to $t=T$, there's the same risk-free rate loans, interest rates on risk-free 
compound interest $r$ is calculated as consecutive terms.

The traditional Black-Scholes warrant price formula is:

$$
C=S N\left(d_{1}\right)-X e^{-r T} N\left(d_{2}\right), \text { Where } d_{1}=\frac{\ln (S / X)+\left(r+\frac{1}{2} \sigma_{S}{ }^{2}\right) T}{\sigma_{S} \sqrt{T}}, d_{2}=d_{1}-\sigma_{S} \sqrt{T} .
$$

The parameters, $\mu$ and $\sigma_{s}$, are the instantaneous rate of return and the instantaneous variable of the asset, respectively. The risk free asset earns at the constant rate $\mathrm{r}$. Let $\mathrm{S}$ be the price dynamics of the underlying security, $\mathrm{C}$ be the price of the warrant, $\mathrm{X}$ be the exercise price, and $N($.$) be cumulative standard normal distribution function.$

As calculated on the convenience and strict logic, traditional Black-Sholes model is commonly used to price warrant. But it neglected many factors because of strict assumption, such as various costs and dividends in the listed time. This article will relax these traditional B-S model assumptions restrictions.

\section{Modification for Warrant Pricing Model}

\subsection{Warrants Pricing Model with the Transaction Cost and Dividend}

In traditional Black-Scholes model, there are no taxes and transaction costs in a frictionless market. It simplifies the model calculations, but makes certain deviations. Basing on Leland's proportional transaction cost model, we relax the second assumption as follows.

According to China's present relevant provisions, fees are paid as follows in stock transaction: Commission (normally no more than the amount of securities trading 0.3\%), Transfer fees (in A-shares, Shanghai Exchange for the deal transaction denomination $0.1 \%$, Shenzhen free transfer fees) and taxes (deal amount $0.1 \%$ before May 30 , 2007). Costs are paid in warrant transactions: Commission (no more than the amount of securities trading $0.3 \%$, starting at five yuan).

Transaction cost is divided into the stock transaction cost and the warrant transaction cost. The warrant transaction cost has different effects on the theoretical value for buyers and sellers, and reflects indefinitely in market price,so the stock transaction cost is considered here with ignoring the warrant transaction cost. A security traded with a proportional transaction cost rate a is supposed. Based on Leland's the proportional transaction cost warrant valuation model, warrant pricing model and B-S model are similar, but in this paper, the fluctuation rate $\delta \rho$ was defined as

$$
\not g=\sigma_{s} \sqrt{1+\sqrt{\frac{2}{\pi}} \times \frac{a}{\sigma_{s} \sqrt{\Delta t}}}
$$

Leland expanded the fluctuation rate $\delta / \rho$. He considered, when $\Delta t \rightarrow 0$, the expanded fluctuation rate offset the transaction cost. Here the ex dividend factor is only considered.

According to discrete dividends B-S model, the new stock price is equivalent to the amount of that the original price of the underlying stocks minus the cash dividend's risk-free rate discount. Then the exercise price's adjustment is a formula according to the stock exchange management:

New exercise price $=$ original exercise price $\times($ shares ex-dividend date reference price/

Ex-dividend one day before the closing price of the underlying stocks)

As the ex-dividend one day before the closing price of the underlying stocks is unknown, shares ex-dividend date reference price could not figure out. So we use the following approximate formula:

New exercise price $=$ original exercise price $\times(1-\mathrm{Cash}$ bonus discount/

The original price of the underlying stocks)

In order to calculate conveniently, we estimate $X_{X}$ as $X_{X}=X \times\left(1-\sum_{i, t_{i}>t} e^{-r t_{i}} D_{i} / S_{0}\right)$ when $t=0$.

\subsection{Warrant Pricing Model with the Dilution and Exercise}

Exercises cost must be paid in warrant exercise. The stock dilution must be considered after exercising in the stock warrant. The dilution and exercise cost interact on each other. These two factors should be considered simultaneously.

Assume that each warrant entitles the owner to receive one shares of stock paying the exercise $\operatorname{cost}$ of $A$. At time $T$, the agent's profit is: $\max \left\{k\left(S_{T}-X_{X}-A\right), 0\right\}$

Consider valuation of a conventional warrant, issued by a firm for its own stock. Suppose that a company 
has $N$ shares of common stock and $M$ warrants outstanding. Each warrant entitles the owner to receive $k$ shares of stock upon payment of $X$ dollars. At time $T$, the value of the firm is $V_{T}$, and when the warrant holders exercise their warrants, the instantaneous value of the firm is: $V_{T}+M k X_{X}$, and the instantaneous value of the share is $\frac{V_{T}+M k X_{X}}{N+M k}$.

Therefore,the agent's profit is:

$k\left(\frac{V_{X}+M k X_{X}}{N+M k}-X_{X}-A\right)$,

and the warrant profit is

$\frac{N k}{N+M k} \operatorname{Max}\left\{\frac{V_{T}}{N}-\left(X_{X}+\frac{N+M}{N} A\right), 0\right\}$

Assume $_{X^{\prime}}=X_{X}+\frac{N+M}{N} A$, so the warrant profit is $\frac{N k}{N+M k} \operatorname{Max}\left\{\frac{V_{T}}{N}-X^{\prime}, 0\right\}$.

We can cognize that the stock warrant is $\frac{N k}{N+M k}$ whose profit is $C_{T}=\operatorname{Max}\left\{\frac{V_{T}}{N}-X^{\prime}, 0\right\}$ at time $T$ options portfolio.According to option pricing formula, the warrant values $C_{t}$ can be obtained arbitrarily.

$$
C_{t}=\frac{V_{t}}{N} N\left(d_{1}\right)-X^{\prime} e^{-r(T-t)} N\left(d_{2}\right)
$$

Where $_{d_{1}}=\frac{\ln \frac{X^{\prime}}{V_{t} / N}+(T-t)\left(r+\frac{1}{2} \sigma^{2}\right)}{\sigma \sqrt{T-t}}, d_{2}=\frac{\ln \frac{X^{\prime}}{V_{t} / N}+(T-t)\left(r-\frac{1}{2} \sigma^{2}\right)}{\sigma \sqrt{T-t}}$

So at time $t$ the value of equity warrant calculated as follows:

$$
\begin{aligned}
& W_{t}=\frac{N}{\frac{N}{k}+M}\left\{\left[S_{t}-\sum_{i, t_{i}>0} e^{-r\left(t_{i}-t\right)} D_{i}+\frac{M}{N} W_{t}\right] N\left(d_{1}\right)-X^{\prime} e^{-r(T-t)} N\left(d_{2}\right)\right\} \\
& =\frac{N}{\frac{N}{k}+M}\left\{\frac{V_{t}}{N} N\left(d_{1}\right)-X^{\prime} e^{-r(T-t)} N\left(d_{2}\right)\right\}
\end{aligned}
$$

Where $d_{1}=\frac{\ln \left[\left(S_{t}-\sum_{i} e^{-r\left(t_{i}-t\right)} D_{i}+\frac{M}{N} W\right) / X^{\prime}\right]+r(T-t)}{\delta / \sqrt{T-t}}+\frac{\delta / \sqrt{T-t}}{2}, d_{2}=d_{1}-\delta / \sqrt{T-t}$

And $W$ is the price of the equity warrant; $M$ is the number of new warrants; $N$ is the number of stocks; $\mathrm{K}$ is the equity warrant rate; $S$ is the stock price; $X$ is the exercise price; $r$ is the risk free rate; $T$ is the expiration date of the warrant; $\delta$ is the fluctuation rate with transaction cost for the firm value; $t_{i}$ is time to pay dividends; $D_{i}$ is the dividends; $N($.) is cumulative standard normal distribution function.

An important problem in this model is that $\delta /$ is unknown, we can assess the fluctuation rate using observable variable warrant pricing model by Ukhov, Andrey D. Define $\Omega_{S}=\frac{\Delta S / S}{\Delta V / V}=\frac{\Delta S}{\Delta V} \frac{V}{S}=\frac{\Delta_{S} V}{S}$, the elasticity of the stock price with respect to the firm value, where $\Delta_{S}=\frac{\Delta S}{\Delta V}$ is a hedge ratio for the stock, it measures the price change for the share of stock when the value of the entire firm changes by one. By $\Omega_{S}$, we get: $\sigma_{S}=\Omega_{S} \sigma_{V}=V \frac{\Delta_{S}}{S} \sigma_{V} \Rightarrow \sigma_{V}=\frac{\sigma_{s}}{V \frac{\Delta_{S}}{S}}$. As $V=N S+M W$, so $N \Delta_{S}+M \Delta_{W}=\Delta_{V}=1$, then $\Delta_{S}=\frac{1-M \Delta_{W}}{N}$. If equation (2) is used, we get $\Delta_{W}=\frac{\partial W}{\partial V}=\frac{k}{N+k M} N\left(d_{1}\right)$. On the mention above,

$\sigma_{V}=\frac{\sigma_{S} S N}{V\left(1-\frac{M k N\left(d_{1}\right)}{N+M k}\right)}$

Basing on the proportional transaction cost warrant valuation model by Leland, we may obtain as follows: 
$\%=\sigma_{V} \sqrt{1+\sqrt{\frac{2}{\pi}} \times \frac{a}{\sigma_{V} \sqrt{\Delta t}}}$.

\subsection{Model with Integrating the Above Factors}

The above factors integrated, warrant pricing is assessed as follows:

$W_{t}=\frac{N}{\frac{N}{k}+M}\left\{\left[S_{t}-\sum_{i, t_{i}>0} e^{-r\left(t_{i}-t\right)} D_{i}+\frac{M}{N} W_{t}\right] N\left(d_{1}\right)-X^{\prime} e^{-r(T-t)} N\left(d_{2}\right)\right\}$

Where $d_{1}=\frac{\ln \left[\left(S_{t}-\sum_{i} e^{-r\left(t_{i}-t\right)} D_{i}+\frac{M}{N} W\right) / X^{\prime}\right]+r(T-t)}{\delta / \sqrt{T-t}}+\frac{\delta / \sqrt{T-t}}{2}, d_{2}=d_{1}-\delta / \sqrt{T-t}$,

$\sigma_{V}=\frac{\sigma_{S} S N}{V\left(1-\frac{M k N\left(d_{1}\right)}{N+M k}\right)}, \%=\sigma_{V} \sqrt{1+\sqrt{\frac{2}{\pi}} \times \frac{a}{\sigma_{V} \sqrt{\Delta t}}}$,

$X^{\prime}=X_{X}+\frac{N+M}{N} A=X \times\left(1-\sum_{i, t_{i}>0} e^{-r t_{i}} D_{i} / S_{0}\right)+\frac{N+M}{N} A$.

And $W_{t}$ is the value of the equity warrant at time $t ; M$ is the number of warrants; $N$ is the number of stocks; $k$ is proportion each warrant entitles the owner to receive shares of stock; $S$ is the stock price; $X$ is the exercise price; $r$ is the risk free rate; $T$ is the expiration date of the warrant; $\delta /$ is the fluctuation rate with all the transaction costs for the firm value; $\sigma_{V}$ is the fluctuation rate on the firm value considering exercise cost; $\sigma_{S}$ is the fluctuation rate of the stocks; $t_{i}$ is time to pay dividends; $D_{i}$ is the dividends; $N_{(.)}$is cumulative standard normal distribution function; $A$ is the exercise cost paid by the owner to receive one shares of stock; $a$ is the proportional transaction cost rate.

\section{Example for Calculation by Modified Warrant Pricing Model}

The warrant mainly has the functions of price discovery and the risk management. It is a tool for effective risk management and the resources allocation. Up to May 30, 2007, the stock markets in China have 33warrants listed. Take Yili CWB1 as example below (Table 1), its value is calculated using the modified warrant price model.

Since May 30, 2007, the securities exchange tax rate from original $0.1 \%$ rises to $0.3 \%$, we just get the date by May, 2007 for validation calculation, and transaction stock cost is the amount of transaction cost $0.4 \%$, that's to say, $a=0.4 \%$.

The fluctuation rate is calculated on the historical data. YiLi Ltd 2005 annual dividend distribution: on April 6, 2006, Yili Co.Ltd in "China Securities" and "Shanghai Securities News" published on the distribution of profits notice: A shares of Stockholder's rights registration date is on April 10, 2006, stock dividend day on April 11, 2006. Total cash paid out is 101,728.9 thousand Yuan, occupying the profits which are distributed for the shareholders $23.07 \%$.

The next transaction day selected from April 11, 2006 is from April 12, 2006 to November 14, 2006. During this period, stock rate is calculated in the stock ransaction. And we got 52.13\% as the YiLi Ltd's fluctuation rate.

The Yili CWB1 lasts 12 months from November 15, 2006. According to former experience Yili Co.Ltd usually distributed dividends in July. It was estimated that the dividends for 2006 is in July, 2007 for every10 shares as 1 Yuan. In order to consider cash dividend influence on the stock initial price and the exercise price are needed to be adjusted.

After the adjustment the new good power price is $X_{X}=7.9556$ yuan, then

$$
\sigma_{V}=\frac{\sigma_{S} S N}{V\left(1-\frac{M k N\left(d_{1}\right)}{N+M k}\right)}=56.6461 \%
$$

When it exercises warrant only accepts stock transfer fees, for the deal transaction denomination $0.1 \%$. YiLi Ltd stock denomination is 1 yuan, so the exercise cost is

$k \times$ stock denomination $\times 0.1 \%=1 \times 1 \times 0.1 \%=0.001$ yuan,

then $A=0.001$, and the adjusted exercise price is $X^{\prime}{ }^{\prime}=X_{X}+\frac{N+M}{N} A=7.9569$ 
The Yili CWB1 lasts one year, a year has 252 transaction days, take $\Delta t=1 / 252$, then $\sigma=\sigma_{V} \sqrt{1+\sqrt{\frac{2}{\pi}} \times \frac{a}{\sigma_{V} \sqrt{\Delta t}}}=59.1251 \%$

From the above calculation method and parameters, we calculated the daily value (Note 2) of Yili CWB1, from April 242006 to May 29, 2007. And the traditional Black-Sholes result is compared with the modified model result. The result is shown in Figure 1.

\section{Validation on the Modified Warrant Model}

In light of the actual situation, the two investment portfolios with the same cost are structured. If the gains and losses for the two investment portfolios differ greatly under the less risk circumstances, the arbitrage opportunities may exist:

Program 1: Stock Investment

Let $S_{t}$ be the stock price, the ratio of the transaction cost for the stock transaction amount is $a, r$ is the corresponding interest rate. At the time $t$, the investment amount: $S_{t} \times(1+a)$; if the dividends is $D_{i}$ at the time of $t_{i}\left(t_{i}<T\right)$, then the assets of the investment program at $T$ time is $G_{1}=S_{T}+\sum_{i} D_{i} \times\left[1+r\left(T-t_{i}\right)\right]$

Program 2: Warrants and Deposits Investment

Warrant price is $W_{t}{ }^{\prime}$, the ratio of the transaction cost for the warrant transaction amount is $g$. This investment program at the time $t$, the investment amount is $W_{t}{ }^{\prime} \times(1+g)$. For the amount of investment at the time of $t$ as same as the assets of the investment program of Program 1, to save $F_{t}=S_{t} \times(1+a)-W_{t}{ }^{\prime} \times(1+g)$ in the bank. At the time of $T$, the bank deposits is $F_{T}=F_{t}[1+r(T-t)]$, so the assets of this program ${ }^{\text {is }} G_{2}=\left\{\begin{array}{cc}S_{T}+F_{T}-X-A & S_{T}>X \\ F_{T}-S_{T} a & S_{T}<X\end{array}\right.$

The income gap between program 1 and program 2 at the time of $T$ is $G_{1}-G_{2}$, and

$G_{1}-G_{2}=\left\{\begin{array}{cc}\sum_{i} D_{i} \times\left[1+r\left(T-t_{i}\right)\right]-\left(F_{T}-X-A\right) & S_{T}>X \\ \sum_{i} D_{i} \times\left[1+r\left(T-t_{i}\right)\right]-F_{T}+S_{T}(1+a) & S_{T}<X\end{array}\right.$

If the Program 1 is better than Program 2, which $G_{1}-G_{2}>0$, it was shown that the expected return on the stock market investment is much more than that on the warrant market. The warrant price was overvalued in the actual market, the actual prices of warrant is higher than the theoretical value, so $W_{t}{ }^{\prime}-W_{t}$ and $G_{1}-G_{2}$ should be approximately equivalent.

According to Monte-Carlo simulation, the warrant options expiration at time $T$, random equation of the underlying stock price is: $S_{T}=S_{t} \exp \left[\left(\mu-0.5 \sigma^{2}\right)(T-t)+\varepsilon \sigma \sqrt{T-t}\right]$

Where, the variable $\varepsilon$ is subject to the standard normal distribution from which the expectation of the $S_{t}$ is estimated without exercise, and thus $E\left(G_{1}-G_{2}\right)$

Taking Yili CWB1 as an example, we constructed investment portfolio. Hereinafter as $W=W_{t}{ }^{-}-W_{t}, G=G_{1}-G_{2}$, we get a fig of difference value $W$ and difference value $G$ during existing period and duration:

The difference value $W$ basically coincides with the difference value $G$ from the above Figure 2 . In fact these two variables are in regression analysis, we can get the regression equation as $W=0.974 G+0.025$. Equation constant and variable $G$ were less than 0.001 significantly.

Referred to the above model and calculation process, the following six products of warrant are analyzed by computing and data analysis, the results are shown as Table 2 and Figure 3.

The estimation for the accuracy of each firm's parameter is different. Each firm has the different effects on the modified B-S model and investment portfolio. According to the above results of the regression, the difference value $W$ and the difference value $G$ are approximately equivalent. So the above modified B-S model is basically rational.In this paper the price of warrant is mostly calculated from the early 2006 to May 30, 2007. In accordance with the terms of warrant prices map, we can see that there's serious overestimated phenomenon of the price of warrant in the listed time. 
A relative error $J_{t}$ set up to measure level of deviation of the actual prices of warrant from the theoretical price. Actual prices $W_{t}^{\prime}$ and theoretical values $W_{t}$ are known, that $J_{t}=\left(W_{t}^{\prime}-W_{t}\right) / W_{t}$. According to the data calculated, choose a time of more than four warrants that is from May 24, 2006 to May 10, 2007. The trends figure on the average is shown as follows:

In accordance with option theoretical knowledge, as the exercise date approaches, the degree of actual price deviation from the theoretical value would be smaller. To reduce the impact of this factor, we selected different starting times of warrant products. As shown in Figure 3, the price of warrant was overestimated seriously. But the general trend was that overestimating the price of subscribing for warrant dropped greatly. However, such phenomenon is well controlled in 2007.

\section{Conclusion}

This paper has presented a warrant pricing with integrating dividends, stock trading costs, warrant exercise cost and dilution of equity warrants. The model is applied to validation analysis. We can see that the market mechanism is not perfect in 2006, investors blindly follow market speculation, and there is an obvious "herding effect". In 2007, the phenomenon for overestimating price of warrant has been effectively controlled. China stock market matures, legal laws and regulations consummation are much better than before. Warrants' actual price was close to the theoretical value and it was rational for the investors to understand the warrant.

However, there has certain defects on the modified model developed in this paper: it is not considered that rise stops and fall stops have influence on the warrant pricing; it is not studied in details that if the price dynamics of the underlying security follows the lognormal process, and if the rate of return $\mu$ and the instantaneous viable of the asset $\sigma$ are parameters, and that how the computational method for expected rate of returnuand the instantaneous viable of the assetбaffects the result. Therefore, there will be further improvement on this model, which is more useful for the practice.

\section{References}

Black, F. \& Scholes. M. (1973). The pricing of options and corporate liabilities. Journal of Political Economy. 81: 637-659.

Boyle, P. \& Vorst. T. (1992). Option Replication in Discrete Time with Transactions Costs. Journal of Finance. 47(1), 271-293.

Galai, D. \& Schneller, M.I. (1987). Pricing of Warrants and the Value of the Firm. Journal of Finance. 33 1333-1342.

Leland, H. (1985). Option pricing and replication with transaction costs. The journal of finance. 40, 5, 1283-1301

R.C Merton. (1973). Theory of Rational Option Pricing. Bell Journal of Financial and Management Science. 4(1):141-184.

Ukhov, Andrey D. (2004). Warrant Pricing Using Observable Variables. The Journal of Financial Research. 27 (3), 329-339.

\section{Notes}

Note 1. YiLi Ltd(580009)warrant bulletin to market, 2006-11-10

Note 2. Dates from http://cn.finance.yahoo.com/

Table 1. Yili CWB1 Basic Information (Note 1)

\begin{tabular}{|l|l|l|l|}
\hline \multicolumn{2}{|l|}{ Yili CWB1 } \\
\hline Warrant Name & Yili CWB1 & Warrant Code. & 580009 \\
\hline Underlying Security & YiLi Ltd & Underlying Security Code & 600887 \\
\hline Warrant publisher & Yili Co.Ltd & Warrant Type & European stock warrant \\
\hline Original Stock Price & 21.73 & Exercise Price (¥) & 8 \\
\hline Risk Free Rate & $2.52 \%$ & $\mathrm{k}$ & $1: 1$ \\
\hline Time to Market & 2006.11 .15 & T & 12 months \\
\hline M & 154940935 & N & 516469784 \\
\hline
\end{tabular}


Table 2. Data analysis for Difference value $\mathrm{W}$ and difference value $\mathrm{G}$

\begin{tabular}{|l|l|l|l|l|l|}
\hline \multirow{2}{*}{ Warrant Name } & \multirow{2}{*}{ Warrant Type } & \multicolumn{2}{l|}{ Difference value W and G } & \multicolumn{2}{l|}{ Significant Level } \\
\cline { 3 - 6 } & & R2 & regression equation & $\begin{array}{l}\text { constant } \\
\text { term }\end{array}$ & G \\
\hline Shouchuang JTB1 & Covered Warrants & 0.999 & $\mathrm{~W}=0.975 \mathrm{G}+0.032$ & $<0.001$ & $<0.001$ \\
\hline Yage QCB1 & Covered Warrants & 0.978 & $\mathrm{~W}=0.879 \mathrm{G}+0.020$ & 0.018 & $<0.001$ \\
\hline Baogang JTP1 & Covered Warrants & 0.999 & $\mathrm{~W}=0.966 \mathrm{G}-0.086$ & $<0.001$ & $<0.001$ \\
\hline Hangang JTB1 & Covered Warrants & 0.987 & $\mathrm{~W}=0.984 \mathrm{G}+0.033$ & $<0.001$ & $<0.001$ \\
\hline Zhonghua CWB1 & European stock warrant & 0.990 & $\mathrm{~W}=0.961 \mathrm{G}-0.008$ & 0.68 & $<0.001$ \\
\hline Yili CWB1 & European stock warrant & 1.000 & $\mathrm{~W}=0.974 \mathrm{G}+0.025$ & $<0.001$ & $<0.001$ \\
\hline
\end{tabular}

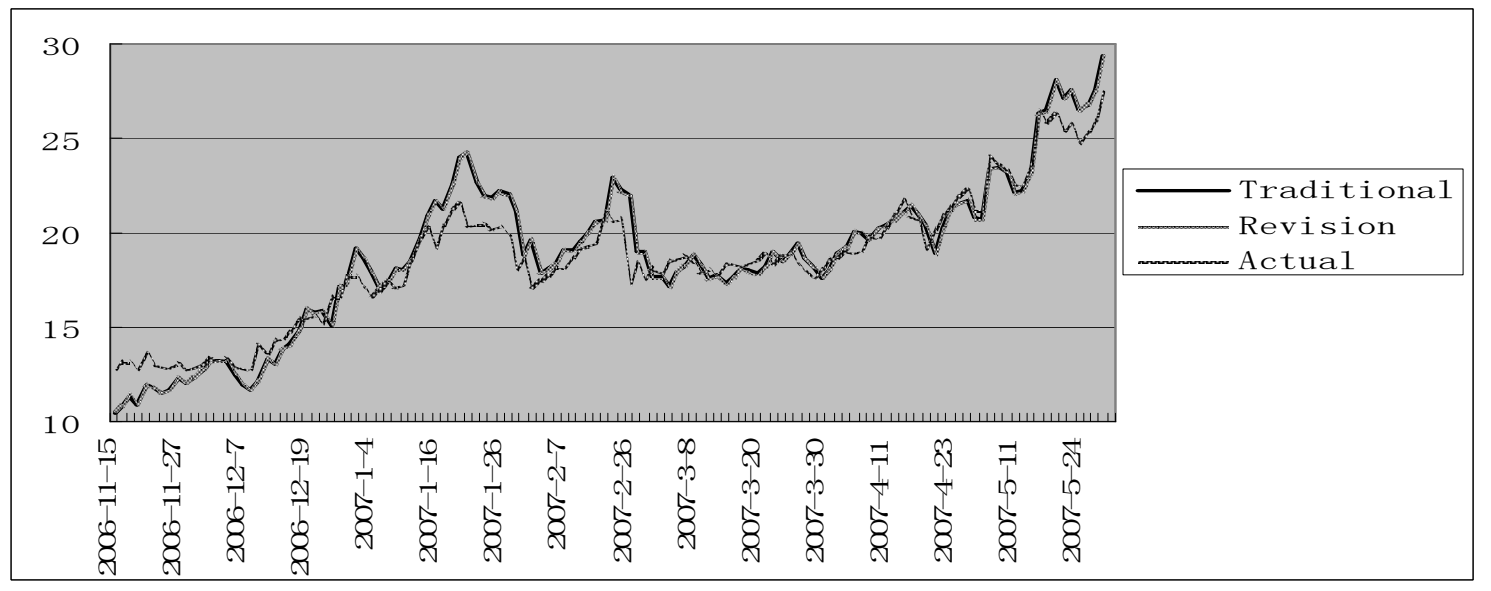

Figure 1. YiLi Ltd actual price and theory price

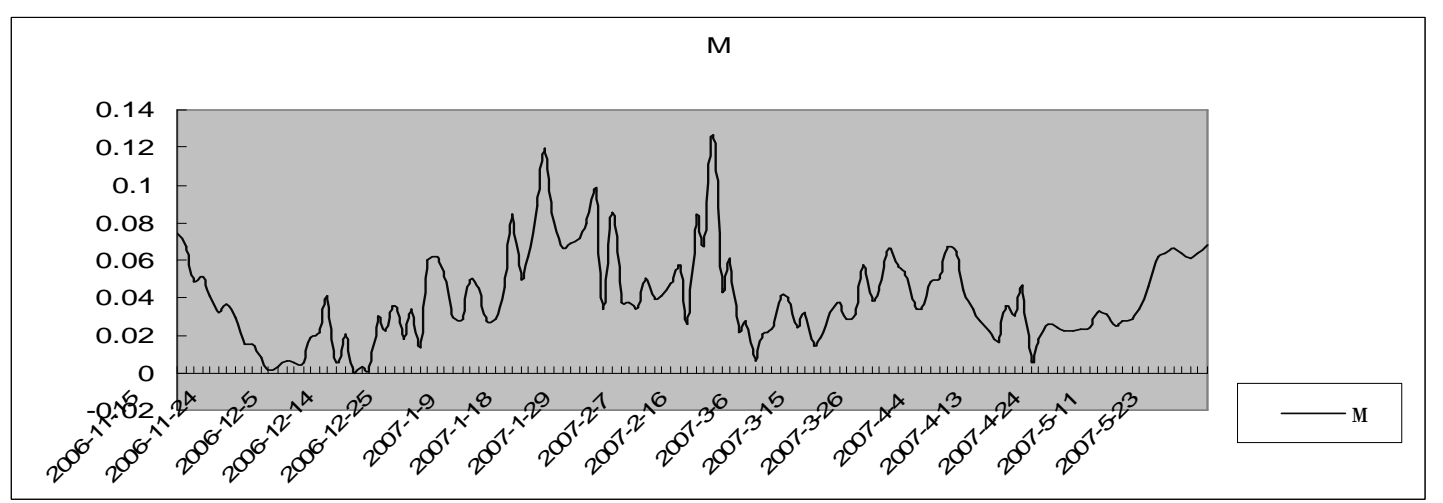

Figure 2. $W_{t}^{\prime}-W_{t}$ and $G_{1}-G_{2}$ differences and similarities 


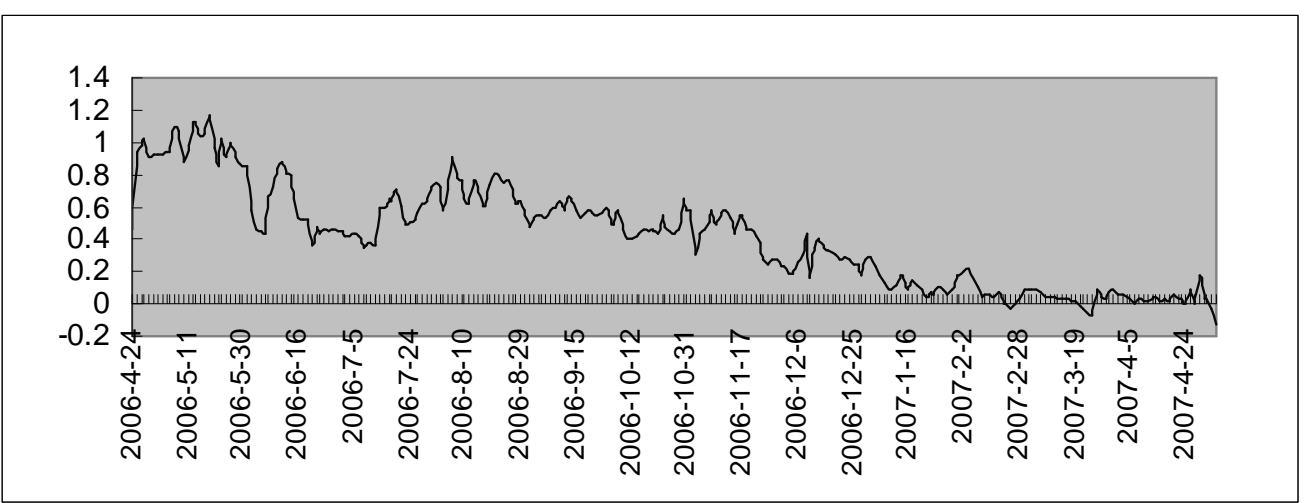

Figure 3. The trends figure of the actual price deviations from the theoretical value 


\title{
The Suitability of the GCC for Monetary Union
}

\author{
Michael Thorpe \\ College of Graduate Studies \\ University of Wollongong in Dubai \\ PO Box 20183, Dubai, UAE \\ Tel: 97-1-43672456_E-mail: michaelthorpe@uowdubai.ac.ae
}

\begin{abstract}
The member states of the Gulf Cooperation Council (GCC) have proposed the establishment of a monetary union in 2010. While this has the potential to generate significant benefits for the group and individual member states in the context of wider economic integration, it also removes some flexibility in the macro-economic management of national economies. It is important, therefore, that alternative adjustment mechanisms are in place and effective in the face of asymmetric shocks to the union. This paper looks at the theoretical and empirical literature and identifies the potential benefits and costs associated with a monetary union. It highlights the criteria used to asses to what extent any particular union would be beneficial and sustainable longer term. The GCC is reviewed with reference to this literature and some observations made as to the likelihood of a successful union and what steps could be undertaken to facilitate this.
\end{abstract}

Keywords: Gulf Cooperation Council (GCC), Monetary union, Economic integration

\section{Introduction}

The member states of the Cooperation Council for the Arab States of the Gulf (GCC) are planning to establish a monetary union in 2010 as part of a wider agenda of economic integration across the group. While this has the potential to realise considerable benefits, it also means that the use of both the exchange rate mechanism and monetary policy as policy instruments will be lost to members. A number of pre-conditions or criteria can be identified to provide a guide as to how likely it is that the proposed union would be successful and what steps are required by member states to ensure benefits are maximised.

The paper is structured as follows. The next section provides a brief overview of the GCC economies in the context of later discussion on the characteristics favouring a sustainable union. This is followed by a discussion of the economic theory underpinning monetary union. The benefits and costs associated with a monetary union are then discussed with reference to this literature, followed by a section identifying pre-conditions. The proposed union is then assessed with reference to these criteria and current economic conditions.

\section{Background to the GCC}

The GCC was created in 1981 with one of its objectives being greater economic integration. The six member states, Bahrain, Kuwait, Oman, Qatar, the Kingdom of Saudi Arabia and the United Arab Emirates (UAE), established a free trade zone in 1983 and in 2001 a decision was made to establish full monetary union with the adoption of a single currency, by the end of January 2010. (Note 1) As a lead-up to the monetary union members officially pegged their currencies to the USD in 2002 and moved to form a customs union in 2005, (Fasano and Iqbal, 2002). (Note 2) Convergence criteria for a number of economic indicators were also agreed to at the end of 2005 as part of this process. Further, a common market was formally agreed to at the end of 2007, which once practically implemented will allow for free movement of labour and capital between the member states under similar policy arrangements.

The proposed currency union should be seen in the context of the wider reform agenda and restructuring occurring within the GCC as it looks to more closely integrate and re-position itself in the global economy. Members are looking to diversify their economies away from dependence on oil and gas exports and increase the non-oil share of GDP in their economies. As well as providing a less volatile base for export income, it is driven also by the need to generate employment in the face of a rapid population growth (Fasano and Iqbal, 2002; Woertz, 2007).

With a combined GDP of USD 725 billion (2006 figures), 45 per cent of the world's oil reserves and a population of 36 million, the proposed union would constitute the biggest currency area outside the Eurozone (Note 3). Although average income puts the GCC in the high-income group by World Bank reckoning, income distribution is uneven across the members. 


\section{The Economies of the GCC Member States}

Despite some evident differences, the members currently exhibit a marked degree of similarity in terms of economic structure (Sturm and Siegfried, 2005). They are relatively open economies and although (energy) resource endowments differ greatly across the region, they are to large degree dependent on oil and gas. (Hebous, 2006) (Note 4). The GCC as a group accounts for just over 42 per cent of global oil reserves and 23 per cent of natural gas reserves (Note 5). The share of oil and gas in export revenues (currently at an average of around 75 per cent for the GCC) is reflected in the sector's importance in both total output and government revenues (Tables 1 and 2).

Despite the strong growth in recent years, the member states face a number of challenges including a need to promote growth in non-oil sectors to create employment opportunities for a growing (and generally young) population (Tables 3 and 4). The work-force in the GCC is growing at 4 per cent annually, with one-third of the population under 15. The capital intensive petroleum industry is not a significant employment creator, while the traditional route for nationals, the civil service, is a limited option longer term. The pressures do vary across the region in respect of current and future energy reserves, population growth, unemployment rates and per capita income levels (Table 5) (Note 6). Bahrain has limited energy resources, while Qatar and Oman have dwindling oil reserves.

There is a growing push for privatisation, labour market reform and greater economic diversification, all of which are inter-related (Sturm and Siegfried, 2005; Darrat and Al Shamsi, 2005; Fasal and Iqbal, 2002). A broader export and output base and reduced reliance on oil revenues will help to insulate economies from terms of trade shocks and provide sustainable longer-term growth and employment opportunities. This is evident in the expansion of banking services, manufacturing and tourism in several countries. In view of the changes being pursued, it is likely that the economic structures of the member states will increasingly diverge in the future.

In terms of intra-regional trade, integration of member states is currently quite limited; it has remained around 5 per cent of total trade for many years. Although this rises to around one-third when only non-oil trade is considered, it varies markedly for different member states (Hebous, 2006; Sturm and Siegfried, 2005). GCC export markets are concentrated in Asia, while the European Union (EU) is the main source of imports. Investment links within the GCC have also been limited to date. Over 1990-2002, only 2 per cent of investment outflows was intra-regional, with substantial financial assets held outside the region. There is evidence that this pattern is changing as more funds are being directed internally.

The pegged exchange rates and openness to capital flows have effectively resulted in alignment of monetary policies (with US interest rates-see below). Inflation has, however, diverged across the members due to domestic supply constraints as well as the effects of the recent USD devaluation against major currencies. Fiscal positions, and hence current debt levels, have also varied across the GCC. These developments have put strains on the group's existing currency arrangements and have raised some doubts as to the likelihood of the 2010 timetable for the union(Note 7).

\section{Exchange Rates and Monetary Policy}

The objective in selecting an exchange rate regime should be to encourage efficient resource allocation and provide effective protection from foreign and domestic shocks for the local economy (Yehoue, 2007). In choosing to link its currency with one or more currencies, a country can adopt an exchange rate peg, a currency area or a monetary union (Tavlas, 1993). A peg involves fixed rates between partners, with no fluctuations, while a currency area goes further and conducts a common monetary policy, no exchange controls within the area and full economic and financial market integration. A monetary union reflects a deeper integration, with a single currency and a common central bank or coordinating body. As a result, there is a community approach to exchange rate management in dealing with the rest of the world.

In the literature an optimum currency area refers to the optimum geographic domain of a single currency or of several currencies, whose exchange rates are irrevocably pegged or will be unified (Mundell, 1961; Kenen, 1969). As a result the linked currencies can only fluctuate in unison against other currencies. Optimality can be considered to the extent that conditions within the area allow for adjustment to certain shocks and support for internal and external balance without the need for nominal exchange rate adjustment, and depending on whether capital is free to move, without the use of monetary policy. The benefits and costs associated with pegged currencies or monetary unions can be addressed by reference to this literature.

In choosing an approach to managing the exchange rate exchange rate policy makers face a fundamental constraint, the so-called macroeconomic policy "trilemma" (Taylor and Obstfeld, 2003; Taylor, 2004). It is not possible for governments to simultaneously conduct an independent monetary policy, have an open capital account and maintain a stable exchange rate. It is possible to choose only two out of these three options. If capital controls are in place, 
then a country can fix its exchange rate and run an independent monetary policy. This choice is not possible when capital flows are not restricted as inflows will tend to offset any monetary policy directed at domestic objectives.

By linking their currencies to the USD the members of the GCC, all of whom maintain open capital accounts, have each opted to forego an active monetary policy as part of the program of stabilization en route to a currency union. This means that one policy tool for responding to asymmetric domestic shocks which are specific to parts of the union has been lost (Karam, 2001) (Note 8). With a common currency this fact will be formalized for the members and should they then maintain a peg to the USD, then the group itself would not have the option of an independent monetary approach (Note 9). Shocks to the anchoring country, in this case the US, tend to be directly transmitted to the targeting country with interest rate changes in the former leading to a corresponding change in the latter (assuming no capital controls) (Note 10).

\section{Benefits and Costs of a Monetary Union}

The benefits of a currency union are identified as stemming from the beneficial impact on trade and investment due to exchange rate stability. Greater economic integration is a result. To the extent that intra-regional trade is stronger pre-establishment of the currency union, then greater benefits are likely (Bayoumi and Mauro, 2001). Currency fluctuations are considered to raise the risks and cost of international transactions and hence reduce the volume of trade (Nitsch, 2002). (Note 11) While empirical studies have tended to find little support for this assertion, there is growing evidence for the converse proposition that reducing exchange rate variability significantly increases trade (Rose, 2001, 2002, Barro and Tenreryo, 2007, Yetman, 2007). Scale economies are also likely in the area's foreign exchange market, reducing prices and volatility in respect of external relations with non-members. With increased liquidity for the regional currency, greater development and integration of capital markets will be facilitated. Where the group's monetary policy is driven by a dominant member, then a member can gain credibility from its alignment within the group.

There is also some evidence on likely distributional effects of a union on the trade of individual member states. While evidence from the EU supports the view that the European monetary union (EMU) has lead to increased intra-regional trade overall, for some members the effect has, in fact, been negative (Aristotelous, 2006, Miccos, Stein and Ordonez, 2003). Countries that are more open to trade are seen to benefit to the greatest extent. The more trade among members is in manufactures where price is set by firms rather than on world markets, then the union is likely to bring greater benefit as well (Note 12).

Currency union is also expected to promote policy coordination and increase price transparency in the region, further enhancing the stability of the business environment. This will lead to direct gains in terms of increased trade as well as assisting the unification of bond and equity markets and the general efficiency of financial services. There should be greater cross-border investment, economic diversification and greater fiscal discipline among member states. In the context of a common market, the GCC will also have a stronger unified voice in its external relationships.

Costs of a currency union tend to centre on the loss of the exchange rate as a tool of managing the economy and the lack of an independent monetary policy capability by members in the face of unexpected, asymmetric shocks to the area (Bayoumi and Mauro, 2001) (Note 13). Shocks that adversely impact some, but not all member states will likely not be handled by a single national monetary policy and so the potential costs are higher if effective policy options for adjustment are lacking. There is debate as to whether, in a currency area, production is likely to become more spatially concentrated, making the area's economy more susceptible to asymmetric shocks or rather, increased integration will lead to greater economic convergence (Tavlas, 1993, de Grauwe, 2005). Without suitable mechanisms for sharing risk and smoothing shocks, including fiscal transfers and integrated capital and credit markets, countries suffering from adverse shocks will have an incentive to leave the system (Yehoue, 2007). To the extent that other adjustment mechanisms are weak, the absence of monetary policy as a tool can not only hamper economic adjustments, but can also exacerbate the impact of an asymmetric shock on individual member states (de Grauwe, 2005). There will also be change-over costs in switching to a new currency and administrative costs due to formation of new institutions.

Often political factors will dominate the economic criteria in assessment of the desirability of currency areas. How smaller members will be affected and how a dominant member(s) uses its influence are important considerations. Historically most currency unions have formed in the context of a political union (Bayoumi and Mauro, 2001) (Note 14).

\section{The Likelihood of a Successful Monetary Union}

The literature deals with a number of criteria or pre-conditions which indicate the likelihood of any currency area or monetary union being successful (Tavlas, 1993, de Grauwe, 2005, Yehoue, 2005, 2007, Bayoumi and Mauro, 2001). Several broad areas can be identified: 
(1) The extent of economic integration and convergence.

(2) The degree of factor mobility and domestic price flexibility.

(3) The existence of a system of fiscal transfers to compensate for failings of factor markets in responding to shocks.

(4) The political will.

These address issues which impact the level of net benefits arising from the union and which are likely to influence the nature and extent of shocks to the union and the ability of economies to subsequently adjust to any shocks.

\subsection{Economic Integration and Convergence}

Smaller and more open economies are likely to be (relatively) favoured by joining a currency area since the exchange rate is less relevant as an adjustment tool (Bayoumi and Mauro, 2001). Moreover, the higher is the area's intra-regional trade and investment linkages, the greater the likely benefits as a result of the reduction in risk and transaction costs. As well, if prices are flexible and trade links are significant, shifts in trade flows can help in responding to asymmetric shocks, providing a reduction in the cost of adjustment (Krugman and Obstfeld, 2003).

The more similar are countries in terms of their production structure it is expected that shocks to the economies will tend to be symmetric as business cycles and longer term economic movements will be closely correlated (Mundell, 1961; Frankel and Rose, 1998) (Note 15). There is some evidence that a union may be self-fulfilling in that it may encourage increased economic and financial integration and similarity in economic structures, raising the likelihood of a greater preponderance of symmetrical shocks for the union (Mongelli, 2005; Jadresic, 2003, Yetman, 2007). However, it has been argued that increased integration post the union could lead to increased regional concentration and agglomeration of industries across economies (Tavlas, 19930). With evidence tending to provide mixed results, de Grauwe (2005) claims that it is in the end an empirical question. To the extent that there are such concentration effects, then sector specific shocks will tend to be country or region specific. For developed economies, at least, intra-regional trade is likely to be more intra-industry in nature, while services, which become relatively more important as economic development proceeds, tend to be less concentrated across an economy. Under such conditions, shocks would be expected to be more symmetrical(Note 16).

\subsection{Factor Mobility and Flexibility}

Intra-regional adjustment to changing conditions without diverging inflation and unemployment rates can be assisted in the short-term by price and wage flexibility (Karam, 2001). This will decrease the need for fiscal transfers and other adjustment measures (given that monetary policy and direct nominal exchange rate control is not available). Mobility of factors reduces the need for factor prices to adjust and will assist in adjustment to more permanent shocks providing a more long term adjustment mechanism (Mundell, 1961). Internal labour mobility will help alleviate unemployment in areas suffering adverse shocks and attenuate inflationary pressures in expanding areas (Creighton, 2006).

Evidence from Europe suggests that wages adjust relatively slowly to shocks for a variety of institutional rigidities in labour markets. There is also low price flexibility as a result of non-competitive tendencies and persisting government market programs. These rigidities raise the cost of monetary union (de Grauwe, 2005). Evidence from the US indicates that the high degree of inter-regional labour mobility acts to mitigate the impact of unemployment shocks, in contrast to the situation in the EU (Mongelli, 2005).

Similarly, FDI provides for a long term adjustment response and also involves full financial integration, including capital and credit markets (Sorensen and Yosha, 1998) (Note 17). Countries in a currency area can also share risk through cross-country asset-holding of residents (McKinnon, 2004). If residents hold claims to dividends, interest income etc from other countries, then this can help smooth adjustments in the short term. Within the Eurozone, FDI flows have risen and have been seen to be responsive longer term to changes in regional economic conditions (Mongelli, 2005). This is seen as increasing the risk-sharing among members ex post.

\subsection{Extent of Fiscal Transfers}

If governments within a union keep control of their own budgetary powers there is the problem that this could increase the likelihood of asymmetric disturbances. A centralized budget would alleviate this problem and allow for fiscal transfers in response to asymmetric disturbances to help maintain incomes across the area. However, this may not be easy to achieve politically. Fiscal integration which allows for fiscal transfers to alleviate uneven shocks can be important for smooth out the impacts (Kenen, 1969).

\subsection{Political Will}

Political factors often dominate the economic factors in successful establishment of monetary integration (Tavlas, 1993), Political commitment is also needed to overcome resistance to issues related to loss of sovereignty which is 
part of joining a monetary union (Fasano and Schaechter, 2003). Jadresic (2002) argues that a lesson from previous monetary unions indicates that a significant level of political integration is needed to ensure success. The role of a dominant state in the union can be important in this regard.

\section{GCC and the Criteria}

Based on the above discussion it is useful to look at the institutional and structural characteristics of the GCC member economies in order to assess the validity of any currency union. This raises a number of questions. To what extent are there favourable conditions in place? If, as is likely, only some criteria are met what does this imply, and to what extent may some of the conditions be established ex post? Are there other issues that need to be considered? While there is no simple check-list, an attempt is made to gauge how the GCC is positioned and what issues need to be addressed.

As evidenced from the EU experience, pre-union convergence was an important element in setting the stage for a successful union, along with a suitable institutional framework for executing agreed monetary policies and fiscal arrangements (Fasano and Schaechter, 2003). Adoption of suitable convergence criteria can foster consistency in sound budgetary stances and price stability across the group. In the GCC, a set of criteria have been agreed in principle by central banks along similar lines to those adopted for the Eurozone. They include the following:

(1) Inflation should be no more than 2 percentage points above the average GCC rate

(2) Public debt (external and local) should be no more than 60 per cent of GDP

(3) Short term interest rates should be no greater than 1.5 percentage points above the GCC average level (of the lowest 3 rates).

(4) Budget deficits should be less than 3 per cent of GDP, although flexibility is recognised because of the susceptibility of revenues and expenditures to the impact of oil price fluctuations; the figure is less than 5 per cent when oil prices are "weak".

(5) Reserves should equivalent to at least four months import cover.

The inflation target is aimed at avoiding the need for large changes in exchange rates when final parities are determined, encouraging stability in the interim arrangement in respect of rates pegged to the USD. Similarity of interest rates should also support more balanced current account flows within the currency area (Tavlas, 1993).

De Grauwe (2005) suggests that linking interest rates will lessen any significant disturbances in national capital markets on establishment of the union. The fiscal criteria seek to ensure that destabilising pressure to bail-out some member states is avoided and they prepare authorities for a cooperative and fiscally responsible policy framework after the union (Sturm and Siegfried, 2005). Countries pursuing widely different fiscal policies could create an undesirable conflict with the union's centralised monetary stance (Fasano and Schaechter, 2003). Negative spill-overs would result for other members. A growing fiscal deficit in one member state, for example, could undermine the zone's exchange rate stability and subject other members to diseconomies through raised interest rates and crowding-out of the private sector (Note 18). As well as economic strains, this would create political issues. Financial difficulties in one member could also affect the credibility of the union with the rest of the world, with wider implications for liquidity and interest rates (Jadresic, 2002). The more co-ordinated and sustainable is fiscal policy, the less cost to each member state from foregoing the use of an independent monetary policy. The level of reserves helps in the management of the exchange rate regimes and will give the GCC flexibility in any choice in respect of its eventual external exchange rate regime.

The following tables provide some evidence as to the progress to date. Interest rates are provided in table 5. Apart from inflation, the member states appear to be performing well on these convergence measures. As noted above, the high inflation in Qatar and the UAE (and to a degree Saudi Arabia) reflects exchange rate effects due to the falling USD and some structural problems in the domestic economy. Consequently it is not considered to be divergent policy settings driving the differences. This issue does highlight some difficulties at present, however, with several members looking to adjust their parity rates against the USD as a result of the current environment (Note 19). The low interest rate differentials reflect a high degree of monetary convergence due to the stable link the members have maintained with the USD and hence the co-movement with US interest rates.

Fiscal convergence is less evident in the GCC states (Tables 7-9). The difference in debt to GDP ratios is related to different approaches to budgetary policy over time and reflects varying oil income sources across states as well as the variability of oil prices and spending priorities. It should be noted, however, that it is often not clear what constitutes the public sector in GCC countries and how significant are undisclosed foreign assets (Sturm and Siegfried, 2005). It is difficult, therefore, to clearly assess the question of sustainability of public finances. Looking at the government fiscal position (inclusive of oil revenues) can be misleading (Table 7). Fiscal stances 
vary across members and are vulnerable to movements in oil revenues. Reference to non-oil budget balances relative to non-oil GDP is considered a preferred measure of a government's fiscal stance (Barrett and Ossowski, 2002). The figures in Table 8 indicate the dependence on oil revenues by GCC governments in order to maintain a sustainable fiscal position. Only the UAE and Kuwait appear to have adopted a more balanced fiscal stance in recent times. As suggested above, some member states, including Oman, face strong pressure to restructure their economies and have indicated that the fiscal criteria is too constraining, to the extent that they have indicated (along with Saudi Arabia) that the proposed date of 2010 is problematic for them (Note 20). The level of reserves (Table 5) currently meets the criteria of four months import cover (Hebous, 2006).

Further consideration of the longer-term sustainability of the union centres on the likely nature of shocks and the effectiveness of adjustment mechanisms. Econometric studies looking at the GCC have tended to focus on how linked are the economies of the member states. Abu-Bader and Abu-Qarn (2006) suggest that there are limited correlations in terms of long run economic relationships and short term business cycles. They also argue that asymmetric shocks will be in large part supply side driven and arise externally. Hebous (2006), on the other hand, indicates that business cycles tend to be highly correlated, while Darrat and Al-Shamsi (2005) find support for long run economic and financial ties connecting the six member states. To the extent that there is convergence of the economies, a supra-national monetary policy is more likely to be effective as there would be less asymmetric shocks.

However, notwithstanding the current position, efforts are under way to diversify and restructure economies with the push for privatisation, greater FDI inflows, attention to corporate governance and a widening and deepening of financial and capital markets (Hebous, 2006; Darrat and Al Shamsi, 2005). This suggests increased integration will result as economies become more complementary and less reliant on oil. (Note 21) Reduction of an existing array of non-tariff barriers and greater harmonisation of institutions, regulations and laws will further assist in this process (Dar and Presley, 2001). This could lead to increased regional concentration and agglomeration of industry with service industries not evenly dispersed across the region and increasing non-oil trade being in large part inter-industry in nature. While enhanced trade flows permit greater benefits arising from the monetary union, in this case it would mean that asymmetric shocks will become more likely and hence it would be increasingly important that effective adjustment mechanisms are in place.

Labour markets are relatively flexible because of the large share of expatriate labour whose numbers can be adjusted readily in response to demand shocks (Sturm and Siegfried, 2005). Cross-border mobility is also encouraged by cultural links, but requires that barriers restricting movement and recognition of qualifications are reduced (Karam, 2001). If more nationals move into the private sector, flexibility needs to be maintained, while harmonisation of labour market policies is also desirable. Increased investment in human capital would assist in development of an increasingly services based economy and address unemployment problems.

Integration of financial and capital markets is not well advanced in the GCC. This may, in fact, be encouraged by the union and hence allow further adjustment mechanisms to operate. (Note 22) Gains could arise from an expansion of these markets across the GCC due to a wider circulation of the single currency (Note 23). A very large and liquid capital market, with integration of bond and equity markets would give greater capitalization and trading; this would in turn serve to encourage savings and investment across the region.

The question of fiscal transfers is a political as much as an economic issue. To the extent that discretionary government transfers are feasible and well managed, then they can play a significant role in any adjustment process and ensure cohesion of the group.

The union will also enhance the collective bargaining position with major economies, including Europe, the US, China and Japan. The common currency could even provide an alternative vehicle for pricing oil and perhaps serve as an Islamic currency.

\section{Concerns}

A GCC consensus is needed in the areas of monetary, exchange rate and fiscal policies for the union, following its establishment. The management of currency reserves, establishing common monetary instruments and a decision as to the nature and location of any central monetary authority or central bank are all matters to be addressed. The nature of the new currency is also a matter of debate. Given that impediments continue to hamper economic integration, a major stumbling block to a successful monetary union remains the matter of political commitment (Darrat and Al Shamsi, 2005).

In the lead-up to 2010, there is already disagreement about some of the convergence criteria, including the matter of public debt caps and setting of interest rates. A framework is needed, therefore, for resolving differences on fiscal policies although the diversity withinin the GCC could make adoption of certain policies such as wealth transfers to 76 
poorer members, complete factor market integration and agreement on institutional arrangements, harder to achieve. Policy setting, along with monitoring and assessing the convergence criteria, will require improved transparency and national data systems in the member states (Sturm and Siegfried, 2005, Krueger and Kovarich, 2006).

The choice of exchange rate regime for the GCC with its trading partners will be critical. The current peg to a (falling) USD has already proved problematic for some members given existing trade patterns. However, the choice would seem to be between a currency pegged to either the USD or a basket of currencies, rather than between a fixed or floating rate (Hebous, 2006).

\section{Conclusion}

The member states of the GCC are planning to establish a monetary union in 2010. Currently there is some debate as to the likelihood of achieving this target date and whether all members are prepared to participate fully. An overview of the GCC economies suggests that while they exhibit a degree of similarity in terms of their economic structures, this is likely to change in the future as energy reserves in some states run-down and as a result of growing pressures to reform and diversify economies.

The literature identifies a number of potential gains that could flow to the member states from the introduction of a union; these centre around increased trade and integration of financial and capital markets across the group and a stronger position with its trading partners. The costs that can arise stem in large part from the loss of the exchange rate and active monetary policy as adjustment policy tools by member states.

The likelihood of the union being successful depends, therefore, on the nature of the economic shocks that are likely to occur following its establishment and to what extent alternative adjustment measures exist and might be effective. Flexibility and stability in the face of asymmetric shocks are key objectives. A number of pre-conditions or criteria are identified as important to maximise expected benefits. These include the extent of trade between members and the similarity in their economic structures, the degree of factor mobility and domestic price flexibility across the group and whether a system of fiscal transfers is feasible between members. While these do not provide a simple check-list against which the GCC can be measured or assessed, they provide a basis for observation and some assessment.

The GCC members have instituted a number of so-called convergence criteria in the lead-up to 2010, aimed at creating a sound fiscal position and price stability. These are basically on track, but have put strains on some members to meet the 2010 deadline. A review of the GCC economies suggests that as the economies diversify, there is greater chance of asymmetric shocks to the group and hence there is a need to ensure that adjustment mechanisms are available. Efforts are needed to encourage greater labour market flexibility across the GCC and to foster capital and financial market integration. Agreement must also be reached regarding some form of fiscal transfer mechanism to assist members adversely impacted by shocks.

A number of political issues also need to be addressed including how a supra-national monetary policy and reserves management will be handled, common monetary instruments and improved transparency in reporting of economic and financial data. The setting of the exchange rate for the common currency with trading partners is obviously a key issue and goes to the question of credibility and sustainability of the union. The key will be the political will of the member states to address institutional issues and forego some degree of sovereignty.

\section{References}

Abu-Bader, S., and Abu-Qarn, A., (2006). On the Optimality of a GCC Monetary Union: Structural VAR, Common Trends and Common Cycles Evidence. Discussion Paper, 06-11, Monaster Center for Economic Research, Ben-Gurion University of the Negev, Israel.

Arab Monetary Fund, (2007). [Online] Available: http://www.amf.org.ae (November, 2007)

Aristotelous, K., (2006). Are There Differences Across Countries Regarding the Effects of Currency Unions on trade? Evidence from EMU. Journal of Common Market Studies, 44, $17-27$.

Barnett, S., and Ossowski, R., (2002). Operational Aspects of Fiscal policy in Oil Producing Countries. IMF Working Paper, 177, International Monetary Fund, Washington.

Barro, R., and Tenreyro, S. (2007). Economic Effects of Currency Unions. Economic Enquiry, 45, 1-23.

Bayoumi, T., and Mauro, P., (2001). The Suitability of ASEAN for a Regional Currency Arrangement. World Economy, 24, 933-54

Creighton, A., ((2006). Labour Mobility and Trans-Tasman Currency Union. Australian Economic Papers, 45, 1, 38-56 
Dar, H., and Presley, J., (2001). The Gulf Co-operation Council: A Slow Path to Integration?. World Economy, 24, 1161-1178.

Darrat, A., and Al Shamsi, F., (2005). On the Path of Integration in the Gulf Region. Applied Economics, 37, 1055-1062.

De Grauwe, P., (2005). The Economics of Monetary Integration. (6 $6^{\text {th }}$ ed.). Oxford University Press.

Eichengreen, B., and Bayoumi, T., (1999). Is Asia an Optimum Currency Area? Can it Become One? Regional, Global and Historical Perspectives on Asian Monetary relations. in S. Collignon, J. Pisani-Ferry and Y.C. Park (Eds.), Exchange rate Policies in Emerging Asian Countries, Routledge.

Fasano, U. and Schaechter, A., (Eds.), (2003). Monetary Union Among Member Countries of the Gulf Cooperation Council. IMF Occasional Paper, 223, International Monetary Fund, Washington.

Fasano, U., and Iqbal, Z., (2002). Common Currency. Finance and Development, December, 39, 1-7.

Frankel, J., and Rose, A., (1998), The Endogeneity of the Optimum Currency Area Criteria. The Economic Journal, 108, 1009-1025.

Hebous, S., (2006). On the Monetary Union of the Gulf States. Kiel Advanced Studies Working Paper, 431, Kiel Institute for the World Economy.

International Monetary Fund, (2007). World Economic Outlook. [Online] Available: http://www.imf.org/external/pubs/ft/weo/2007/02/pdf/statapp.pdf, (December, 2007)

International Monetary Fund, (2007a). Regional Economic Outlook, [Online] Available: http://www.imf.org/external/pubs/cat/longres.cfm?sk=20327.0, (October, 2007)

Jadresic, E., (2002). On a Common Currency for the GCC Countries. IMF Policy Discussion Paper, 02/12, International Monetary Fund, Washington.

Karam P., D., (2001). Exchange Rate Policies in Arab Countries: Assessment and Recommendations. Arab Monetary Fund Economic Papers, December, Arab Monetary Fund, Abu Dhabi, UAE.

Kenen, P., (1969). The Theory of Optimum Currency Areas: An Eclectic View. in Mundell, R. and Swoboda, A. (Eds), Monetary Problems of the International Economy, University of Chicago Press.

Krueger, R. and Kovarich, E., (2006). Some Principles for Development of Statistics for a Gulf Cooperation Council Currency Union. IMF Working Paper, 06/141, International Monetary Fund, Washington.

Krugman, P. and Obstfeld, M., (2003). International Economics: Theory and Policy. Addison-Wesley.

McKinnon, R., (2004). Optimum Currency Area and Key Currencies: Mundell I versus Mundell II. Journal of Common Market Studies, 42, 689-715.

McKinnon, R., (1963). Optimum Currency Areas. American Economic Review, 53, 717-25.

Miccos a., Stein, E., and Ordonez, G., (2003). The Currency Union Effect on Trade: Early Evidence from the European Union. Economic Policy, 18, 315-56.

Mongelli, F., (2005). What is European Economic and Monetary Union Telling us About the Properties of Optimum Currency Areas?. Journal of Common Market Studies, 43, 607-35.

Mundell (1961). A Theory of Optimal Currency Areas. American Economic Review, 51, 657-65.

Nitsch, V., (2002). Honey, I Shrunk the Currency Union Effect on Trade. The World Economy, 25, 457-74.

Sturm, M., and Siegfried, N., (2005). Regional Monetary Integration in the Member States of the Gulf Cooperation Council. European Central Bank Occasional Paper Series, 31, June, European Central Bank.

Rose, A., (2002). Honey, the Currency Union Effect on Trade Has'nt Blown Up. The World Economy, 25, $475-79$.

Rose, A., (2000). One Money, One Market: Estimating the Effects of Common Currencies on Trade. Economic Policy, 15, 7-33.

Rose A., and Stanley, T., (2004). A Meta-Analysis of the Effects of Common Currencies on International Trade. Journal of Economic Surveys, 19, 347-65.

Sorensen, B., E., and Yosha, O., (1998). International Risk Sharing and European Monetary Unification. Journal of International Economics, 45, 211-38.

Tavlas, G., (1993). The New Theory of Optimum Currency Areas. The World Economy, 16, 663-85.

Taylor A. (2004). Global Finance: Past and Present. Finance and Development, March, 41, 28-31. 
Taylor A. and Obstfeld M. (2004), Global Capital Markets; Integration Crisis and Growth. Cambridge University Press.

Woertz, E., (2007). Demography and Political Violence in the Middle East. Gulf Monitor, October, 1, 2007, 16-19, [Online] Available: http://www.grc.ae/data/contents/uploads/Gulf_Monitor_no_6_3450.pdf (December, 2007).

World Bank, (2006).World Development Report 2007. Washington.

Yehoue, E., B., (2007). The CFA Arrangements-More than Just an Aid Substitute?. IMF Working Paper, 07/19, International Monetary Fund, Washington.

Yetman, J., (2007). Currency Unions, Trade Flows and Capital Flows. Pacific Economic Review, 12, $189-204$.

Table 1. Oil and Gas Activities as Share of Economic Activity 2004 (Per cent)

Source: Arab Monetary Fund (2007); Hebous, 2006

\begin{tabular}{|l|l|l|l|}
\hline & GDP & $\begin{array}{l}\text { Government } \\
\text { Revenues }\end{array}$ & Exports \\
\hline Bahrain & 23.3 & 72.6 & 76.5 \\
\hline UAE & 47.6 & 77.7 & 35.8 \\
\hline Kuwait & 43.8 & 91.4 & 92.8 \\
\hline Oman & 62.2 & 66.2 & 68.0 \\
\hline Qatar & 86.8 & 55.3 & 90.0 \\
\hline Saudi Arabia & 35.8 & 84.1 & 88.4 \\
\hline GCC & 69.9 & 74.6 & 75.0 \\
\hline
\end{tabular}

Table 2. Confirmed Oil and Gas Reserves (Per cent of world production)

\begin{tabular}{|l|l|l|}
\hline & Oil & Gas \\
\hline Bahrain & - & 0.1 \\
\hline UAE & 8.2 & 3.4 \\
\hline Kuwait & 8.3 & 0.9 \\
\hline Oman & 0.5 & 0.6 \\
\hline Qatar & 1.3 & 14.4 \\
\hline Saudi Arabia & 22.1 & 3.8 \\
\hline GCC & 40.4 & 23.2 \\
\hline Middle East & 64.0 & 40.0 \\
\hline Latin America & 10.0 & 4.0 \\
\hline E Europe & 8.0 & 32.0 \\
\hline Africa & 10.0 & 8.0 \\
\hline
\end{tabular}

Source: (Steinhilber, 2006; Shihab-Eldin, 2006, Fasano and Iqbal, 2002) 
Table 3. GDP Growth (Per cent per annum)

\begin{tabular}{|l|l|l|l|l|l|l|l|}
\hline & $1998-2002$ & 2002 & 2003 & 2004 & 2005 & 2006 & 2007 \\
\hline Bahrain & 4.8 & 5.2 & 7.2 & 5.4 & 6.9 & 7.1 & 6.3 \\
\hline UAE & 4.0 & 2.6 & 11.9 & 9.7 & 8.5 & 11.5 & 5.8 \\
\hline Kuwait & 2.5 & 5.1 & 13.4 & 6.2 & 8.5 & 11.5 & 5.8 \\
\hline Oman & 3.6 & 2.6 & 2.0 & 5.6 & 6.7 & 7.1 & 5.7 \\
\hline Qatar & 7.4 & 7.3 & 5.9 & 11.2 & 6.5 & 6.7 & 4.7 \\
\hline Saudi Arabia & 1.5 & 0.1 & 7.7 & 5.3 & 6.6 & 5.8 & 6.5 \\
\hline
\end{tabular}

Source: International Monetary Fund (2007)

Table 4. Population and Unemployment in the GCC

\begin{tabular}{|l|l|l|l|l|}
\hline & $\begin{array}{l}\text { Population mid-2005 } \\
\text { (Million) }\end{array}$ & $\begin{array}{l}\text { Population < 15 years 2004 } \\
\text { (Per cent) }\end{array}$ & $\begin{array}{l}\text { Population Growth 2004 } \\
\text { (Per cent per annum.) }\end{array}$ & $\begin{array}{l}\text { Unemployment } \\
2004 \\
\text { (Per cent })\end{array}$ \\
\hline Bahrain & 0.73 & 28 & 2.6 & 17.5 \\
\hline UAE & 4.62 & 25 & & 3.0 \\
\hline Kuwait & 2.58 & 26 & 7.5 & 4.9 \\
\hline Oman & 2.43 & 33 & 2.0 & 17.5 \\
\hline Qatar & 0.76 & 25 & 7.5 & 3.0 \\
\hline Saudi Arabia & 24.57 & 37 & 2.3 & 15.0 \\
\hline GCC & 35.72 & 33. & 7.0 & n.a. \\
\hline
\end{tabular}

Source: World Bank (2006)

Table 5. (Economic Indicators 2005)

\begin{tabular}{|l|l|l|l|l|l|l|l|l|}
\hline & $\begin{array}{l}\text { Fiscal } \\
\text { Balance } \\
\text { (Per cent } \\
\text { of GDP) }\end{array}$ & $\begin{array}{l}\text { Government } \\
\text { Debt (Per cent } \\
\text { of GDP) }\end{array}$ & $\begin{array}{l}\text { Inflation } \\
\text { (Per cent } \\
\text { p.a.) }\end{array}$ & $\begin{array}{l}\text { Per } \\
\text { capita } \\
\text { GDP } \\
\text { (USD) }\end{array}$ & $\begin{array}{l}\text { Exports } \\
2003 \\
\text { (Per cent } \\
\text { of GDP) }\end{array}$ & $\begin{array}{l}\text { Current } \\
\text { Account } \\
\text { (Per cent } \\
\text { of GDP)* }\end{array}$ & $\begin{array}{l}\text { Short-run } \\
\text { interest } \\
\text { rates } \\
\text { (Per } \\
\text { p.a.) }\end{array}$ & $\begin{array}{l}\text { Official } \\
\text { Foreign } \\
\text { Exchange } \\
\text { Reserves } \\
\text { (USD B)** }\end{array}$ \\
\hline Bahrain & 1.4 & 30.3 & 2.6 & 15412 & 83.9 & 20.6 & 2.0 & 2.1 \\
\hline UAE & 27.4 & 9.6 & 8.0 & 22643 & 79.1 & 21.0 & 1.2 & 23.6 \\
\hline Kuwait & 46.9 & 13.1 & 3.9 & 23069 & 54.8 & 52.5 & 1.7 & 7.0 \\
\hline Oman & 14.5 & 10.8 & 3.2 & 11890 & 56.2 & 19.4 & 2.1 & 4.0 \\
\hline Qatar & 11.8 & 30.5 & 8.8 & 44500 & 72.0 & 49.1 & 2.4 & 3.3 \\
\hline $\begin{array}{l}\text { Saudi } \\
\text { Arabia }\end{array}$ & 18.4 & 39.0 & 0.7 & 10936 & 45.9 & 33.1 & 1.8 & 23.4 \\
\hline GCC & 24.0 & - & & & & & 36.2 & - \\
\hline
\end{tabular}

* 2006

** Underestimates reserves held in Ministries and investment agencies

Source: Arab Monetary Fund (2007) 
Table 6. Inflation (Per Cent per annum)

\begin{tabular}{|l|l|l|l|l|l|l|l|}
\hline & $1998-2002$ & 2002 & 2003 & 2004 & 2005 & 2006 & 2007 \\
\hline Bahrain & -0.8 & -0.5 & 1.7 & 2.3 & 2.6 & 2.6 & 3.0 \\
\hline UAE & 2.2 & 2.9 & 3.1 & 5.0 & 8.0 & 10.0 & 5.0 \\
\hline Kuwait & 1.5 & 0.8 & 1.0 & 1.3 & 3.9 & 3.5 & 3.0 \\
\hline Oman & -0.3 & -0.2 & 0.2 & 0.8 & 1.9 & 3.5 & 2.0 \\
\hline Qatar & 1.7 & 0.2 & 2.3 & 6.8 & 8.8 & 9.0 & 8.0 \\
\hline Saudi Arabia & -0.7 & 0.2 & 0.6 & 0.4 & 0.7 & 1.0 & 1.0 \\
\hline GCC & 0.2 & 0.8 & 1.2 & 1.8 & 2.9 & 3.2 & 2.4 \\
\hline
\end{tabular}

Source: International Monetary Fund (2007a).

Table 7. Central Government Fiscal Balance (Per cent of GDP)

\begin{tabular}{|l|l|l|l|l|l|l|l|}
\hline & $1998-2002$ & 2002 & 2003 & 2004 & 2005 & 2006 & 2007 \\
\hline Bahrain & -0.6 & -3.9 & -2.0 & 0.3 & 1.4 & 4.2 & 0.7 \\
\hline UAE & 1.6 & 10.5 & 13.8 & 19.5 & 27.4 & 30.2 & 31.4 \\
\hline Kuwait & 20.5 & 19.3 & 18.0 & 23.6 & 46.9 & 58.0 & 62.5 \\
\hline Oman & 3.9 & 5.6 & 5.8 & 8.5 & 14.5 & 18.1 & 17.6 \\
\hline Qatar & 0.8 & 8.4 & 4.3 & 18.9 & 11.8 & 18.1 & 19.7 \\
\hline Saudi Arabia & -4.3 & -5.9 & 1.2 & 9.6 & 18.4 & 18.5 & 20.3 \\
\hline
\end{tabular}

Source: International Monetary Fund (2007)

Table 8. Central Government Non-Oil Fiscal Balance (Per cent of Non-Oil GDP)

\begin{tabular}{|l|l|l|l|l|l|l|l|}
\hline & $1998-2002$ & 2002 & 2003 & 2004 & 2005 & 2006 & 2007 \\
\hline Bahrain & -25.4 & -33.9 & -33.1 & -29.3 & -29.8 & -30.3 & -29.0 \\
\hline UAE & -32.0 & -30.7 & -28.0 & 21.3 & -17.3 & -14.9 & -12.1 \\
\hline Kuwait & -39.8 & -44.9 & -47.5 & -48.7 & -39.4 & -31.9 & -28.3 \\
\hline Oman & -52.1 & -55.8 & -56.1 & -64.9 & -66.5 & -69.5 & -70.4 \\
\hline Qatar & -50.4 & -42.1 & -47.0 & -42.6 & -61.3 & -56.5 & -50.9 \\
\hline Saudi Arabia & -41.9 & -46.9 & -46.7 & -46.5 & -52.3 & -55.2 & -54.8 \\
\hline
\end{tabular}

Source: International Monetary Fund (2007)

Table 9. Government Debt (Per cent of GDP)

\begin{tabular}{|l|l|l|l|l|l|l|l|}
\hline & $1998-2002$ & 2002 & 2003 & 2004 & 2005 & 2006 & 2007 \\
\hline Bahrain & 29.0 & 32.2 & 37.1 & 35.1 & 30.3 & 26.0 & 23.5 \\
\hline UAE & 5.5 & 5.3 & 6.7 & 8.4 & 9.6 & 9.0 & 7.3 \\
\hline Kuwait & 40.0 & 30.0 & 23.8 & 18.5 & 13.1 & 10.0 & 9.0 \\
\hline Oman & 27.4 & 17.4 & 16.4 & 15.5 & 10.8 & 8.4 & 7.4 \\
\hline Qatar & 59.9 & 47.1 & 41.5 & 34.0 & 30.5 & 23.1 & 20.3 \\
\hline Saudi Arabia & 96.7 & 96.9 & 82.0 & 65.0 & 39.0 & 15.2 & 7.1 \\
\hline
\end{tabular}

Source: International Monetary Fund (2007)

\section{Notes}

Note 1. A renewed interest in currency or monetary unions has been driven in large part by the experience of the European Monetary Union (EMU), "dollarisation" experience in Latin America and recent financial crises in East 
Asia and elsewhere.

Note 2. Members, under different arrangements, had to various degrees been effectively fixed to the USD for some time prior to this (Fasano and Iqbal, 2002). Europe had similar experiences with some countries linking to the Deutschemark ahead of the establishment of the EMU.

Note 3. Saudi has 70 per cent of total GCC population and accounts for more than half of the group's output. The next largest, the UAE, about 12 per cent of the population and about 20 per cent of the group's output.

Note 4. The average trade to GDP ratio is around 88 per cent with the trade balance having risen sharply over the past 5 years.

Note 5. Reserves also are currently being depleted much more slowly in the GCC than in other areas. The area's share of global oil and gas output is 22 per cent and 6.5 per cent respectively.

Note 6. Differences in per capita income levels are not as great, in fact, as those experienced in the EU.

Note 7. Although Oman has already opted out of the current timetable for domestic economic reasons, other member states are continuing to support the 2010 union, albeit with varying enthusiasm. Kuwait has moved its peg away from the US dollar to a basket of currencies. Other member states have been considering a similar response to the falling dollar or alternatively, revaluation of their dollar pegs. Any policy adjustments in light of changing external situations need not necessarily undermine the basic motivation for a currency union, nor necessarily of themselves hinder the process.

Note 8. Interest rate changes within the union can not be targeted at individual member states, irrespective of growth and unemployment conditions there.

Note 9. The question of what the exchange rate policy should be in respect of the common currency is not the focus of this paper; some observations are made, however.

Note 10 . To the extent that monetary and policy making institutions are weak or under-developed then fixing to a more "credible" currency can be beneficial. Similarly, within a union, weaker states are locked-in to the monetary discipline (or not) of the central authority.

Note 11. There is debate as to the impact of exchange rate volatility on trade, both from a theoretical and empirical perspective (de Grauwe, 2005, Rose, 2000).

Note 12. Exchange rate fluctuations have a more pronounced affect on the price of differentiated products than on homogeneous commodities which typically have a world price (Bayoumi and Mauro, 2001).

Note 13. Shocks could represent a host of factors. Oil price rises, for example, would be seen as symmetric to the extent that all members were significant oil exporters. Sectoral shocks would be more likely asymmetric if different countries or regions within the union were more specialized; shocks could be specific, for example, to the tourist sector, property market, manufacturing or finance markets and the regional impact could be quite varied.

Note 14. Examples include the CFA franc zone and the rand zone in southern Africa. By way of contrast, the EU is a union of countries which traditionally have been strongly independent politically and in terms of internal economic management (Bayoumi and Mauro, 2001). Any system needs to consider the particular needs of the group. To that extent, the EU or other experiences are a guide only.

Note 15. Economies that are themselves more diversified in terms of their production mix will be better able to deal with shocks to the economy and would better be able to adjust to sector specific shocks (Kenen, 1969).

Note 16. Evidence from the EU indicates that such concentration effects are not evident. However, that reflects the significant level of intra-industry trade in differentiated manufacturing products and the dominance of service industries (de Grauwe, 2005)

Note 17. Cross-ownership of assets and cross-border savings and credit flows will help share risk through smoothing of consumption over time and across members (Yehoue, 2007).

Note 18. The issue of moral hazard exists, with incentives existing for members to pursue independent deficit strategies in anticipation of being bailed-out by the union.

Note 19. The recent sharp decline in the value of the USD against major currencies has been a cause of concern for members. A meeting of the governors of the central banks of GCC members in December 2007 agreed to maintain existing currency pegs to the USD in an effort to keep the proposed monetary union on track. It is likely, however, that revaluation within this arrangement for some or all members will be likely in the future, perhaps with a shift by some to a peg against a basket of currencies, reflecting a desire for a monetary policy independent of that in the US. 
Note 20. In particular the limit of 3 per cent of GDP for public debt is seen as a restraint on the economy in Oman as it seeks to diversify in the face of declining oil revenue and high unemployment. Kuwait, meanwhile, has disagreed with the common inflation targets.

Note 21. After establishment of a monetary union, increased efficiency in financial services and general resource allocation, improved transparency in prices and more coordination in investment activities will all create a more favorable environment for integration to expand (Fasano-Filho and Schaechter, 2003).

Note 22. Restrictions still exist on foreign ownership of equity and real estate, hindering establishment of cross-border commercial presence and permitting limited cross-listing of stocks; there is little cooperation across exchanges.

Note 23. In the EU financial market integration has risen since the formation of the monetary union. This provides a degree of private risk-sharing. 


\title{
Resistance, the Echo of Change
}

\author{
Wenhe Yue \\ School of Management, Shenyang Jianzhu University, Shenyang 110168, China \\ E-mail: bobo1012@sina.com
}

\begin{abstract}
Change can be seen everywhere, and all people and organizations are affected by change more than ever before. This article aims to identify the resistance to change, illustrate these resistance changes. Finally, give some recommendatory practices might managers adopt to improve the prospect of successful change implementation.
\end{abstract}

Keywords: Resistance, Change, Organization

In the new century, when business and political leaders-indeed, entire governments-assert their dedication to change, but how to manage the reactions to that change may be the greatest challenge. Change creates anxiety, uncertainty and stress, even for those managing change, and even of they are fully committed to change (Carnall, 1990, p.138). These reactions often are lumped under "resistance" to change. Resistance is habitually a reaction to a loss of control, not necessarily to the change itself. The less knowledge for a person to know the rational for the change and the implications of the change and how to operate the change, the greater the threat to that person's control over his or her environment (Jick and Peiperl, 2003). Resistance to change seems to be always more powerful in strategic changes (Del Val and Fuentes, 2003)

But now with the increase of echoes of change, resistance need not be frightening under the wisely management. Manager trying to improve processes in their organizations need to understand why people resist change, and this is just a good information resource for them to control the processes (Jager, 2001, p.24).

\section{What is the resistance?}

Resistance at its most obvious is a slow motion response to meet agreements or even a complete refusal to cooperate with change. It can either be intentional or unintentional, covert or overt (O'Connor, 1993, p.30).

Vakola cited Burnes (1992) that resistance to change is a critical issue in all change initiatives because it may lead to a lack of co-operation and communication among those involved and affected by the change process.

Resistance is sometimes portrayed by consultants and managers as the result of employee weakness, and individuals may be stereotyped and called saboteurs, shirkers, dinosaurs, ostriches, loony lefties, and loss of morale, distrust, becoming self-centered, narrow-minded and so on (Cascio, 1993).

In the organizations, employees will often psychologically resist change when it involves altering their work values and self-concept; some professionals find marketing and administration duties unsatisfying when they take up time that could have been spent executing professional work (Whittington, McNulty and Whipp, 1994).

Many professionals in the public and in the private sector are facing increased responsibility for marketing and administration and some of them are unsure how much of their newly defined role they should accept their reluctance to change is partly a consequence of their occupational commitment to professional work; their unwillingness to take on more duties is rarely just a case of irrational resistance (Morris and Pinnington, 1998)

\section{Why resistance to change}

As mentioned before, resistance is a natural phenomenon in change progress. The failure of many large-scale corporate change programs can be traced directly to employee resistance (Maurer, 1997). During 1993 and 1996 , 500 large Australian organizations revealed that employee resistance was the most frequently cited implementation problem encountered by management when introducing change (Bovey and Hede, 2001). Why is there resistance to change in the organization? And what then are the sources of resistance to organizational change?

Ford, Ford and McNamara (2002) explained that resistance occurs because it threatens the status quo, or increases fear and the anxiety of real or imagined consequences including threats to personal security and confidence in an ability to perform. In addition, Change threatens the way people make sense of the world, calling into question their values and rationality, and prompting some form of self-justification or defensive reasoning. Or, people distrust or have past resentments toward those leading change; they have different understandings or assessments of the situation, or are protecting established social relations that are perceived to be threatened.

Resistance to change occurs when it creates too much role incompatibility for employees. Expecting shop-floor workers to communicate with a larger number of teams and managers in the plant will mean they have to adopt a broader role set; that is, they will have to cooperate with various groups and learn to behave and respond to different 
expectations. Some employees will find developing a broader set of relationships at work to be a stimulating new challenge and personally fulfilling; however, others may find these new relationships to be incompatible with their more restricted concept of self, and experience increased role strain and stress. People who are "resistant" are not necessarily being stubborn but may be slower in having "insight" into the situation (Pinnington and Lafferty, 2003)

Effective change has been characterized as unfreezing old behaviours, introducing new ones, and re-freezing them (Appelbaum and Wohl, 2000). Change is difficult and threatening. It is natural for change to be met with resistance people resist things they are unsure of. The bigger of change, the greater resistance to create change (Maurer, 1998). People resist change due to many factors, some of which are a lack of information on the proposed change and a comfort in the stable environment to which they have become accustomed and in which they find predictability and security (Weiss, 1998). As an example, aging baby-boomers are moving into risk-averse zones. Facing personal, financial and career changes, they want change without high risk (Tapsell, 1998). Effective strategic change requires approaches to leadership that are more likely to enhance workplace change through employee participation, motivation and commitment. Change can only succeed if it is based solidly on an understanding of how people behave, what motivates them, and how improved positive attitudes can be developed (Zeffane, 1996).

Bennis (1973, cited in Coghlan, 1993, pp.10-11) suggests six types of response that individuals may mobilize: oppose, resist, tolerate, accept, support and embrace. Since every change involves some forms of loss and disappearance of something familiar, the choice of these responses is affected by the degree of ambiguity of the change, the degree of control over the change and environment, the degree of trust in the change initiators. Meet with organizational changes, employees often wonder what the goal of the change is, why need to change, what benefits it brings to company and to me, and what affects my own work and job development etc, because changes requires going from the known to the unknown (Bovey \& Hede, 2001, p.534). Lack in satisfying information and understanding of change, change may be misunderstood, and at the same time all kinds of different attitudes will appear, besides acceptance and support, suspicion, disbelief, refusal, and denial will also be shown in front of managers. And thus, resistance emerges.

Understanding the sources of resistance allows creation of a management strategy to deal with it. To resolve resistance, a manager must willingly explore what causes it. There is no other way. O'Connor (1993) believes that resistance results from differences involving ideas, motives, plans, or priorities, and brought forward five common sources of resistance as follows:

(1) Lack of belief that there is a serious need for change.

(2) Different descriptions of the need for change.

(3) No agreement about goals for change.

(4) Lack of belief that the goal is attainable.

(5) No confidence in the manager of change.

Recognizing the sources of resistance guides the development of better understanding. And once a source of resistance is identified, managers can encourage the debate of issue about the identified source and work to integrate these differences and therefore minimize resistance.

\section{Resistance, as enemy in change}

In recent society, change is considered as inevitability for many organizations. However, nearly two-thirds of major change programs prove unsuccessful and, according to Fortune 500 executives, the primary reason for this is not a lack of skill or resource, but resistance (Anonymous, 2002, p.21). Resistance is therefore understood to be the enemy of change.

\subsection{Rational vs. Irrational Resistance}

Rational resistance can occur where an individual's own rational assessment of change outcomes differ from these of management. So it can be overcome with reasonable explanation for any proposed change (Jager, 2001, p.26). If the reasons to change are persuasive enough, then resistors will willingly adopt the change.

Taking on something new largely means giving up something that is familiar, comfortable and predictable, so people will feel that they are uninvolved in new process. Another rational reason why people resist change is that they fear having to learn something new. Sometimes it is not that they disagree with the benefits of some new process; rather, they simply fear the unknown future and doubt their ability to adapt to it (Davidson, 2002, p.21). In another words, it means fear may stop people from taking first steps to change, even when they know that the result of change will greatly benefit them.

However, irrational resistance does exist, too. It means individual reaction to change is also a function of 
predispositions and preferences not necessarily based on a rational assessment of change (Anonymous, 2002, p.22). Simply speaking, there are a few people never accept change, even if evidence, proof, demonstration, or persuasion are urging them to willingly adopt the change. They simply don't want to change, and they always find a problem with any changes. According to Geisler (2001), these people are so-called bottom-feeders, who seem to be the most dissatisfied and the most vocal. Resistance therefore becomes an enemy that is a serious preventer in the change process, and hard to conquer.

\section{Resistance, as assistance in change}

Usually, resistance is regarded as an obstacle that prevents change process from successful developing. So people always try to compete with it until diminishes. But in fact, as an essential element in understanding any change progress, it is not totally passive, but is rather a powerful, effective, and dynamic energy. Handled properly, it can serve as a valuable assistance and contribution to the change process (Coghlan, 1993, p.11; Heifetz \& Linsky, 2002, p.69; Jager, 2001, p.24). But it should be remembered that it is a fallacy to consider change itself to be inherently good, because change can only be evaluated to be good or not through its consequences until sufficient time has passed (Anonymous, 2002, p.22).

Appearance of resistance may mean an influx of energy added into the change process. Those employees who resist plan for change may in fact have different definitions of the problem or beliefs about its seriousness. Monitoring these different responses and listening to them will make managers aware of the issues that need to be addressed during the change process (Freda, Arn \& Gatlin-Watts, 1999, pp.32-33). There is a real danger of apathy when dealing with significant program where resistance occurs. It is impossible for managers to examine more closely the sources of the existing problems, which means latent crisis to change in the long run. In this respect resistance can become a useful source of innovation. Furthermore, without resistance, any proposal favoured by managers will be accepted, which can be detrimental to lead to an organizational change limitation (Anonymous, 2002, p.23).

CEO of Belgian Telecommunication Co. (Vas, 2001, p.84) has said in an interview that resistance sometimes is not against change; it means a shortage of personnel, unready process and unsuccessful data processing on time that is what people criticize, not in itself. In other words, resistance reveals defects behind of an organization, and assists to find out better resolvents. As a result, more and more major organizational changes or innovations start to anticipate resistance, especially if proposed changes alter values and visions related to the existing order (Trader-leigh, 2002, p.139). All in all, facing resistance, we cannot deny and reject it blindly, but listen, learn, understand and lead it.

\section{How to overcome the resistance}

King and Anderson cited Kotter and Schlesinger (1979) that there are six strategies overcoming the resistance: communication, participation, facilitation, negotiation, manipulation and coercion.

\subsection{Facilitation}

Many organizations still believe that their success depends largely on the commitment of their employees (Emshoff, 1994). Appelbaum and Wohl cited Dowd (1998) that managers must provide support during the change process. Making oneself available, providing adequate information, being positive, actively listening, and showing personal interest and respect are strategies that mangers can use to help minimize the frustration of those coping with change. The manager should try to preserve the dignity of those negatively affected by change and help staff to find an outlet for their anger and frustration. The manager must also recognize that employees may suffer a sense of loss during a change process and that change may be painful. A supportive approach by the manager can minimize these elements that may increase resistance to the change. For example, in downsizing organizations, for the laid-off worker, organizations can provide help in outplacement services, redeployment. Meanwhile, the surviving employees will act as they see appropriate according to how the organization treated its laid off workers. When they perceived that layoff victims had been properly taken care of, they reacted positively, then performing as well as they had and feeling as loyal as the organizations as before (Appelbaum, Everard and Hung, 1999)

\subsection{Participation}

Employees should be involved in decision-making and new program development. It is one of the best methods of handling resistance, simply because that employee involvement in the stage of a change process significantly influences the eventual outcome. Change has a significant impact on the work that people do, will have a significant impact on their self-esteem (Carnall, 1990, pp.138-141). People will feel better about a decision in which they played a part, because they experience a sense of ownership that are likely to creatively change aspects of their organizations to solve problem and to exert extra effort to develop their products or services (Dirks, Cummings \& Pierce, 1996). Thus their self-esteem will be enhanced to a certain height, and they won't show resistance to change any more, even they will feel angry to others who disagrees the change process they participate in. 
Murer (2002) suggested that adapting to change in the organization is not a solo effort. It is a team sport that requires the involvement of many people. Although it is very popular that manager or boss must lead change, many change programs fails because of employees' resistance as mentioned before. Representatives from different departments in an organization should be brought together to discusses and make suggestions for improvement. At the same time, boss or manager should listen carefully to the responses, and then get interested employees involved in designing the program (Smith 1993). As a result, negative attitudes of employees to the new program will be eliminated, especially when some of their suggestions or advices have been adopted, because they feel a sense of worth, which is a basic human need (Pihulyk, 2002).

\subsection{Communication}

Communication is the key to the survivors' understanding the new corporate strategy and their accurate interpretation of the organization's goals and objectives. The more information is made available, the better cope with the new situation. Further open communication will also be effective in reducing employee resentment and resistance. Communicating what is known and asking for employees to do the best with what information is available will help minimize conflict and promote change. An effective and comprehensive communications plan, with feedback loops for employees to air their concerns, must be in place from day one (Attaran, 2000).

Managers should let staff know bad news rather than manipulate it into good news. Effectively communicating the change process aids in maintaining positive staff morale during the change (Sherer, 1997). People are trying to find out facts during transitions. If communication is frequent, open, and honest, even fuzzy answers are appreciated. When change is imminent, people want to know the specifics of any change ----- why, who, what, when and how---till they believe that useful change is possible, or they will not make the sacrifices required of the change process (Axley, 2000, pp.21). The question he suggested as followed.

Why?

Why is the change needed?

Why is the change needed in this way, at this time and place?

What?

What is the change and what preparation is needed for it?

What processes, structure, goal, and standards will be affected by the change?

What will successful change look like?

What does the change mean to those affected by it?

Who?

Who will be affected by the change?

Who should have input to the changes processes?

How?

How will the change proceed and affect the organization?

How can we help facilitate the change?

How will we know if the change has been successful?

When?

When will key changes take place?

When should messages about the change be communicated?

The above questions about $4 \mathrm{Ws}+1 \mathrm{H}$, which are just a part of questions should be asked before a change will be launched. And these questions raised here can help serve as useful guides in creating the communication, which is the first important step in any endeavour. In the two-way communication both management and employees can voice their opinions, concerns, desires and provide information.

\subsection{Negotiation}

Negotiations with individuals involved and the forces imposing the change can minimize resistance to change. When this is a possible, individual involved in the change will feel they have some control and be more likely to view the change as palatable. Providing as many avenues as possible for staff to provide input, help make decisions, and have some control over matters that affect them facilitates change. Furthermore, spreading the change out over time can also reduce the trauma of change. Time can allow the individual to move through a grief process slowly 
and experience it less intensely (Dowd, 1998)

\section{Conclusion}

In recent society, change is considered as inevitability for many organizations. Resistance to change is an essential factor to be considered in any change process, since a proper management of resistance is the key for change success or failure. Resistance is a natural and normal response to change because change often involves going from the known to the unknown (Coghlan, 1993). Resistance is a powerful organizational force. Although it is impossible to eliminate the resistance, it still needs to set up a better way to manage the resistance and try to minimize it. Use the knowledge to confront it. To begin with, educating employees can make them understand their roles and functions in making change happen. In addition, when the managers will do more clear and honest communication throughout the organization, which can be in reducing anxiety and harnessing assistance at all levels. What is more, foster and create employees to test the new change and give some recommendations with the new way of operating. Motivating and retaining employees' opportunities to participate in decision is an important aspect. Further more; managers are not only responsibility to the company, but also to the employees. It is better for them to negotiate with the employees and try to make agreement. Finally, using some manipulation and coercion strategies can identify and overcome potential sources of resistance as well and make the organization survive and thrive.

\section{References}

ANonymous. (2002). Resistance to change: Enemy or ally? Strategic Direction. Vol.18, No.6, pp.22-23.

Appelbaum, S.H. and Wohl, L. (2000). Transformation or change: some prescriptions for health care organizations. Managing Service Quality., Vol.10, No.5, pp. 279-98.

Appelbaum, S.H., Everard, A. and Hung, L.T.S. Strategic downsizing: critical success factors. Management Decision. Vol.37, No.7, pp. 535-552.

Attaran, M. (2000). Why does reengineering fail? A practical guide for successful implementation. The Journal of Management Development, Vol.19, Iss.9/10, pp. 794.

Axley, S.R. (2000). Communicating change: Questions to consider. Industrial Management. Vol.42, No.4, pp.20-21.

Bennett, J.L. (2001). Change Happens. HR Magazine. Vol.46, No.9, p.152.

Bovey, W.H., and Hede, A. (2001). Resistance to organisational change: the role of defence mechanisms. Journal of Managerial Psychology. Vol.16, No.7, pp. 534-548.

Carnall, C.A. (1990). Managing Change in Organization, Prentice Hall, London, UK.

Casciom W.F. (1993). Downsizing: what do we kNow? What have we learned? Academy of Management Executive. Vol.7, No.1, pp.95-104.

Coghlan, D. (1993). A person-centred approach to dealing with resistance to change. Leadership \& Organization Development Journal, Vol.14, No.4, pp. 10-14

Davidson, J. (2002). Overcoming resistance to change. PM. Public Management, Vol.84, No.11, p.21.

Del Val, M. P. and Fuentes, M. (2003). Resistance to change: a literature review and empirical study. Management Decision. Vol.41, No.2, pp. 148-155.

Dirks, K.T., Cummings, L.L. \& Pierce, J.L. (1996). Psychological ownership in organizations: Conditions under which individuals promote and resist change. Research in Organizational Change and Development, Vol.9, p.8.

Dowd, S.B. (1998). Helping staff cope with change. Hospital Material Management Quarterly, Vol.20, No.1, pp. 23-8.

Emshoff, J. R., (1994). How to increase employee loyalty while you downsize. Business Horizon, Vol.37, No.2, pp. 49-57.

Ford, J. D., Ford, L.W. and McNamara, R.T. (2002). Resistance and the background conversations of change. Journal of Organizational Change Management. Vol.15, No.2, pp. 105-121.

Freda, G.G., Arn, J.V. \& Gatlin-Watts, R.W. (1999). Adapting to the speed of change. Industrial Management, Vol.41, No.6, pp.32-33.

Geisler, D. (2001). Bottom-feeders: People who reject change. Executive Excellence. Vol.18, Iss.12, p.19.

Heifetz, R.A. \& Linsky, M. (2002). A survival guide for leader. Harvard Business Review, Vol.80, No.7, p.69.

Jager, P.D. (2001). Resistance to change: A new view of an old problem. The Futurist. Vol.35, No.3, p.24.

Jick, T.D. and Peiperl, M.A. (2003). Managing Change: case and concepts, $2^{\text {nd }}$ edn, McGraw Hill/Irwin, New York, 88 
pp. xxi

King, N., and Anderson, N. (1995). Chapter 8. Resistance to change. InNovation and Change in Organizations, pp. 156

Maurer, R. (1997). Transforming resistance. HR Focus, Vol.74, No10, pp. 9-10.

Maurer, R. (1998). Is it resistance, or isn't it?. Management. Vol.50, No.1, pp. 28-9

Maurer, R. (2002). When people are ready to act. The Journal for Quality and Participation, Vol.25, No.3, p.24.

Morris, T. J. and Pinnington, A. H. (1998). Promotion to partner in professional firms. Human Relations, Vol.51, No.1, pp.3-24

O'ConNor, C.A. (1993). Resistance: The repercussions of change. Leadership \& Organization Development Journal. Vol.14, No.6, p.30.

Pihulyk, A. (2002). Understanding needed to overcome resistance to change. Canadian HR Reporter, Vol.15, iss.9, p.4.

Pinnington, A. and Lafferty, G. (2003). Chapter 9. Managing People. Human Resource Management in Australia, Oxford New York

Sherer, J. (1997). The human side of change. Healthcare Executive, Vol.12, No.4, pp. 8-14

Smith, P.G. (1993). Why change is hard. Across the Board. Vol.30, No.1, p.55.

Tapsell, S. (1998). The challenge of change and fear of the unkNown. Management, Vol.45, No.7, pp. 60.

Trader-leigh, K.E. (2002). Case study, Identifying resistance in managing change. Journal of Organization Change Management, Vol.15, Iss.2, p.139.

Vakola, M. (2000). Exploring the relationship between the use of evaluation in business process re-engineering and organisational learning and inNovation. The Journal of Management Development, Vol.19, iss.9/10, pp812

Vas, A. (2001). Top Management Skills in a Context of Endemic Organizational Change: The Case of Belgacom. Journal of General Management. Vol.27, No.1, p.84.

Weiss, W.H. (1998). Change: how to bring it about and meet its challenge. Supervision, Vol.59, No.8, pp. 9-10

Whittington, R., McNulty, T,.and Whipp, R. (1994). Market-driven change in professional service: problems and processes. Journal of Management Studies, Vol.31, No.6, November, pp.829-45

Zeffane, R. (1996). Dynamics of strategic change: critical issues in fostering positive organizational change. Leadership \& Organization Development Journal, Vol.17, No.7. 


\title{
Body Language in Business Negotiation
}

\author{
Hui Zhou \& Tingqin Zhang \\ Daqing Petroleum Institute at Qinhuangdao, Qinhuangdao 066004, China
}

\begin{abstract}
Human beings communicate through a variety of channels. Language is not the sole means by which humans exchange information. In conversation, we express our ideas and feelings not only with words but also through facial expressions, voice tones, and gestures. These non-verbal languages are called "Body Language". It is just like our verbal language, is also a part of our culture.

In business negotiations, body language plays a significant role in the communication. It is necessary to master the skills of using and reading body language. This article mainly discusses the art of body language in negotiation. It states its functions and importance in business negotiations, then explores how to use and understand body language in negotiations. Different people have different ways of making nonverbal communication. A comparative study of Chinese and American body language shows a number of similarities and diversities of body language. It shows the importance of knowing the specific signals that go together with a language. It finally emphasizes the necessity and importance of learning body language in non-verbal communication and business negotiations.
\end{abstract}

Keywords: Body language, Negotiation, Different culture, Different ways

\section{Introduction}

Some studies show that up to 90 percent of communication is nonverbal. Though you might say one thing, your body movements may indicate something entirely different. All types of language that take place without words are defined as nonverbal language. Language that doesn't use words takes place all the time. When we converse with others we communicate by much more than words. By our expressions, gestures and other body movements we send messages to these around us a smile and an outstretched hand show welcome. A frown is a sign of displeasure. Nodding one's head means agreement- "Yes". Waving an outstretched hand with open palm is the gesture for "Goodbye". Leaning back in one's seat and yawning at a talk or lecture shows lack of interest, boredom.

Many people may think that to have a successful negotiation, the negotiators must master the language skills of negotiation and bargaining, to some extent, they are right. But that is far more enough. In fact, many negotiators are not aware that they communicate nonverbally. Most nonverbal messages are involuntarily. Verbal language really play important role in negotiations, but it is not the only means by which negotiators exchange information. In negotiation, for example, negotiators express their ideas and feelings not only with words, but also through facial expressions, voice tones and gestures. Even clothing and grooming may send message of one kind or another to others. Some experts say only 30 percent of communication comes from talking. Your gestures and other nonverbal actions matter too. An old saying goes: "actions speak louder than words." That's true according to communication experts.

\section{The definition of body language and the necessity and importance of learning body language in negotiation}

We all instinctively give gestures and facial expressions which reveal our inner thoughts. It's hardwired into our brains and stretches back to our earliest days in the cave when facial expressions and gestures were all we had to communicate with. Like music tracks on a CD these communication tools have been burned into our brains. Our body language becomes part of our conversation. It sends signals to another person about us. Present ourselves with confidence and authority and practice good posture. Stand with our back straight, shoulders back, and our chin up. Our voice does not sound clear when our chin is dropped toward our chest. Keep our arms relaxed at our side and avoid clasping our hands behind our back or hugging our arms in front. Portray calmness. Avoid nervous gestures such as tapping our foot or jingling coins in our pocket or playing with a pen. Keep our hands off our face and never pick at our nose. The way we walk and the way we talk all tell something about our social status. These gestures have come to be accepted in general as having the meanings mentioned, at least to Chinese and Americans.

\subsection{The definition of body language}

As we mentioned earlier, it is impossible for us to stop communicating non-verbally. We all lean, point and look away. We move our hands to emphasize in our talk. We frown, smile, fold our arms, and move toward objects or people, then move away. How we stand, walk, eat, and gesture reveals much about our personality. It is called "body language". It is an important media through which people communicate with each other. It refers to the patterns of facial expressions and gestures that people use to express their feelings in communication. 
"Body language" also defined as the nonverbal communication or the communicative functions of body, it is also called kinesics. It is part of the way in which we communicate. This "body language", like our verbal language, is also a part of our culture.

\subsection{The necessity and importance of learning body language in negotiation}

It is an extremely powerful tool which can improve our life in many ways. With patience, persistence, and practice we can use nonverbal behavioral patterns to more easily detect truth and lies, project a more confident, powerful presence, persuade, influence, and sell better, put people at ease, create a sense of trust, make friends. It is especially important in business negotiations. If you are only aware of a negotiator's verbal message, you will likely miss the major portion of the overall communication. Being aware of both nonverbal and verbal messages will give you an important edge.

Communication is more than verbal. Good negotiators must first be good communicators. Unfortunately, many negotiators think of communication only as oral or written verbal exchanges. But verbal exchanges account for only a fraction of the messages people send and receive. Research has shown that between 70 and 90 percent of the entire communication spectrum is nonverbal. Consequently, you should be aware of the different forms of nonverbal communication that you are likely to encounter during negotiation conferences.

\section{The concrete types and application of the body language in negotiation}

\subsection{Types of body language}

Body language or kinesics can be understood by recognizing the following six important aspects.

\subsubsection{Distance between people conversing}

Watch an Arab and an Englishman in negotiation. The Arab, showing friendliness in the manner of his people, will stand close to the Englishman. The latter will move back, watching to the Englishman. The Arab will then move forward to be closer; the Englishman will keep moving backward. By the end of the negotiation, the two may be quite a distance from the negotiation; the two may be quite a distance from the place where they were originally standing!

Here, distance between the two is the key factor. Different people have different ideas about the proper distance between people conversing. According to studies, it seems there are four main distances in American social and business relations: intimate, personal, social, and public. Intimate distance ranges from direct physical contact to a distance of about 45 centimeters; this is for people's most private relations and activities, between man and wife, for example. Personal distance is about 45-80 centimeters and is most common when friends, acquaintances and relatives converse. Social distance may be anywhere from about 1.30 meters to 3 meters; people who work together, or people doing business, as well as most of those in conversation at social gatherings tend to keep a distance is farther than any of the above and is generally for speakers in public and for teachers in classrooms.

The important thing to keep in mind is that most English-speaking people do not like people to be too close. In negotiations being too far apart, of course, may be awkward, but being too close makes people uncomfortable, unless there is a reason, such as showing affection or encouraging intimacy. But that is another matter.

\subsubsection{Physical appearance and physical contact}

Physical appearance conveys messages. It plays a very important role in creating first impression. You need be aware of the effect that your physical appearance may have on nonverbal communication. Awareness may permit you to build on your natural advantages. However, awareness of any natural disadvantage may be even more important.

Research has found that:

Physical attractiveness affects the way you perceive yourself and the way other perceive you.

Personal Dress: The importance of how we dress is highlighted by the cliché, "Dress for success." Clothing has been found to affect perceptions of credibility, likeability, attractiveness, and dominance, but researchers agree that clothing has the most potent affect on credibility.

Unfortunately, many otherwise good negotiators ignore the importance of personal dress during negotiations, and that ignorance negatively affects their ability to attain mutually satisfactory negotiation results.

In English-speaking countries, physical contact is generally avoided in conversation among ordinary friends or acquaintances. Merely touching someone may cause an unpleasant reaction. If one touches another person accidentally, he/she usually utters an apology such as "Sorry, Oh, I'm sorry, Excuse me."

In China, a common complaint of western mothers is that Chinese often fondle their babies and very small children. 
Such behavior-whether touching, patting, hugging or kissing—can be quite embarrassing and awkward for the mothers. They know that no harm is meant, and that such gestures are merely signs of friendliness or affection, therefore they cannot openly show their displeasure. On the other hand, such actions in their own culture would be considered rude, intrusive and offensive and could arouse a strong dislike and even repugnance. So the mothers often stand by and watch in awkward silence, with mixed emotions, even when the fondling is by Chinese friends or acquaintances.

The matter of physical contact between members of the same sex in English-speaking countries is a delicate one. Once past childhood, the holding of hands, or walking with an arm around another's shoulder is not considered proper. The implication is homosexuality, and homosexuality generally arouses strong social disapproval in these countries.

\subsubsection{Eye contact}

Eye contact is an important aspect of body language. One could draw up quite a list of "rules" about eye contact: to look or not to look; when to look and how long to look; who and who not to look at.

There are different formulas for the exchange of glances depending on where the meeting takes place. If you pass someone in the street you may eye the oncoming person till you are about eight feet apart, then you must look away as you pass. Before the eight-foot distance is reached, each will signal in which direction he will pass. This is done with a brief look in that direction. Each will veer slightly, and the passing is done smoothly."

In conversations with people who know each other, however, American custom demands that there should be eye contact. This applies to both the speaker and the listener. For either one not to look at the other person could imply a number of things, among which are fear, contempt, uneasiness, guilt, indifference, even in public speaking there should be plenty of eye contact. For a speaker to "burry his nose in his manuscript", to read a speech instead of looking at and talking to hid audience, as some Chinese speakers are in the habit of doing, would be regarded as inconsiderate and disrespectful.

In conversation, a person shows that he is listening by looking at the other person's eyes or face. If the other person is speaking at some length, the listener will occasionally make sounds like "Hmm", "Ummm", or nod his head to indicate his attention. If he agrees with the speaker, he may nod or smile. If he disagrees or has some reservations, he may slant his head to one side, raise an eyebrow, and have a quizzical look.

Staring at people or holding a glance too long is considered improper in English-speaking countries. Even when the look may be one of appreciation—as of beauty_it may make people uneasy and embarrassed. Many Americans traveling abroad find the stares of the local people irritating. They become extremely self-conscious and often end up quite indignant about the "rudeness" of the people there, not realizing that the practice may be quite common in the country and may be nothing more than curiosity. Many English-speaking people in china have heard to complain about this.

The difference in interpreting a simple eye gesture was a lesson in cultural diversity that we would not easily forget. For example, Chinese avoid long direct eye contact to show politeness, or respect, or obedience, while North Americans see eye contact as a sign of honesty and a lack of eye contact or shift eyes as a sign of untruthfulness. Though speaking the same language, the British, unlike the Americans, believe that looking someone directly on the eye to be a mark of rudeness until a more familiar relationship is established. An American businesswoman told a story that they (Americans) felt as if the British were hiding something because none of them would look them in the eye throughout the presentation. The failure of the British to look her in the eye almost "ruined the relationship and suck the deal," she said. "I understand it now, but I still don't like it".

The amount of eye contact varies greatly among cultures. For example, in business meetings, the French will demand at least some direct eye contact. To refuse to meet someone's eyes an unfriendly gesture. Compare this to the attitude of Japanese, who believe that the less eye contact, the higher the level of esteem. To divert eyes from a business colleague is a sign of respect and reverence.

Rules about eye-language are numerous and complex. What has been mentioned gives a good idea of this; we shall not go further into detail.

\subsubsection{Facial expression}

As the most expressive part of the body, the face is probably the single most important source of non-verbal communication. It is capable of conveying several emotions simultaneously. The face not only can communicate a great deal, but also seemed to be the type of non-verbal behavior that people are beat able to control. However, facial expressions should be interpreted in cultural context and with caution. Take for example smiles and laughter. 
Smiles and laughter usually convey friendliness, approval, satisfaction, pleasure, joy and merriment. This is generally true in China as well as the English-speaking countries. However, there are situations when some Chinese will laugh that will cause negative reactions by westerners.

Other facial expressions also vary from culture to culture. For instance in some US businesses, it is considered acceptable to frown, swear, and yell, but not to cry. But for the Japanese in situations of strong emotion it is considered acceptable to smile or laugh, but not to frown or cry.

\subsubsection{Gestures}

Gesture is the expressive movement of a part of the body, especially the hand and the head. People talk with their hands, but what they mean depends on their culture. As with verbal language, non-verbal codes are not universal. Same gestures have different meanings in different cultures.

The forefinger near lips with the sound "shah", which is a sign for silence in UK and America, means disapproval, hissing in China.

In different cultures different gestures are used for the same meaning. For coming here, Chinese gesture is a hand extended toward the person, open palm, fingers crooked in a beckoning motion; the American is a hand extended toward person, close hand, palm up, with forefinger only moving back and forth. For Americans, the Chinese coming-here gesture is like good-bye gesture. Many Chinese would see American coming-here gesture as offensive.

The same is true with some commonly used gestures. The OK sign (the circle formed with the thumb and first finger), which has the similar meaning in most of Western Europe, is a vulgar insult in Greece, an obscene gesture in Brazil, Mediterranean countries and Southern Italy, a sign for the sex act in some Latin American nations and can mean "you're worth nothing" in France and Belgium .

Like hand movements, head movements differ from one culture to another. In Bulgaria, for example, people may nod their heads to signify no and shake their heads to signify yes. So gestures can be very confusing inter-culturally. But there are some gestures that have widely understood meanings. For example, foot-shaking, finger-tapping and fidgeting with a tie or hair usually signify nervousness or boredom; a clench fist typically indicates hostility or aggression.

Specialists in the study of body movement emphasize that no single gesture carries meaning in and of itself. The gestures just discussed do not always mean the same thing. To understand a person's meaning, pay attention to all the cues they are sending and the context in which the cues occur, not to just a single gesture.

When one communicate in a certain language, it is generally advisable to use the non-verbal behavior that goes with that particular language.

\subsubsection{Posture}

The way people carry themselves communicates volumes. People from different cultures learn to sit, to walk and to stand differently. The impact of culture on non-verbal communication is so strong that even people with great experience in cross-culture communication might be unaware of how meaning of a non-verbal act varies from culture to culture. The wife of a former president of the United States was said to have shocked her Arab hosts by crossing her legs during a public meeting, which is an indecent posture in Arab culture.

Posture offers insight into a culture's deep structure. For instance, in the United States where being casual and friendly is valued; people often fall into chairs and slouch when they stand. In many European countries, such as Germany, where lifestyle tends to be more formal, a slouching posture is considered a sign of rudeness and poor manners. Similarly, in Japan, the formality is important and the Japanese value the ability to sit quietly. They might see the Americans fidget and shift as an indication of lack of mental or spiritual balance.

But there are similarities. For instance, even in North America, swinging a foot in interview makes negative impression. Also, people respond unfavorably to standing with weight back on heels and hands in pockets at work place or sitting with feet up on the desk in office. And slouching or leaning on the lectern in business presentation may make the audience feel that the speaker's ideas area as careless as his or her posture,

Generally, standing erect, shoulders back, head held high display confidence, energy, and self-assurance, which gains more attention from the audience. And a relaxed posture, a comfortable seating position, uncrossed arms, and lack of stiffness indicate openness with no communication obstacles. On the other hand, abrupt movements, shifting seating positions, crossed arms or legs may signal defiance, disinterest or an unwillingness to listen.

Women in many settings will often hold their arms closer to their bodies than men. They will also keep their legs close together and seldom cross them in mixed company. 


\subsection{Application of the body language in negotiation}

Good negotiators know how to use body language to their advantage. They also know how to read other people's body language to gain the upper hand. Crossed arms, raised eyebrows, wandering eyes - they all mean something. Pay attention and you'll be surprised what you might learn about what is really going on in the negotiation regardless of what is being said with words.

\subsubsection{Body language affects negotiation}

Body Language and Attitudes: Body language research has catalogued 135 distinct gestures and expressions of the face, head, and body. Eighty of these expressions were face and head gestures, including nine different ways of smiling. These gestures and expressions provide insight into the attitude of the originator. Simultaneous physical signals often reinforce each other and reduce the ambiguity surrounding the message. For example, eagerness is often exhibited with the simultaneous physical displays of excessive smiling along with frequent nodding of the head.

Common attitudes communicated nonverbally during negotiations can be grouped into two broad classifications—-positive attitudes and negative attitudes.

Positive Attitudes: Positive attitudes indicated by body language may signal a sincere effort to achieve win/win results. Key indicators of positive attitudes are listed below.

Gestures: Be particularly careful when you are interpreting or using gestures. A gesture that means one thing in one society can mean something completely different in another. There is a good chance that you will encounter differing interpretations whenever you are negotiating with someone from another part of the world. Even if the other party is from the United States, some of these differing interpretations may remain as part of the person's heritage.

(1) Shaking your head up-and-down means "yes" in the United States and left-to-right means "no". In some parts of the world the meanings are just the opposite.

(2) The hand signal for O.K. in the United States is an obscene gesture in some societies.

(3) The thumbs-up gesture is a positive sign in most of the world, but in some cultures it considered a rude gesture.

(4) The V-shaped hand gesture with the index finger and middle finger may mean victory or peace in the United States, but in some countries it could be interpreted as an obscene gesture.

\section{How to use and understand body language in negotiation}

\subsection{How to use body language in negotiation}

Using nonverbal communication can manage yourself and others. In negotiations, once you become aware of your counterpart's body language, you can change your own nonverbal communication. By putting your notepad on the table, sliding forward in your seat, and uncrossing your legs, you can change your position to a much more receptive one. Once you begin to manage your nonverbal behavior and that of your counterpart, you will start reaping the benefits of "speaking the language." Body language reflects people's true feelings. The better you understand that language, the more you will be able to use it to your advantage.

In contract negotiation, you can use the knowledge of body language in several ways:

As you prepare for the negotiation conference, you should briefly review key elements of body language with members of the Government team.

The most important observation you can make about a room full of people is the personal space each person commands. Human nature dictates that people considered more powerful are typically awarded greater personal space by the other people in the room.

Control over the dominant chair (usually the head of the table) may be the most obvious sign of power. Remember Archie Bunker? He didn't control a clear position of power at work, so his chair became a symbol of his status at home.

Once the spatial relationships are established, they are not easy to change. Take a moment before your next meeting and think about what relationship you want to establish with the other attendees. Arrange the seating accordingly.

Making first contact

Begin every meeting with great body language. Let your enthusiasm and energy show. Meet the other person's eyes and give a good, firm handshake. Let the flesh between your thumb and forefinger meet the other person's flesh between the thumb and forefinger. Press—do not squeeze - the hand. One pump accompanied by eye contact is 
plenty. One or two more may express great enthusiasm; any more than that can make the person uncomfortable.

Women greeting women in America can touch both hands at the same time as an alternative to a handshake.

Handshaking is far from uniform around the world. Germans are a nation of one-pump people. The French often shake one hand while putting the other on the opposing shoulder. The Japanese may forego the handshake for a bow.

\section{Gauging reception}

If you pay attention to body language early in a negotiation, you can spot signals of how receptive (how ready to listen and how open to your ideas) your counterpart is. Table 1 shows the positive and negative cues associated with being receptive and unreceptive.

Legs and feet Sitting: Legs together, or on in front of the other slightly (as if at the starting line of a race). Standing: Weight evenly distributed, body tilted toward the speaker. Standing: Crossed legs, pointing away from the speaker. Sitting or standing: Legs and feet pointing toward.

Receptive people look relaxed with open hands, displaying the palms, indicating openness to discussion. They lean forward, whether they are sitting or standing. Receptive negotiators unbutton their coats. By contrast, people who aren't willing to listen may lean back in the chair or protectively fold their arms across their chest. Having one leg up on the arm of the chair appears to be an open posture, but more often, this position signals a lack of consideration.

\section{Seeing a change of heart}

Observing how someone is sitting or standing is the first step in reading body language-but people aren't frozen like statues. Their positions and gestures change with their attitudes and emotions. Notice these shifts.

Looking out the window, holding the head up with one hand, doodling in a way that seems to absorb the doodler's complete attention, drumming fingers on the table all indicate that the listener is no longer paying attention.

One more thing to keep in mind: Body language works both ways. If your opponent is an experienced negotiator, chances are good that he or she will be observing your posture, gestures, breathing patterns, etc. Be aware of this and try to use it to your advantage. By using your body to transmit the appropriate message to your negotiating opponent, you can enhance the chances of securing the right deal and, just as importantly, keeping the negotiation amicable.

\subsection{How to understand body language in negotiation}

Learning the language of nonverbal communications is almost as difficult as acquiring fluency in a foreign language. Reading body language is perhaps the most powerful form of human communication! And armed with the right information about reading body language, you can almost read people's minds. In addition to studying your own gestures and the meaning you are conveying, you must also become aware of what your counterpart is conveying.

\subsubsection{Gesture Clusters}

Many skeptics argue that it is difficult to tell what someone is thinking by singling out one gesture-and they are right. A single gesture is like a single word; its true meaning is difficult to understand out of context. However, when gestures come in clusters, their meaning becomes clearer. For example, while a person's fidgeting may not mean much by itself, if that person is avoiding eye contact, holding his hands around his mouth, touching his face and fidgeting, there's a good chance he is not being totally honest.

Involuntary hand movements can be particularly telling. People often touch their nose, chin, ear, arm or clothing when they are nervous or lack confidence in what they are saying.

Legs: When asked why they cross their legs, most people say they do so for comfort. Although they are being truthful, they are only partially correct. If you have ever crossed your legs for a long period of time, you know that this position can become painfully uncomfortable.

Studying what you and your counterpart in the negotiation process are not saying is critical to achieving a win/win outcome. The following chart is a "dictionary" that will help you translate your counterpart's body language, and use your own to say what you really mean to say.

\section{Conclusion}

The study of body language should be complementary to the study of language in communications. The understanding of one should be helpful in the further understanding of the other. Some authorities feel that the two are dependent on each other. This is certainly true in most situations. But it is also true that in certain situations body action contradicts what is being said, just as the spoken words may mean something quite different from what body 
language communicates. When this occurs, one must try to get further information, or guess the meaning from the context of the situation. In a sense, all body language should be interpreted within a given context; to ignore the overall situation could be misleading.

A word of general advice: when one negotiate in a certain language, it is generally advisable to use the nonverbal behavior that goes with that particular language. Observation shows that a truly bilingual person switches his body language at the same time he switches languages. This makes negotiation easier and better.

A powerful piece of body language which you can have control over is the closeness between you and the buyer. To conclude a negotiation there needs to be a feeling of connection. If the buyer is well away from his desk or leaning back, place some brochures on the table but sufficiently far away that he has to come closer to you. You should then mirror his action and move closer as well. The end result is that you will be in a better position to strike a deal.

Trying to spot the body language, listen to what is being said and deciding what your next action takes practice and patience.

\section{References}

Fast Julius. (1971). Body Language. Pocket Books. N.Y.: Random House Value Publishing, Inc.

Jamesw .H ALL . (1994). Body Language. Chicago: The University of Chicago Press.

J o Toole. (1992). The Process of Drano: Negotiation Art and Meaning. London: Folcroft Library Editions.

Liu, Yongfa \& Liu, Xuan'en. (1997). The Practical Body Language. BeiJing: Hua Wen Press.

RE Axtell. (1991). The Do's and Taboo's of Body Language. Boston: James Munroe.

Robinett, Betty W. (1978). Teaching English to speakers of other Language: Substance and Technique. N.Y.: McGraw-hill.

Samovar L. A. (1981). Understanding Intercultural Communication. London: Wadsworth Publishing Company.

Shen Minxian. (1999). The Use of the Body Language in Elementary School. Shanghai: Shanghai Education Vol.

Stern H. H. (1983). Fundamental Concepts of Language Teaching. London: Oxford University press.

T Morrison, WA Conaway \& GA Borden. (1994). How to Do Business in Sixty Countries. Oxford: Oxford University Press. 


\title{
The Characteristics of ISBN and Its
}

\section{Functions in Book Purchasing and Compiling}

\author{
Chunlan Qiu \&Yonglin Xiao \\ Library of Jiangxi University of Science and Technology, Gangzhou, Jiangxi 341000, China \\ E-mail: jxust@126.com
}

\begin{abstract}
This paper analyzes the structure and the characteristics of ISBN and the functions of ISBN in book purchasing and compiling of libraries.
\end{abstract}

Keywords: ISBN, Book purchasing and compiling, Functions

With the application of computer technology in the administration of libraries, various internet applications on book administration are widely applied, so book purchasing and compiling has gained strong technology support. In book purchasing and compiling, to fully acknowledge and master the characteristics of ISBN and to apply the characteristics of ISBN in it will bring along great convenience for the job. ISBN is the abbreviation of International Standard of Book Number and is the unique number the International ISBN Agency assigns to the literatures of a publishing company. China joined in LSBN system in 1982 and started to execute CSBN in 1987. CSBN is the abbreviation of China Standard of Book Number. CSBN makes supplementary on the basis of ISBN and consists of two parts. One of the two is LSBN, the main body of cabin, which can be used independently; the other is the supplementary part, consisting of the basis classifications and type serial numbers of China Library Classification Method. " $\square /$ " is used to separate the main body from the supplementary part and "." is used to separated book classification number from type serial number. The form is group number-publisher number-book number-verification number/book classification number type serial number, for example, the CSBN of The Modernization Road of Chinese Finance is 7-100-04478-2IF-500, of which "7-100-04478-2" is LSBN, the main body, and the part after " $/$, " $F \cdot 500 "$, is the supplementary part. "F" here means that the book belongs to economic class in China Library Classification Method and " 550 " means that the book is the $550^{\text {th }}$ book classified as " $F$ " that the publishing company has ever published.

\section{The structure of ISBN}

ISBN consists of ten digits with ISBN as the title, of which 9 are effectively assigned digits and the $10^{\text {th }}$ is the verification number. The ten digits form four groups of numbers, respectively group number, publishing number, book name number and verification number, separated by “-”, namely, group number-publishing number-book name number-verification number. For example, in "ISBN 7-5366-7065-6", the group number, publishing number, book name number and verification number are respectively "7", "5366", "7065" and "6". These numbers represent different meanings. The first group of number is the group number and can also be called region number, which represents the language number of a country or a region. A group number can at most consist of 15 digits. The more digits a group number consists of, the less the publishing amount is; the less digits a group number consists of, the larger the publishing amount is. The group number is assigned by International Standard Book Number Center, with the shortest consisting of 1 digit and the longest consisting 5 digits. As a general rule, group number takes into account language types, countries and regions. 0 and 1 represents English and Australia, Canada, Ireland, New Zeeland, Porto Rico, South Africa, Britain, America and Zimbabwe use these two codes; 2 represents French and France, Luxemburg, Belgium and the French area of Switzerland use this code; 3 represents German and Germany, Austria and the Germany area of Switzerland use this code; 4 is the code representing Japanese publications; 5 Russian publications and 7 Chinese publications. The second group is the code for publishing companies, so it is also called publisher number. The publisher number represents the number of a publisher and can consist of one to seven digits. The larger the scale of a publishing company is and the more books it publishes, the fewer the number of the digits is. The publisher number is set and assigned by the ISBN center of a country or region. The third group is book serial number and is also called book name number. Book name number is a serial number representing a publication. The number of digits of book name number is determined by the sum of the numbers of digits in group number and publisher number. The book serial number of a publishing company is fixed, with the shortest being 1 digit and largest 6 digits. The larger the scale of a publishing company and the more books it publishes, the longer the book name number is. Book name number is determined by the publisher. The fourth group is the computer verification code and is also called the verification number. The verification number is the last digit in ISBN number, 
whose function is to verify whether the LSBN is legitimate. The verification of ISBN adopts weighted method, which means to multiply the first to the ninth number in ISBN number respectively by $10,9,8,7,6,5,4,3,2$, add the verification value to the sum of the products, and then divide the result by 11 to see if the result can be divided exactly. If the result can be divided exactly, the ISBN number is legitimate. If not, the ISBN number is illegitimate. Let us take ISBN 7-5366-7065-6 as an example, whose calculation formula is $7 * 10+5 * 9+3 * 8+6 * 7+6 * 6+7 * 5+0 * 4+6 * 3+5 * 2+6=286,286 \div 11=26$, where 286 can be divided by 11 exactly, so this book is a legitimate publication. The publications that adopt ISBN number include printings, micropublishing products, mixed media publications, computer soft wares, Braille publications, atlases, maps, discs, education TV or movies, and teaching films. ISBN number is usually printed on the striking place and sometimes ISBN number will appear at several places, for example, ISBN number can appear in the bottom part of the back cover, the copyright page of vip information http://www.cquvip.com, the overleaf of book name page, or the CIP data of the republication numbers of books.

\section{The characteristics of ISBN}

\subsection{World uniqueness}

Each ISBN number only represents books of certain editions. When the printing ways, edition, formats or frames of books of same types are different, the ISBN numbers will be different. For the world uniqueness of ISBN, it is very important for the purchasing, compiling and catalogue programs of library literatures. What is more, if using ISBN to search, the correctness and the speed of the search is far higher than searching through book names and writer names.

\subsection{Identification characteristic}

Through the four group of numbers of ISBN, we can get to know the real information of the books, such as the publishing regions, the scale of the publishers, the amount of the published books, and whether the publications being comprehensive or professional.

\subsection{Verification characteristics}

We can use the verification method of ISBN, weighted method, to determine whether the ISBN is legitimate. Weighted method means to multiply the first to the ninth number in ISBN number respectively by $10,9,8,7,6,5,4$, 3,2 , add the verification value to the sum of the products, and then divide the result by 11 to see if the result can be divided exactly. If the result can be divided exactly, the ISBN number is legitimate. If not, the ISBN number is illegitimate. Therefore, ISBN can itself verify its status and has the capacity of error correcting, so ISBN greatly improves reliability and correctness of the data of book purchasing and compiling.

\subsection{Standardization}

The structure of ISBN number is simple and the hiberarchy is clear, which provides great convenience for computer processing, searching, booking and purchasing, classification and compiling and is an important searching basis for readers to search books. It is more convenient and faster to use ISBN to search information about books.

\section{The functions of ISBN in book purchasing and compiling}

\subsection{The functions of ISBN in book purchasing}

There are generally three kinds of ways to purchase books, with the first one being searching and purchasing through ISBN bar code numbers, the second being through book names, and the third being through the date of book booking. Among the there purchasing ways, the first two are the important ways that libraries usually adopt, which is to search and purchase through the ISBN bad code numbers and the names of books. Years of book purchasing experience proves that the repetition of book names is very common. The main problems to use book names to search and purchase are that books of the same names but of different types are taken as repetition by computers and it is hard to correctly search and purchase. For example, Chinese writer, Mao Dun wrote a long novel named Rainbow, while British writer, Lawrence also wrote a long novel named Rainbow, so just depending on the book names, we cannot distinguish the two books. Therefore, the best way to purchase books is to adopt ISBN bar code numbers of books whose characteristic is world uniqueness to search and purchase. The correctness and speed of using ISBN to search is far higher than using book names because bar code readers can be used to scan and input ISBN number, which not only saves time, but also increases the input correctness. By this way, we can cut down the phenomenon of repeated and missed purchasing and improve the correctness of book purchasing.

\subsection{The functions of ISBN in book catalogue work}

Book catalogue work is the first pass in book administration work. To make the administration, circulation and use of books more convenient, the basic requirement on book catalogue work is to ensure catalogue quality. The 
requirement on book catalogue correctness is high too, or else, the borrowing, searching and circulating of books will be influenced. At present, computers take place of hand operation in book catalogue work. To fully make use of the characteristics of ISBN data will bring along great convenience for book catalogue work. To use ISBN to make catalogues of books refers to that in the process of book catalogue making, catalogue personnel can use bar code readers to directly scan and input ISBN bar code numbers and then to record data and search the repeated rather than to use keyboard to input ISBN bar code numbers, ISBN numbers, book names and writer names. To use bar code readers to directly record date and search the repeated will save operation time and improve the input correctness. The most obvious advantage to adopt ISBN number in book catalogue making is the uniqueness of ISBN. ISBN covers information on the publishing scale of books and the publishers, the present publishing amount of books, and whether the publisher being comprehensive or professional. In automitization systems, if we set up a data base where codes are matched with publishers, the names of the publishers will be automatically given and there is no need to input the names. In the information catalogues of machine reading CNMARC books, the necessary number in ISBN is "010". Because all automitization systems have set up ISBN data bases, catalogue personnel need only to input "010"into ISBN numbers when working on CNMARC data, and then the systems will automatically generate information, such as publishing places and publishing companies. Meanwhile, when conducting catalogues of discs annexed to the books, we can generate resource visiting links according to the recorded ISBN numbers and copy these links to chipboards, and then we can conveniently copy these links to " 856 " field when OPAC system arrives. Therefore, the " 856 " field in catalogue system will automatically generate the information about the discs, which will make the work of library catalogue personnel more convenient, cut down repeated labor, and improve work efficiency.

\section{References}

Chen, Lijuan. (1999). The arriving method of ISBN in machine reading catalogues. Knowledge of Library and Information Science, pp.57-59.

Li, Lu. (2004). The application of ISBN and ISSN in library operations. Journal of Library and Information Sciences in Agriculture, pp.219-220

Song, Jinyan, Cao, Yongmei \& Wu, Guiping. (2005). International standard book number will be enlarged to 13 digits. Library Theory and Practice, pp.93-94.

Zheng, Xisheng. (2002). A discussion on missed searching phenomenon in using ISBN to conduct check on repeated computer catalogues. Jiangsu Library Journal, pp.19-20. 


\title{
The Risky Value in the Capital Market of Incomplete Information
}

\author{
Xuhong Tan \& Mingjun Tan \\ Department of Economics\& Management, Heilongjiang Institution of Science and Technology \\ Harbin 150027, China
}

\begin{abstract}
Risk is everywhere, especially in the capital market of incomplete information, which is full of speculation, so it is particularly important for investors to define risk, identify risks, and control the investment activities with the application of risk value to. It is analyzed quantitatively on risk value in the paper, with the Knowledge of game theory, economics and mathematical statistics, on the basis of the explanation of risk and risk value.
\end{abstract}

Keywords: Risky value, Incomplete information, Risk Aversion, Investment Portfolio

\section{Introduction}

What is risk? Different scholars have different interpretations. Some people think that risk is a kind of uncertainty, including the uncertainty whether the incident may be determined or the Probability of the occurrence; while some people think that risk is a concern for future events, including some doubts on the outcome of the future and some doubts on the possibility of the objectively existed damage. Although these explanations are true in certain degree, it seems not be exact to express the real content of risk. We think that risk is kinds of uncertainties of various results in certain period and certain conditions. This definition includes two Connotations: (1) risk is the uncertainty of the event which is objective. Specifically, it means various results under uncertain conditions, and the possibility of the occurrence. Therefore, risk is objective, but whether people are willing to and how to take risks is subjective. Strictly speaking, uncertainty and risk exists some differences, risk refers the results and the probability of events, which is measurable; while uncertainty is immeasurable, which means it's impossible to predict the results and the probability of various outcomes. (2) the degree of the risk is change with the passage of time. That is, Specific risk exists in a certain period of time, during which, as time goes by, the uncertainty of events is diminishing, and when it's completed at the end; the results can be fully identified. Therefore, it is necessary to adjust the early predictive number in accordance with the progress in the process of risk prediction. In the angle of mathematical statistics, the mathematical models of risk can be expressed as:

$$
\sigma=\sqrt{\sum_{i=1}^{n}\left(x_{i}-\bar{x}\right)^{2} \cdot p_{i}} \quad \text { OR } \quad v=\frac{\sigma}{\bar{x}}
$$

Where, $\sigma$ denotes standard deviation; $x_{i}$ denotes earnings of investment; $\bar{x}$ denotes anticipated earnings; $p_{i}$ denotes the Probabilities of events; $v$ denotes the ratio of standard deviation.

On the basis of definition on the concept of risk, we are now to discuss risky value. The so-called risky value is the excessive earnings requested by investors, which is more than the present value of investment funds. Generally speaking, the greater the risk, the more he returns requested, vice versa, following is the model:

$$
k=k_{0}+k_{R}=k_{0}+b v
$$

Where, $k$ denotes the rate of return requested by the investors; $k_{0}$ denotes the rate of risk-free return; $k_{R}$ denotes the rate of risky return; $b$ denotes the coefficient of risky value; $v$ denotes the rate of standard deviation.

\section{Incomplete information and risky value}

The so-called incomplete information means that the market participant is not able to take full possession of the all knowledge or information in the certain economic environment, which is particularly obvious in the initial stage of the imperfect market. According to the principle of effective capital market, the present value of the investment to any financial instrument is zero, that is, it is impossible for any investor to increase shareholders' value by trading of financial assets in the capital markets, and it's impossible to obtain excess earnings for any speculation. However, in the view of new Keynesian, incomplete information is more economic reality than complete information. The presence of incomplete information will lead to malfunctioning of the market price mechanism. In the capital markets ,trading parties take investment transactions on the principles of returns maximization, but the imperfection of the market and incomplete information will lead the market failures, and more importantly, the dissemination of information is usually in large cost, as well, the limitations of market communications systems and the objective and 
subjective factors such as market participants release the market noise, will also seriously hamper the exchange of information and effective communication. As previously mentioned, the results is that the price information can not be timely passed to each market participant who needs the information, and trading activities and its results can not be promptly transmitted through the price system, Therefore, the market prices cannot reflect sensitively the supply and demand in the market, which, makes the price of certain financial assets far away from its intrinsic value, resulting in the formation of various speculative.

\section{The application of risky value}

In the capital market of incomplete information, it is an important subject on how to avert risk in risk investment and risk management. The so-called risk aversion refers how to minimize risk the in certain income or how to maximize the income at certain risk. The most commonly used measure is investment portfolio (it's also named scattered effect), the method takes an important role in decentralizing the non-systemic risk. Under the conditions of the investment portfolio, the risk models:

$$
\begin{aligned}
& \sigma=\sqrt{\sum_{i=1}^{m} \sum_{j=1}^{m} w_{i} w_{j} r_{i j} \sigma_{i} \sigma_{j} \quad(m \geq 2)} \\
& r_{i j}=\frac{\sum\left[\left(x_{i}-\bar{x}_{i}\right)\left(x_{j}-\bar{x}_{j}\right)\right]}{\sqrt{\sum\left(x_{i}-\bar{x}_{i}\right)^{2}} \sqrt{\sum\left(x_{j}-\bar{x}_{j}\right)^{2}}}
\end{aligned}
$$

Where, $m$ denotes the types of investment portfolio; $w_{i}$ and $w_{j}$ denotes the weights of the investment $i$ and $\mathrm{j}$; $\sigma_{i}$ and $\sigma_{j}$ denotes the standard deviation of the investment $i$ and $\mathrm{j} ; r_{i j}$ denotes the correlation coefficient of the investment $i$ and $\mathrm{j}$.

Following is the specification to model (3.1):

(1) when $\mathrm{m}=2$, then $\sigma=\sqrt{w_{1}^{2} \sigma_{1}^{2}+w_{2}^{2} \sigma_{2}^{2}+2 w_{1} w_{2} \sigma_{1} \sigma_{2} \cdot \operatorname{Corr}\left(x_{1}, x_{2}\right)}$

Where, $\operatorname{Corr}\left(x_{1}, x_{2}\right)$ denotes correlation coefficient.

(2) when $m>2$, that is, exists a variety of asset portfolio, the following is to prove the feasibility of dispersion effects from the perspective of game theory:

Located exist $m$ combination of options, for which the corresponding income is: $x_{1}, x_{2}, \ldots x_{m}$, and its distribution is independent, then there is a viable strategy vector $\mathrm{C}=\left\{w_{1}, w_{2}, \ldots w_{m}\right\}$, in which, $w_{i}$ is the weights in the portfolio $i$, and $\sum_{i=1}^{m} w_{1}=1$, then its net payment $\tilde{y}=\sum_{i=1}^{m} w_{1} x_{i}$. Now consider any viable alternative strategies for:

$$
\sum_{i=1}^{m} w_{i} x_{i}=\tilde{y}+\sum_{i=1}^{m}\left(w_{i}-\frac{1}{m}\right) x_{i}
$$

If the conditions mean for $\sum_{i=1}^{m}\left(w_{1}-\frac{1}{m}\right) x_{i}$ is zero, then:

$$
E\left[\sum_{i=1}^{m}\left(w_{i}-\frac{1}{m}\right) x_{i} \mid \tilde{y}\right]=\sum_{i=1}^{m}\left(w_{i}-\frac{1}{m}\right) E\left[x_{i} \mid \tilde{y}\right]
$$

According to symmetry, $E\left[x_{i} \mid \tilde{y}\right]$ is independent to $i$, then:

$$
E\left[\sum_{i=1}^{m}\left(w_{i}-\frac{1}{m}\right) x_{i} \mid \tilde{y}\right]=c \sum_{i=1}^{m}\left(w_{i}-\frac{1}{m}\right)=0
$$

It's proved that alternative strategies were second-order random dominant to completely decentralized strategy, which means that all the parties who are risk-averters will choose completely decentralized strategy. And when $n \rightarrow \infty$, it is allowed to replace the unit risky earning $x_{i}$ with its expected value in the strategy, and that is an application of large number theorem.

\section{Conclusion}

In the capital market of incomplete information, particularly in China's capital market which is in a special period of economy transformation, it is the most important aspect in China's socialist market economy that how to regulate the operational mechanisms of the capital market, and how to establish the mature capital market and improve the security mechanism of risk investment. Of course, we have reasons to believe that, as the healthy and stable 
development of china's economy and the continuous self-improvement of China's capital market, risk investment in China will be more developed, and investors' awareness of the risk management will become increasingly strong, investment behavior will more rational, as well.

\section{References}

Jewitt. (1965). Risk aversion and the choice between risky prospcts: the preservation of comparative staticts. Review of economic studies. 54:73-85.

Jowett Paul \& Margaret. Rothwell. (1986). The economics of information technology. st. martin's press.

Kimball. (1972). Standard risk aversion. Econometric. 61:589-611. 


\title{
The Significance of Cross-cultural
}

\section{Communication in International Business Negotiation}

\author{
Tingqin Zhang \& Hui Zhou \\ Daqing Petroleum Institute at Qinhuangdao, Qinhuangdao 066004, China
}

\begin{abstract}
With china's entrance to WTO as well as the international trade global integration, we must carry on the international commercial negotiations inevitably. If we want to achieve a goal in intercultural negotiation, we should understand different negotiation styles in different countries. Because of the culture accumulation, the thinking mode as well as the different cognitive ways, the people in the West and China encounter the cultural conflict, which causes the failure of international commercial negotiations. So we must look for effective strategies and tactics, in order to break the deadlock in international business negotiation and make negotiation successful.

In terms of intercultural communication, the thesis lists some cultural factors which influence negotiation, for example, the thesis talks about cultural diversity in intercultural negotiations, analyzing the difference in time and space and others among different countries. The thesis also puts forward a series of effective methods, namely, intercultural strategies and responding tactics in international business negotiation, so that people can avoid the deadlock. Based on the thorough study, the thesis lists some key points which we must pay much attention to in intercultural negotiations, so as to avoid mistakes in details, and finally achieve successful negotiations.
\end{abstract}

Keywords: Cross-cultural communication,Business negotiation style, Cultural diversity, Intercultural strategies

\section{Introduction}

By "culture", anthropology means the total life way of a people, the social legacy the individual acquires from his group. Or culture can be regarded as that part of the environment that is the creation of man., another formal definition is that "A culture is a collection of beliefs, habits, living patterns, and behaviors which are held more or less in common by people who occupy particular geographic areas" Culture and communication are inseparable because culture not only dictates who talks with whom, about what, and how the communication proceeds. In fact, our entire repertory of communicative behaviors is dependent largely on the culture in which we have been raised. Culture, consequently, is the foundation of communication. And, when cultures vary, communication practices also vary. Now consider a situation where there is little shared knowledge, few common values and a different language is spoken and we can readily see just how complicated negotiating international transactions can become. While intercultural communication is communication between members of different cultures. This definition is simple, but the process is complex. Intercultural communication involves differing perceptions, attitudes and interpretations. We know that even two people from the same culture can have communication problems. The art of negotiation is hard enough in our own country, dealing with colleagues who think like us, process information as we do, share a common set of values and speak the same language.

Difficulties in intercultural communication arise when there is little or no awareness of divergent cultural values and beliefs. In intercultural interaction, speakers sometimes assume that what they believe is right, because they have grown up thinking their way is the best. This ethnocentric assumption can result in negative judgments about other cultures. Whether it will succeed depends largely on the understanding of culture diversity.

As new markets open up for world trade and global competition intensifies, businesses of all sizes and in all sectors are expanding their operations overseas at unprecedented rates, which necessitate an increase in strategic alliances and hence intercultural negotiations. Intercultural negotiation involves discussions of common and conflicting interests between persons of different cultural backgrounds trying to reach an agreement of mutual benefit. This passage explores how culture differences manifest themselves in business negotiation, identifies and compares cultural characteristics and patterns among countries and suggests ways in which cultural conflicts are effectively handled.

\section{Different negotiation styles}

According to the different culture, the types of the negotiation are greatly different. If we want to be successful businessmen, knowing the different types of negotiation will help us a lot. And of course, the research and observations by most scholars indicate fairly clearly that negotiation practices differ from culture to culture and that culture can influence "negotiation style" - the way persons from different cultures conduct themselves in 
negotiating sessions.

International business negotiation is a negotiation among different countries and regions. Because of the difference system in politics and economy of the world, they have different history and cultural tradition. If we want to win the negotiation, we should know well businessmen in cultural background. As for different opponents, we should adopt different negotiation style.

The characteristics of negotiation style in the west: because of difference of language and culture between the East and the West, they also have different negotiation styles. For example, U.S. negotiators tend to rely on individualist values, imagining self and other as autonomous, independent and self-reliant. They are competitive in their approach to negotiations, including coming to the table with a fall-back position but beginning with an unrealistic offer, and they are also energetic, confident, and persistent; they enjoy arguing their positions, and see things universally i.e., they like to talk about broad applications of ideas. Of course, they are direct and honest in delivering their negative evaluations. So if we meet Americans in international negotiation, we should avoid adopting indirect express with them, we should be direct to express our doubt when we don't understand what they mention. Or it is easy to make negotiation impasse.

Even when different negotiations across national cultures are identified, change is constant. International business culture tends to privilege Western approaches to negotiation, centered in problem-solving and linear communication, as do many settings. As Western norms are balanced with Eastern values, and local traditions are balanced with regional and national approaches, negotiation practices continue their global evolution.

\section{Cultural factors that influence negotiation}

In terms of international business negotiation, negotiating styles of the West and the East, represented respectively by the United States, German, Japan and China, have attracted many experts to make a comparison because distinguished differences do exist in the two kinds of cultures that are the deep-seated reasons why the westerners negotiate quite differently from the easterners do and how these differences are produced. The two different negotiating styles exemplified by the U.S., Japan and China are typical enough to be compared in the studies of international business negotiation. Negotiators with different cultural backgrounds vary in their preference for negotiating strategies. Cultural factors are one of the most important parts responsible for the success or failure of the negotiations in which people with different cultures meet together. Here, we look at some concrete cultural factors that are in play and are generally believed to have an enormous impact on the West and Eastern business negotiations.

\subsection{Time orientations}

Two different orientations to time exist across the world: monochromic and polychromic . Monochromic approaches to time are linear, sequential and involve focusing on one thing at a time. These approaches are most common in the European-influenced cultures of the United States, Germany, Switzerland and Scandinavia. Japanese people also tend toward this end of the time continuum. Polychromic orientations to time involve simultaneous occurrences of many things and the involvement of many people. The time it takes to complete an interaction is elastic, and more important than any schedule. This orientation is most common in Mediterranean and Latin cultures including France, Italy, Greece, and Mexico, as well as some Eastern and African cultures.

Negotiators from polychromic cultures tend to start and end meetings at flexible times. Take breaks when it seems appropriate. Be comfortable with a high flow of information. Expect to read each others' thoughts and minds, sometimes overlap talk; view start times as flexible and not take lateness personally.

Negotiators from monochromic cultures tend to prefer prompt beginnings and endings, schedule breaks, deal with one agenda item at a time, rely on specific, detailed, and explicit communication, prefer to talk in sequence, view lateness as devaluing or evidence of lack of respect.

\subsection{Space orientations}

Space orientations differ across cultures. They have to do with territory, divisions between private and public, comfortable personal distance, comfort or lack of comfort with physical touch and contact, and expectations about where and how contact will take place. In Northern European countries, personal space is much larger than in Southern European countries. For a German or a Swedish person, for example, the Italians or the Greeks get too close. An American etiquette manual advises this about personal space: "When we meet someone, don't stand too close. An uncomfortable closeness is very annoying to the other person, so keep our physical distance, or he'll have to keep backing off from us. A minimum of two feet away from the other person will do it."

Seating arrangements for negotiations should take norms for space into account. In general, Americans tend to talk with people seated opposite them, or at an angle. For the Chinese, these arrangements may lead them to feel 104 
alienated and uneasy. They may prefer to converse while sitting side by side.

There are large differences in spatial preferences according to gender, age, generation, socioeconomic class, and context. These differences vary by group, but should be considered in any exploration of space as a variable in negotiations.

\subsection{Individualism - collectivism}

In individualistic cultures the focus of one's behavior can be unashamedly self-centered. The individual can make objections, state his feelings and be openly judgmental. Success or failure is left to the individual and does not cause the same degree of shame among the group. In individualistic cultures, people tend to put tasks before relationships and to value independence highly. People in these cultures are expected to take care of themselves and to value the needs of the individual over those of the groups, community or society. Individualistic cultures prefer linear logic and tend to value open conflict. Members from individualistic societies expect the other side's negotiators to have the ability to make decisions unilaterally.

In many cultures the interest of the group, whether the family or the community is given priority over those of the individual. Such cultures, called "Collectivist", rely on group consensus and the avoidance of conflict. By contrast, cultures that value collectivism emphasize solidarity, loyalty and strong interdependence among individuals. Relationships are based on mutual self-interest and are dependent on the success of the group. Collectivist cultures define themselves in terms of their membership within groups. Maintaining the integrity of groups is stressed so that cooperation, conflict avoidance and conformity dominate the culture. Collectivist societies tend to stress abstract, general agreements over concrete, specific issues.

\subsection{Power differential}

The idea of power differential describes the degree of deference and acceptance of unequal power between people. Cultures where there is a comfort with high power differential are those where some people are considered superior to others because of their social status, gender, race, age, education, birthright, personal achievements, family background or other factors. Cultures with low power differential tend to assume equality among people, and focus more on earned status than ascribed status. Generally speaking, the more unequally wealth is distributed, the bigger will be the power differential in any national setting. National cultures with a high power differential include Arabian countries, Malaysia, the Philippines, Mexico, Indonesia, and India. Negotiators from these countries tend to be comfortable with.

\section{5 uncertainty avoidance}

The idea of uncertainty avoidance has to do with the way cultures relate to uncertainty and ambiguity, and therefore, how well they may adapt to change. Generally, countries that show the most discomfort with ambiguity and uncertainty include Arab, Muslim and traditional African countries, where high value is placed on conformity and safety, risk avoidance, and reliance on formal rules and rituals. Trust tends to be vested only in close family and friends. It may be difficult for outsider negotiators to establish relationships of confidence and trust with members of these national cultures.

The United States, Scandinavia and Singapore are identified as having a higher tolerance for uncertainty. Members of these national cultures tend to value risk-taking, problem-solving, flat organizational structures and tolerance for ambiguity. It may be easier for outsiders to establish trusting relationships with negotiating partners in these cultural contexts.

\subsection{Masculinity - femininity}

The terms masculinity and femininity are used to refer to the degree to which a culture values assertiveness or nurturing and social support. The terms also refer to the degree to which socially prescribed roles operate for men and women. Countries and regions such as Japan and Latin America are rated as preferring values of assertiveness, task-orientation and achievement. In these cultures, these tend to be more rigid gender roles and "live to work" orientations. In countries and regions rated feminine, such as Scandinavia, Thailand, and Portugal, values of cooperation, nurturing, relationship and solidarity with those less fortunate prevail, and the moral belief is more one of "work to live". Of course, it is important to remember that associations with gender vary greatly across cultures, so that elements considered masculine in one culture might be considered feminine in another. Negotiators may find it useful to consider the way gender roles play out in the cultural contexts of their negotiating partners.

\subsection{Context orientation in major cultures}

The powerful effect that culture has on negotiation: A key factor is context which relates to the framework, background and surrounding circumstances in which communication or an event takes place. 
High-context cultures (including much of the Middle East, Asia, Africa, and South America) are relational, collectivist, intuitive and contemplative. This means that people in these cultures emphasize interpersonal relationships. Developing trust is an important first step to any business transaction. These cultures are collectivist, preferring group harmony and consensus to individual achievement. People in these cultures are less governed by reason than by intuition or feelings. Words are not so important as context, which might include the speaker's tone of voice, facial expression, gestures, postures — and even the person's family history and status. High-context communication tends to be more indirect and more formal. Flowery languages, humility, and elaborate apologies are typical.

Low-context cultures (including North America and much of Western Europe) are logical, linear, individualistic and action-oriented. People from low-context cultures value logic, facts and directness. Solving a problem means lining up the facts and evaluating one after another. Decisions are based on fact rather than intuition. Discussions lead to actions. Communicators are expected to be straightforward, concise and efficient in telling what action is expected . To be absolutely clear, they strive to use precise words and intend them to be taken literally. Explicit contracts conclude negotiations. This is very different from communicators in high-context cultures who depend less on language precision or legal documents. High-context business people may even distrust contracts and be offended by the lack of trust they suggest.

So we can know that every nation has their own different culture, they are different in some ways: for example, space Orientations, individualism - collectivism, power differential, uncertainty avoidance, masculinity femininity, context orientation in major cultures and so on. Cultural diversity influences the negotiation a lot. Of course, every nation's negotiation type will be different, too.

\section{Preparation and strategies for negotiations}

Business negotiation can be understood as a process in which two or more parties come together to discuss common and conflicting business interests in order to reach an agreement of mutual benefit. Negotiation can be considered a delicate business, made even more delicate by different cultural understandings. How can we avoid the subtle pitfalls and make deals go smoothly? I will give us a detail way to solve this situation.

\subsection{The preparation before the intercultural negotiation}

A good pre-preparation is a key note to have a successful negotiation. If we have a negotiation in hurry, we will know little about our partner and we can not get the most benefits during the intercultural negotiation. And of course, our partners will think that we did not pay much attention to this negotiation, so it can show our careless attitude about the business and our partner. Therefore we will fail in the negotiation. So it is important to make a good preparation before we go into the intercultural negotiation, but how to make preparations before we begin the negotiation? Next I will give us some advice. First we must organize our team well, because the team is the foundation of our successful negotiation. We can keep our team as small as possible. But it does not mean what the less people our team has, the more effective work we can get. Some people who have specialized skills, communication ability, team spirit and gamesmanship must be contained in our team .

\subsubsection{Selecting team members}

The company must choose a cross-section of technical skills and personal attributes that will create a compact and efficient team. One team member's weakness must be offset by another's strength. Technical knowledge must be accompanies by the ability to communicate and apply that knowledge. Putting a team together is similar to assembling a jigsaw puzzle: there is no success unless all of the pieces fit.

\subsubsection{Gathering of information}

Once the negotiating team has been organized, the first and most important step in preparing for a specific negotiation is gathering information. It is common to learn as much as possible about a potential client or partner before negotiations begin. Various kinds of information are necessary, finance, market, technology, policy, even the background of a particular executive. The next step is to analyze the various data so as to size up the probable goal and preferences of our counterpart, using his perspectives rather than ours as well as our own.

\section{(1) Obtaining information}

Given the critical nature of business negotiations, knowledge a particular executive's background, and family status can be a great advantage.

More important, the gathering of information includes that of market, science and technology, policy and regulations, etc.

Such as: the big issues that are to be gathered, the political system, the legal system, the business system, the 106 
financial system, infrastructures and logistics system, the counterpart.

(2) Analyzing information

The next step is to analyze the various data so as to size up the probable goal and preferences of our counterpart, using his perspectives as well as ours.

With so much information at hand, it is advisable to do a feasibility study before the negotiation. It should arrive at definitive conclusions on all the basic issues after consideration of various alternatives such as those listed below using a project negotiation as an example, political and social background, social and economic analysis, detailed analysis, location and site, main costs, manpower, schedule implementation, financial and economic evaluation.

4.1.3 The negotiating brief

(1) The negotiating brief

The negotiating brief is in written form and the manager responsible for the outcome of the negotiation signs it.

The brief should: Define the negotiating objective in terms of the major issues to be discussed. State the minimum acceptable level for each of the major items. Suppose we are the seller, our brief may state the minimum acceptable level about the following major issues, price, terms of payment, delivery, warranty. State the time period that the negotiation should be concluded. Identify the team leader and other members of the negotiating team, such as the names and jobs titles of the team members. Set up the lines of communication and the reporting system. It should state who is responsible for reporting to management and how.

(2) The negotiation plan

The plan provides discipline and organization that can be critical to a team's success. It will serve as the negotiating team's guide as the negotiations ensue. While the negotiating brief consists of the instructions given to the team leader by management; the negotiation team develops the negotiating plan. In defining the initial strategy and stating the possible measures or tactics, set down some basics and allow flexibility in different situations. The location of the negotiation is perhaps the most important situational factor for several reasons, both practical and psychological. As to the administrative arrangements, two factors should be taken into account. If the team is negotiating at home, in making arrangements for the meetings, they have the advantage of selecting the meeting rooms, an adjournment meeting room, negotiating facilities, etc. if the team is to go abroad, Attention should be given to the choice of a hotel with the best available business facilities, reference material, some portable office equipment, etc.

In addition, there are two interconnected aspects that need to be considered before entering into cross cultural negotiation.

The basis of the relationship: in much of Europe and North America, business is contractual in nature. Personal relationships are seen as unhealthy as they can cloud objectivity and lead to complications. In South America and much of Asia, business is personal. Partnerships will only be made with those they know, trust and feel comfortable with. It is therefore necessary to invest in relationship building before conducting business.

Information at negotiations: Western business culture places emphasis on clearly presented and rationally argued business proposals using statistics and facts. Other business cultures rely on similar information but with differences. For example, visual and oral communicators such as the South Americans may prefer information presented through speech or using maps, graphs and charts.

\subsection{The bridge-building between the different cultures}

But just making those preparations are not enough, we must know what will happen during the intercultural negotiation. Next this thesis will give us a detail explanation to the problems.

Supposed there are two persons: Tom in the West and Marry in the Eastern country. They have the same likes and dislikes, and Tom recently spoke for days with Marry, his potential business partner and yet the barriers between them were never broached — and the deal didn't get inked .

The problem had to do with different conceptions of the negotiation process itself and misinterpretations of the other's behavior. For Tom, negotiation is about pushing through a deal period. When he didn't think their discussion was moving forward as quickly as he thought it should, his arguments became increasingly forceful. Because his opposite read this as disrespect, the negotiation essentially ended days before their talks did.

Although globalizing communications and marketing have made the world smaller in many ways, deep differences between cultures remain. Despite similar tastes, Tom and Marry each approach negotiation in a way heavily conditioned by his national culture. Because they sat down at the table without understanding the other's assumptions about the negotiation process, all they ended up with was an impasse. 
So, we must pay attention to the question that is how to build the bridges between the different cultures so that the degree of mistrust is diminished until it is non-existent. In order to prepare for our negotiations try the following:

(1) Get to know the individuals that we will be personally dealing with. Making a one-to-one human connection is one of the best ways to overcome mistrust!

(2) Background: checks into the company that we are doing business with. Get to know the company as much as possible. Have credit checks done on the company. Learn about their financial situation in any way possible.

(3) Research the culture of the foreign company and sensitize ourselves to the possible differences that we may be confronted with.

(4) Get the assistance of a company that is expert in dealing with such cultural differences that can give us some tips.

\subsubsection{Offensive strategy}

Claiming is not restricted to the most powerful states. While offensive claiming by the weak against the strong is rare, defensive claiming is common among all states. In international business any countries is attempting to shift strategies from one party to another, or use both of them. If our strength is superior to our opponent's, we will adopt the offensive strategy, and we'd better put to use tactics correspondingly.

Ask questions. There are four kinds of question: probing, specific, attacking, and yes\no questions. Probing questions are difficult to answer because they are phrased in general terms. They are intended to gain information for one party to secure the weak point in the opponent's proposal before a major attack. Specific questions are designed to force an admission based on the information gained form the probing questions and data that are already known.

Tit for tat. It is an effective tactic in business negotiations. Sometimes we need to be hard shelled to make our opponent give up. In most cases, this technique can serve to push the negotiation forward if the negotiator deals with it appropriately. It can usually fool the opponent into making concessions and closing the deal.

Feign a blow to east and attack in the west. One party will over emphasize the apparent importance to their securing a particular point when their real objective is the exact opposite. Some negotiators are suspicious of any proposal made by their counterparts.

Use of commitments. The use of commitments, for example, national laws and regulations, standard negotiating procedures of the company, instructions from a superior, previous precedents, etc., is needed to persuade the opponent of the truth of the statements the party makes. It is a major offensive negotiating tactic that both sides will us. When the commitments are of different levels, the higher one normally prevails.

Uncover the counterpart's interests and "the right answer". As negotiating about interests is a better way to conduct technology trade negotiation, uncovering the other side's interests becomes paramount. When two parties have conflicts of interests, which are pretty difficult to resolve, they may try the right answer strategy. It works this way: 1) agree that a state of deadlock exists; 2) step out of the role of negotiators; 3) study the problem objectively; 4) seek the right answer; 5) agree on the right answer; 6) return to the role of negotiators and see if the right answer offers acceptable solutions.

Search for contextual irregularities or discrepancies. Keep in mind that the person who understands the context best will probably "win" the negotiation. A contextual irregularity is some factor in the negotiation that arouses suspicion or appears to be incorrect, given the overall context of the transaction. The term "discrepancy" specifically refers to inconsistencies associated with the prices or numbers in a seller's proposal. In other words, it is a method of challenging the validity of a proposal. A case will be found in which application of the proposal would be absurd, so the person who posed it is challenged to redefine it in more limited ways.

In many cases, a careful analysis of these elements will reveal errors suggesting that the proposal may be unsound. In this way, we can make the other party appear unreasonable. If the negotiator can find out elements like the two mentioned here, he can occupy an advantageous stance.

Be aggressive. Aggressive negotiators attack frontally and generally. They use the other party's belief in their own strength against them.

Present arguments. In negotiation, a party often feels the need to show the other side that they know exactly where the other's real interests lie and will not compromise theirs. The valid reasons must be put into some kind of an order. Each point should be stronger than the one before until the argument reached its climax. That is to say, it ends with the strongest point, the point that the other party will find most convincing. 


\section{Conclusion}

International business negotiation is playing a more and more important role in our economic lives in modern society. Obviously, international business negotiations take place across national boundaries. This means that understanding the different cultural environments that exist among nations and considering cultural differences in all facets of business are crucial for negotiators in the operation of international business negotiation.

International business negotiators are distinguished from each other not only by geographic location, language spoken, more importantly by the specific cultures in which they grow up. Cultural differences influence negotiation in many aspects, even before the face-to-face negotiation starts

The understanding of negotiation in the western culture is alien to that of the eastern culture. Many Americans see negotiation as a good approach to resolve conflicts while Japanese or Chinese do not like it at all. The composition of negotiation team relies greatly on culture that defines the number and the selecting criteria of negotiators. Japanese or Chinese negotiation team is often large, usually led by an old person with high status. Whereas, American team tends to be small and its negotiators are chosen on the basis of competence at the issue under negotiation. Simultaneously, people from different cultures prefer to use different negotiating strategies and styles. Therefore selection of different strategies and tactics results in different outcomes in international business negotiations.

Different selection of pragmatic strategies may produce different results in a business negotiation: a win-lose result, a win-win result or lose-lose result. In order to maintain a long-term cooperative business relationship between both negotiating parties concerned in a win-win business negotiation situation, the selection of strategies should be of crucial importance.

Our nation is mentioning to establish harmonious society, if we want to be a successful negotiator, we should set up an atmosphere of harmony. I think the best result is a win-win result in international negotiation. So we will have many chances cooperate with our foreigner. Our Chinese people also can become the successful men.

\section{References}

Donald W. Hendon, Rebecca Angeles Hendon \& Paul Herbig. (1996). Cross-cultural Business Negotiation. London: Quorum Books. 189.

Foster, D.A. (1992). Bargaining across Borders: How to negotiate business successfully anywhere in the world. New York: McGraw-Hill. 82.

Jeffrey Edmund Curry. (2000). International Negotiation. Shanghai: Shanghai Foreign Language Education Press. 45.

Jin, Meilin. (2004). English Readings of International Business Culture. Beijing: Beijing Hangkong Hangtian University's Publishing House. 2.

Larry A. Samovar, Richard E. Porter, \& Lisa A. Stefani. (2003). Communication Between Cultures. Beijing: Foreign Language Teaching and Research Press. 79.

Lederach, John Paul. (1995). Preparing for Peace. Syracuse, NY: Syracuse University Press. 43.

Michele J. Gelfand \& Jeanne M. Brett. (2004). The Handbook of Negotiation and Culture. California: Stanford Business Books. 56.

Novinger, Tracy. (2001). Intercultural Communication: A Practical Guide. Austin, TX: University of Texas Press. 121.

Robert T. Moran \& William G. Stripp. (1991). Successful International Business Negotiations. Houston: Gulf Publishing Company. 105. 165.

$\mathrm{Xu}$, Lisheng. (2004). Introducing Intercultural Communication. Hangzhou: Zhejiang University's Publishing House. 1.

Yu, Muhong. (2005). Business negotiation. Beijing Foreign Language Teaching and Research Press. 98. 99.167. 
